\title{
EFEITOS DA PALHA DE CANA-DE-AÇÚCAR (Saccharum spp) SOBRE O MANEJO DE PLANTAS DANINHAS E DINÂMICA DO BANCO DE SEMENTES
}

\section{DANIEL MEDEIROS}

Engenheiro Agrônomo

Orientador: Prof. Dr. PEDRO JACOB CHRISTOFFOLETI

Dissertação apresentada à Escola Superior de Agricultura "Luiz de Queiroz", Universidade de São Paulo, para a obtenção do título de Mestre em Agronomia, Área de Concentração: Fitotecnia

PIRACICABA

Estado de São Paulo - Brasil

Outubro - 2001 


\section{Dados Internacionais de Catalogação na Publicação (CIP) DIVISÃO DE BIBLIOTECA E DOCUMENTAÇÃO - ESALQ/USP}

Medeiros, Daniel Efeitos da palha de cana-de-açúcar (Saccharum spp) sobre o manejo de plantas daninhas e dinâmica do banco de sementes / Daniel Medeiros. - - Piracicaba, 2001. $126 \mathrm{p}$.

Dissertação (mestrado) - - Escola Superior de Agricultura Luiz de Queiroz, 2001. Bibliografia.

1. Banco de semente 2. Controle quimico 3. Dormência em plantas 4. Fisiologia vegetal 5. Palha de cana-de-açúcar 6. Pesticida 7. Plantas daninhas I. Titulo

CDD 633.61

\section{"Permitida a copia total ou parcial deste documento, desde que citada a fonte - $\mathrm{O}$ autor"}


A Deus pelas graças concedidas na minha vida.

Aos meus queridos pais Eliseu e Elisa, por todo o apoio e incentivo ilimitado em todas as etapas e fases de minha vida,

\section{AGRADEÇO}

Aos meus irmãos Gabriel e Carolina e a Dellis pelo apoio e carinho em todos os momentos.

Aos meus avós...

\section{DEDICO}




\section{AGRADECIMENTOS}

Meu reconhecimento ao Professor Associado Pedro Jacob Christoffoleti da ESALQ/USP, pela sua extremada orientação, amizade e confiança.

À FAPESP - Fundação de Amparo à Pesquisa do Estado de São Paulo pelo apoio financeiro e institucional prestado para a realização deste trabalho.

Ao Professor Titular Ricardo Victoria Filho da ESALQ/USP pelos conhecimentos transmitidos, atenção e colaboração no trabalho de pesquisa.

À Escola Superior de Agricultura "Luiz de Queiroz", Universidade de São Paulo, e aos Professores do Departamento de Produção Vegetal pelos conhecimentos transmitidos e dedicação aos alunos.

A todos os colegas do Programa de Pós-Graduação em Fitotecnia e de outros cursos da ESALQ.

Aos funcionários do Departamento de Produção Vegetal da ESALQ/USP, Luiz Ferrari, Aparecido Mendes e Ony Rodrigues de Campos, pelo grande apoio durante a execução desta pesquisa.

Às secretárias do Programa de Pós-graduação Ivete, Luciane e às secretárias do Departamento de Produção Vegetal, Bete, Célia, Silvia e Helena, pelo apoio dado a todos os alunos do Programa de Pós-Graduação em Fitotecnia.

Aos amigos José Lavres Junior, Gildemberg A. Leal Júnior e aos amigos da República Lesma Lerda pela união fraterna. 
Aos Eng. Agrônomos Adhair Ricci Júnior e Célio Manechini, da Copersucar, pelo apoio prestado para a realização desta pesquisa.

À bibliotecária Eliana Sabino pela revisão das Referências Bibliográficas.

Ao Estatístico Osmir José Lavoranti (Embrapa Florestas), Doutorando em Estatística e Experimentação Agronômica pela ESALQ/USP, pelo auxílio nas análises estatísticas.

Às Usinas Santa Luiza, Iracema e São Martinho pela colaboração cedendo as áreas.

Ao Eng. Agrônomo Sérgio Y. Utiyama (Du Pont) pelo auxílio na execução do experimento na Usina Santa Luiza. 


\section{SUMÁRIO}

Página

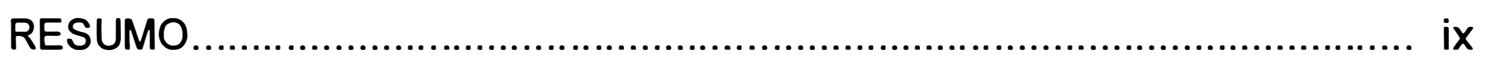

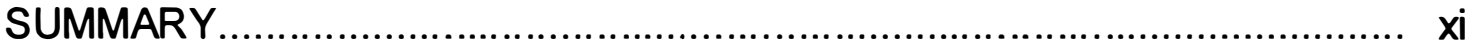

1 INTRODUÇÃO

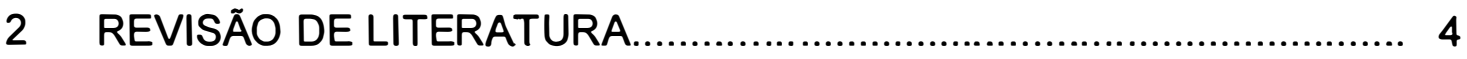

2.1 Dinâmica do Banco de Sementes........................................................... 4

2.2 Metodologia para Estudo do Banco de Semente................................ 7

2.3 Efeitos da Palha de Cana-de-açúcar sobre o Estabelecimento de

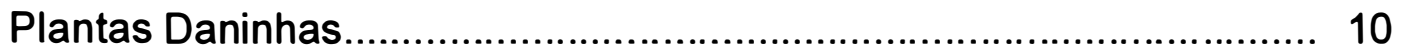

2.4 Manejo de Plantas Daninhas em Cana Crua...................................... 15

3 EFEITOS DA PALHA DE CANA-DE-AÇÚCAR NA INFESTAÇÃO DE PLANTAS DANINHAS E NA EFICÁCIA DO CONTROLE QUÍMICO.... 22

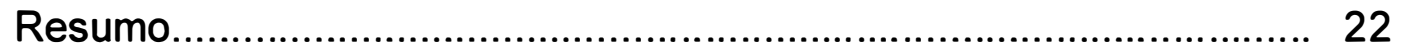

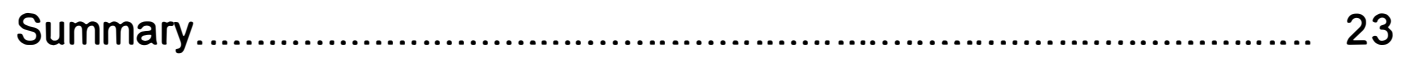

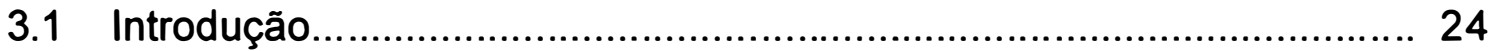

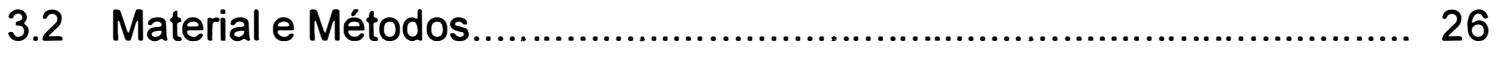

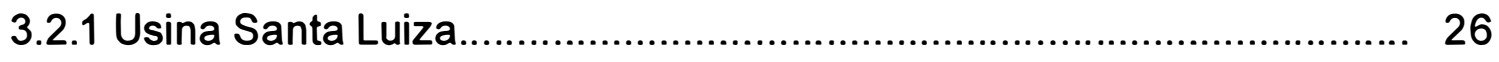

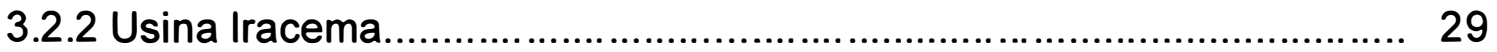

3.3 Resultados e Discussão.............................................................. 31

3.3.1 Usina Santa Luiza.................................................................. 31

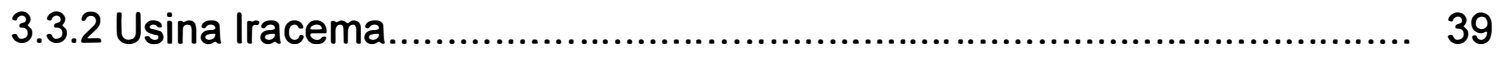

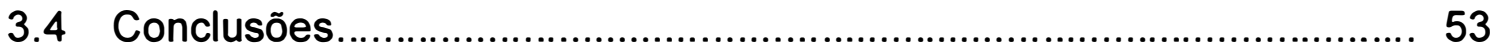


4 EFEITO RESIDUAL DA FORMULAÇÃO COMERCIAL DE DIURON + HEXAZINONE EM ÁREAS COM COLHEITA MECANIZADA DE CANA-DE-AÇÚCAR SEM QUEIMA .................................................. 54

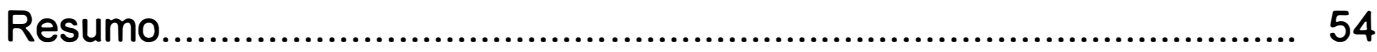

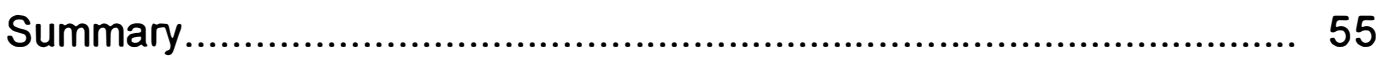

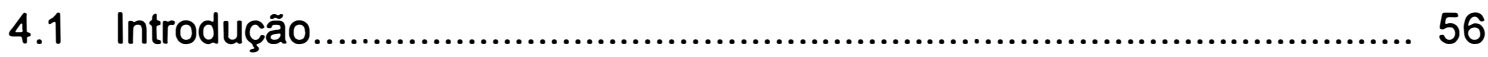

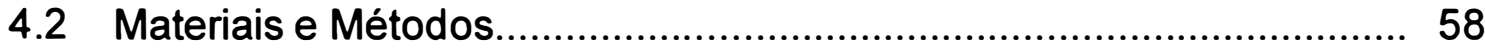

4.2.1 Período Residual do Herbicida Diuron + Hexazinone em Áreas de Cana Crua Determinado através de Bioensaio..................................... 58

4.2.2 Curva de Dose Resposta da Mistura Comercial dos Herbicidas Diuron + Hexazinone, sobre Plantas de Pepino............................... 61

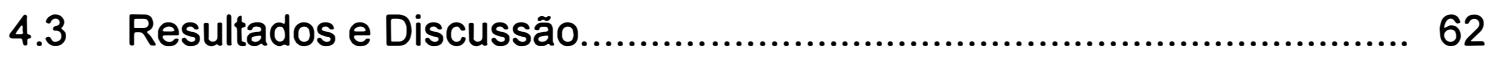

4.3.1 Período Residual do Herbicida Diuron + Hexazinone em Áreas de Cana Crua Determinado através de Bioensaio.................................. 62

4.3.2 Curva de Dose Resposta da Mistura Comercial dos Herbicidas Diuron + Hexazinone, sobre Plantas de Pepino................................. 64

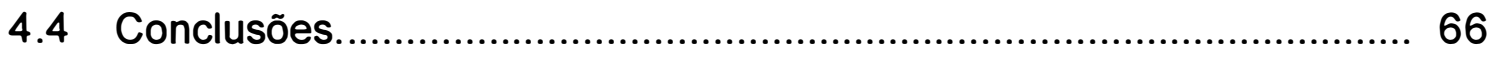

5 EFEITO DA INTENSIDADE DE CHUVA E QUANTIDADE DE PALHA DE CANA-DE-AÇÚCAR SOBRE A EFICÁCIA DE

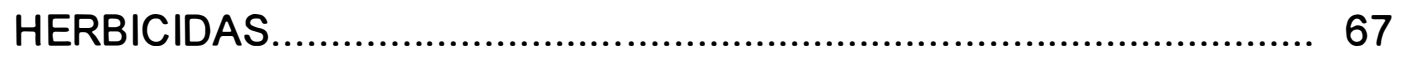

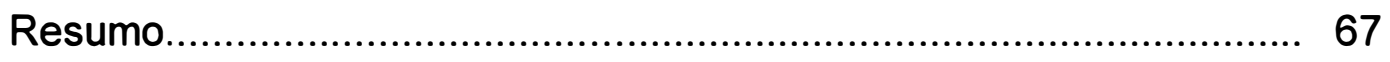

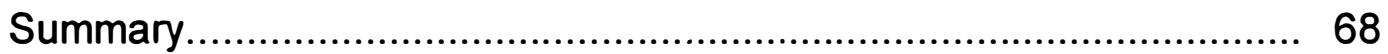

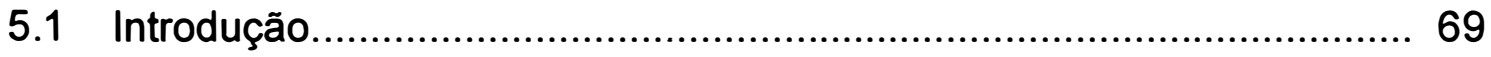

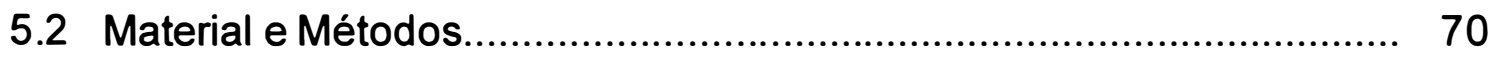

5.2.1 Mistura Formulada dos Herbicidas Diuron + Hexazinone ................... 71

5.2.2 Herbicida Sulfentrazone............................................................... 73

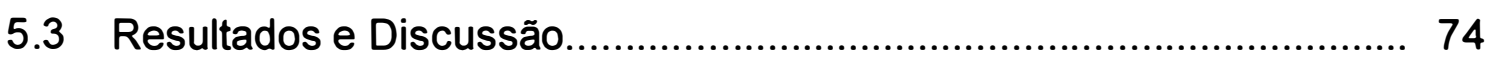

5.3.1 Mistura Formulada dos Herbicidas Diuron + Hexazinone.................. 74

5.3.2 Herbicida Sulfentrazone ............................................................... 79

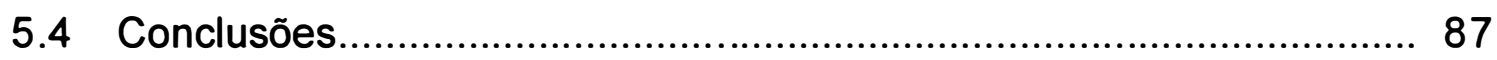


6 DINÂMICA DO BANCO DE SEMENTES EM ÁREAS DE COLHEITA DE CANA QUEIMADA X ÁREAS DE COLHEITA MECANIZADA SEM

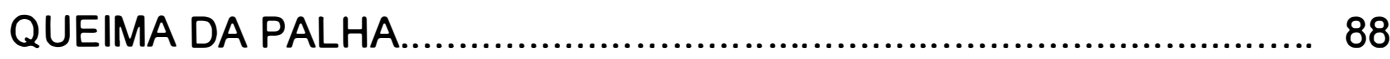

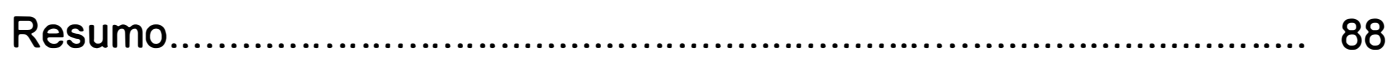

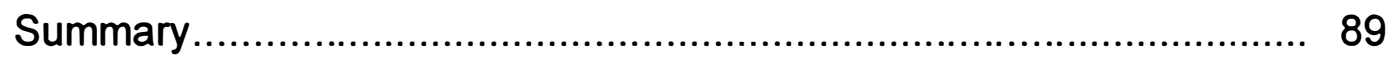

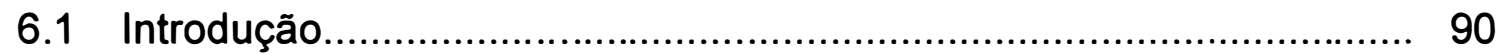

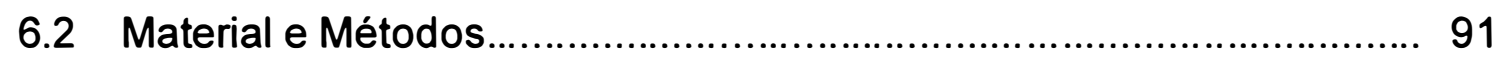

6.2.1 Coleta das Amostras de Solo...................................................... 91

6.2.2 Quantificação do Banco de Sementes pela Técnica de Emergência em Casa-de-Vegetação.................................................................... 95

6.2.3 Quantificação do Banco de Sementes pela Técnica de Separação de

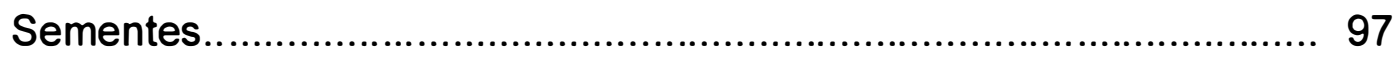

6.3 Resultados e Discussão .................................................................... 98

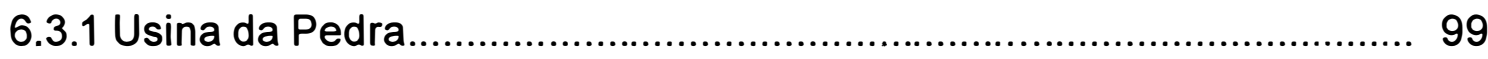

6.3.2 Usina Santa Luiza.................................................................... 101

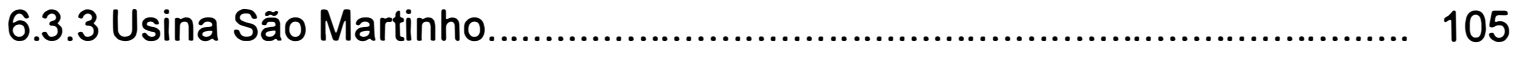

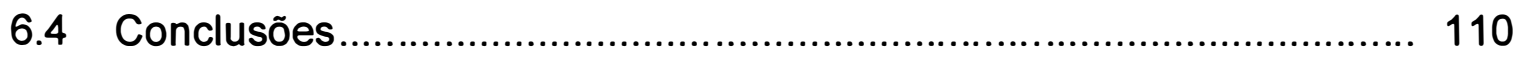

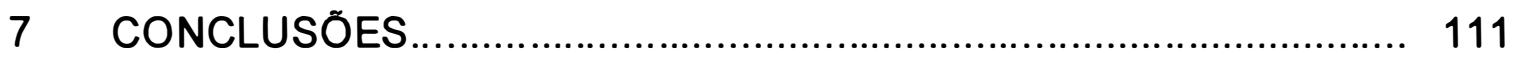

REFERÊNCIAS BIBLIOGRÁFICAS.................................................. 113 


\title{
EFEITOS DA PALHA DE CANA-DE-AÇÚCAR (Saccharum spp) SOBRE O MANEJO DE PLANTAS DANINHAS E DINÂMICA DO BANCO DE SEMENTES
}

\author{
Autor: Daniel Medeiros \\ Orientador: Prof. Dr. Pedro Jacob Christoffoleti
}

\section{RESUMO}

Este trabalho de pesquisa foi desenvolvido com o objetivo de avaliar os efeitos da palha de cana-de-açúcar, resultante da colheita mecânica da cultura sem queima (cana crua), sobre a eficácia do manejo químico e dinâmica do banco de sementes, comparativamente com áreas de colheita convencional (cana queimada), sendo realizado em três etapas. $\mathrm{Na}$ primeira etapa, foram conduzidos dois experimentos, ambos na estação chuvosa, porém em épocas distintas, onde testou-se as doses $0,936+0,264 ; 1,117+0,330$ e $1,404+0,396 \mathrm{~kg}$ i.a ha ${ }^{-1}$, da formulação comercial de diuron + hexazinone, além da testemunha sem herbicida, sobre as espécies de plantas daninhas Brachiaria decumbens Stapf; Brachiaria plantaginea (Link) Hitchc; Digitaria horizontalis Willd; Euphorbia heterophylla L.; Panicum maximum Jacq.; Ipomoea grandifolia (Dammer) O'Donell e infestação natural das plantas daninhas na área, em parcelas com cana queimada em comparação com cana crua. Foram avaliadas a porcentagem de controle e cobertura das espécies daninhas, e o efeito residual do herbicida através da determinação da quantidade de herbicida 
no solo de forma indireta, utilizando planta teste. Para a segunda etapa, os herbicidas diuron + hexazinone foram aplicados em vasos contendo 20 sementes das espécies Ipomoea grandifolia e Ipomoea hederifolia L, Euphorbia heterophylla e Digitaria horizontalis nas doses de 0,936 +0,264 e 1,404 +0,396 $\mathrm{kg}$ i.a. ha ${ }^{-1}$ de diuron + hexazinone respectivamente, além de uma testemunha sem herbicida, sobre quantidades de palha de cana-de-açúcar correspondentes a 0,$0 ; 5,0 ; 10$ e $15 \mathrm{t} \mathrm{ha}^{-1}$. Após $24 \mathrm{~h}$ foram simuladas chuvas com intensidades de 0,$0 ; 10 ; 20 ; 30 ; 40$ e $50 \mathrm{~mm}$. O herbicida sulfentrazone foi aplicado em vasos contendo 10 tubérculos de Cyperus rotundus L., nas doses de 0,$0 ; 0,6 ; 0,7$ e $0,8 \mathrm{~kg}$ i.a.ha ${ }^{-1}$, sobre as quantidades de palha correspondentes a de 0,0; 10 e $15 \mathrm{t} \mathrm{ha}^{-1}$. Após $24 \mathrm{~h}$ foram simuladas chuvas de 0,$0 ; 10 ; 20 ; 30$ e $40 \mathrm{~mm}$. Avaliou-se a biomassa da parte aérea das plantas daninhas, além de biomassa e contagem do número de tubérculos de tiririca. $\mathrm{Na}$ terceira etapa, foram coletadas amostras de solo nas profundidades de 0-10 cm e 10-20 cm em parcelas de campo com colheita de cana crua e cana queimada, em três experimentos já em andamento há 5 anos. Avaliou-se o tamanho e a composição do banco de sementes através das técnicas de emergência em casa-de-vegetação e separação física de sementes. Conclui-se a partir dos resultados das três etapas que áreas de cana crua apresentam menor necessidade do uso de herbicidas pré-emergentes, entretanto, se necessário o herbicida diuron + hexazinone poderia ser utilizado, porém seu período residual é reduzido pela presença da palha. Os herbicidas diuron + hexazinone e sulfentrazone tem sua eficiência reduzida em função da presença de grandes quantidades de palha (10 e $15 \mathrm{t} \mathrm{ha}^{-1}$ ); no entanto, chuvas a partir de 10-20 mm, $24 \mathrm{~h}$ após sua aplicação são suficientes para lixiviar boa parte dos herbicidas para o solo. O banco de sementes em áreas de cana crua é ligeiramente maior do que em áreas de cana queimada e apresenta maior proporção de sementes dormentes. 


\title{
EFFECTS OF SUGARCANE (Saccharum spp) HARVEST RESIDUE ON WEED MANAGEMENT AND SEEDBANK DYNAMICS
}

\author{
Author: Daniel Medeiros \\ Adviser: Prof. Dr. Pedro Jacob Christoffoleti
}

\section{SUMMARY}

The objetive of this research was to evaluate the effects of sugarcane harvest debris left on soil surface after mechanical harvest of the crop without previos burning (mechanical harvest), on the efficacy of chemical weed management, and on the dynamic of the weed soil seedbank, compared to areas with conventional harvest, burned before harvest (manual harvest). The research was conducted in three steps. In the first step, it was installed two experiments, both conducted during the rainy season, testing the rates $0.936+$ $0.264 ; 1.117+0.330$ and $1.404+0.306 \mathrm{~kg}$ a.i. ha ${ }^{-1}$ of the commercial formulation of the mixture of diuron + hexazinone, besides a check plot without herbicide application, on the control of the weeds Brachiaria decumbens Stapf; Brachiaria plantaginea (Link) Hitchc; Digitaria horizontalis Willd; Euphorbia heterophylla L.; Panicum maximum Jacq.; Ipomoea grandifolia (Dammer) O'Donell and natural weed infestation in the plot, comparing treatments of mechanical $x$ manual harvest. It was evaluated the weed control percentage and soil coverage by the weeds, and the residual effects of the herbicides through determination of the concentration of the herbicide in the soil by a bioassay using test plants. In the second step, diuron + hexazinone were sprayed in pots 
containing 20 seeds of the weed species Ipomoea grandifolia and Ipomoea hederifolia L, Euphorbia heterophylla and Digitaria horizontalis at rates of 0.936 +0.264 and $1.404+0.364 \mathrm{~kg}$ a.i. ha ${ }^{-1}$ of diuron + hexazinone besides a check plot without herbicides, on sugarcane debris placed on the surface of the soil in quantities correspondent to $0.0 ; 5.0 ; 10$ and 15 tha $^{-1}$. Twenty four hours later it was simulated amounts of rainfalls of $0.0 ; 10 ; 20 ; 30 ; 40$ and $50 \mathrm{~mm}$. Sulfentrazone was sprayed in pots containing 10 tubers of Cyperus rotundus L., at rates of $0.6 ; 0.7$ and $0.8 \mathrm{~kg}$ a.i. $\mathrm{ha}^{-1}$ besides a check plot without herbicide, on sugarcane debris placed on the surface of the soil in quantities correspondent to $0.0 ; 10$ and 15 t.ha $^{-1}$. Twenty four hours later amounts of rainfalls of $0.0 ; 10 ; 20$; 30 and $40 \mathrm{~mm}$ were simulated. It was evaluated the weed shoot biomasses plus the tubers biomass and number. In the third step, soil samples were collected from depths of $0-10 \mathrm{~cm}$ and $10-20 \mathrm{~cm}$ from field plots with mechanical and manual harvest. It was evaluated the size and composition of the soil seed bank through greenhouse emergence technique and seed exumation from the samples. It was concluded that in areas of mechanical harvest there was less need of pre-emergence herbicide application; however, if necessary diuron + hexazinone could be sprayed, but its soil residual effect on weed control is reduced due to presence of sugarcane debris on the soil surface. Diuron + hexazinone and sulfentrazone have the efficacy reduced as a function of greater amount of sugarcane debris left on the soil surface after mechanical harvest (10

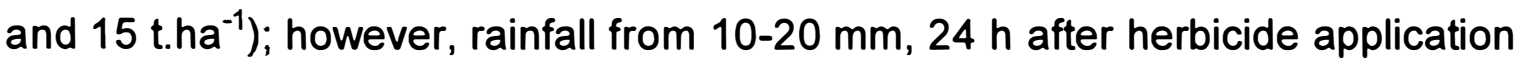
are enough to leach most of the herbicide sprayed on the soil. The weed seedbank in areas of sugarcane harvested mechanically is slightly higher than sugarcane harvested manually, and presenting higher proportion of dormant seeds. 


\section{INTRODUÇÃO}

A mudança do sistema de colheita convencional da cultura de canade-açúcar, onde a palhada é queimada, para o sistema mecanizado de colheita, sem a queima da palhada, que vem ocorrendo nos últimos anos no Brasil, tem causado consideráveis mudanças nas práticas culturais que seguem a colheita e, principalmente na dinâmica populacional das plantas daninhas. No entanto, pouco se conhece sobre as mudanças na dinâmica populacional das plantas daninhas nas áreas colhidas por este novo sistema; sendo assim, o manejo de plantas daninhas vêm sendo feito de forma empírica. Para que o produtor de cana faça um planejamento do manejo de plantas daninhas neste novo sistema de produção de forma racional e embasada cientificamente, como é feito no caso do sistema convencional, é necessário que trabalhos de pesquisa sejam desenvolvidos com o objetivo de esclarecer os efeitos desta prática sobre a dinâmica populacional e manejo das plantas daninhas em áreas de colheita mecanizada sem a queima da palhada.

Uma rápida expansão da área total cultivada em que é utilizada algum tipo de cobertura vegetal morta tem sido observada nos últimos anos no Brasil. Esta expansão é decorrente principalmente da adoção crescente deste sistema de produção pelos produtores. O cultivo mínimo em reflorestamentos que mantém a serapilheira na superfície do solo, já é uma tecnologia predominante em todas as regiões e empresas produtoras de madeira (Velini \& Negrisoli, 2000). A cana-de-açúcar colhida sem queima deixa sobre o solo uma espessa camada de palha, cuja quantidade pode variar entre $8-20 \mathrm{t} \mathrm{ha}^{-1}$, em função principalmente da variedade e idade do canavial. 
A cobertura vegetal morta deixada na superfície do solo afeta o desenvolvimento das plantas daninhas através de efeitos físicos, químicos e biológicos (Almeida, 1988; Toledo \& Begliomini, 2000). O efeito físico é importante na germinação das sementes e na taxa de sobrevivência das plântulas de algumas espécies. Existem sementes de plantas daninhas cuja germinação é dependente de amplitudes térmicas para iniciar o processo germinativo (Vicent \& Roberts, 1977; Harris et al., 1998). Além disso, diversos trabalhos na literatura tem evidenciado a influência da luz na quebra de dormência das sementes de plantas daninhas (Radosevich \& Holt, 1984; Sauer \& Struik, 1964; Wesson \& Waring, 1969a; Wesson \& Waring, 1969b; Scopell et al.,1994; Gallagher \& Cardina,1998a e Gallagher \& Cardina, 1998b).

Dentre os efeitos químicos, a alelopatia das palhadas tem sido responsável pelas alterações na comunidade infestante em sistemas de plantio direto, em função da decomposição da palha emitindo aleloquímicos. $O$ efeito biológico é causado pelo microambiente criado pela palha que aumenta a microbiocenose na superfície do solo, principalmente nos primeiros centímetros do perfil, de tal forma que diversas sementes de plantas daninhas podem ser deterioradas e algumas plântulas predadas (Pitelli, 1995). Desta forma, quando é usado algum tipo de cobertura vegetal morta, fica evidente através dos fatores mencionados, que existe uma alteração na dinâmica banco de sementes. Segundo Buhler et al. (1997) a dinâmica do banco de sementes influencia tanto a população de plantas daninhas, como o sucesso das estratégias de manejo das mesmas em uma determinada cultura.

Tradicionalmente, o controle de plantas daninhas na cultura da cana-de-açúcar é feito principalmente com herbicidas aplicados em préemergência e/ou pós-emergência inicial. Entretanto, a palhada presente na superfície do solo intercepta uma quantidade considerável de herbicida aplicado em condições de pré-emergência, o qual não atinge o solo. Desta forma, a aplicação de herbicidas pré-emergentes em áreas de colheita de cana crua é 
restrita aos produtos herbicida que atingem o solo, através da palhada deixada na superfície.

Tanto a passagem pela palha como a atuação dos herbicidas neste sistema são variáveis, e dependem de fatores ligados à palha (quantidade; características químicas; decomposição, etc); à cultura e ao herbicida (degradação, interação com lixiviados da palha, solubilidade e percolação). Segundo Velini \& Negrisoli (2000), a meia vida do herbicida oxyfluorfen no solo pode variar de 5-55 dias na presença de luz, e de 292 dias, na ausência de luz, fato este que pode ocorrer em cana crua caso o produto consiga atravessar a camada de palha.

Os objetivos deste trabalho foram: a) estudar a eficiência do uso de herbicidas pré-emergentes em áreas de colheita de cana crua; b) analisar o efeito da palha de cana-de-açúcar resultante da colheita de cana crua sobre a emergência e desenvolvimento de algumas espécies de plantas daninhas; c) avaliar a dinâmica do banco de sementes em áreas de colheita de cana crua (durante cinco anos) comparativamente com áreas de colheita de cana queimada. 


\section{REVISÃO DE LITERATURA}

\subsection{Dinâmica do Banco de Sementes}

O termo banco de sementes tem sido usado na literatura internacional para descrever 0 montante de sementes viáveis e outras estruturas de propagação presentes no solo ou nos restos vegetais (Carmona, 1992). Segundo Buhler et al. (1997), a característica do banco de sementes influência tanto a dinâmica de populações de plantas daninhas, como o sucesso de manejo das mesmas em uma determinada cultura.

O tamanho e a composição botânica das espécies que compõem uma população de sementes no solo, num dado momento, é o resultado do balanço entre entrada de novas sementes e perdas por germinação, deterioração, parasitismo, predação e transporte (Hoffman et al., 1998). Os principais meios de enriquecimento do banco de sementes são: o transporte por máquinas e implementos, animais, vento, água de irrigação e a produção de novas sementes no ano agrícola anterior ou na entre safra. $O$ decréscimo do banco de sementes no solo varia em função da espécie, dormência, condições ambientais, presença de predadores e microorganismos que decompõem as sementes, além do grau de senescência natural das espécies (Carmona,1992).

Para fins agrícolas, a determinação do banco de sementes é voltada aos estudos relativos às plantas daninhas. Estudos dos efeitos de práticas agronômicas sobre a dinâmica do banco de sementes são de grande importância para se determinar problemas com infestações futuras, além de permitir o uso de medidas preventivas no manejo de plantas daninhas (Ball 
1992). Suas informações permitem a construção de modelos de estabelecimentos populacionais ao longo do tempo que dessa forma, possibilitam a definição de programas estratégicos de controle (Martins \& Silva, 1994). Sendo assim, através do levantamento do banco de sementes e de parâmetros relacionados a planta daninha, como produção de sementes, porcentagem de emergência, taxa de sobrevivência, é possível construir modelos de previsão de dinâmica de populações de plantas daninhas (Kropff et al., 1999).

Através do comportamento diferenciado entre as espécies sob diferentes sistemas de manejo, é possivel prever seu potencial e agressividade e estabelecer modelos de ocupação e alterações na composição florística, em função de parâmetros relacionados ao sistema de produção e às plantas daninhas (Colbach et al., 2000). Sabe-se que além de influenciar na distribuição vertical das sementes de plantas daninhas no solo (Clements et al., 1996; Yenish et al.,1992), os sistemas de cultivo também influenciam no tamanho do banco de sementes.

O efeito das práticas empregadas no preparo do solo, assim como do sistema de cultivo sobre as características do banco de sementes, principalmente em relação à germinação, é função da distribuição vertical das sementes ao longo do perfil do solo, antes e após as operações de preparo. Tal distribuição pode ser afetada pelo sistema de cultivo, tipo, velocidade e profundidade de trabalho do implemento utilizado, textura do solo e umidade (Carmona, 1992).

O uso de arados tende a distribuir melhor as sementes ao longo do perfil preparado, enquanto que o plantio direto ou preparo superficial do solo resulta na concentração de sementes próximas à superfície (Hoffmann et al., 1998). Sob sistema de plantio direto, mais de $60 \%$ de todas as sementes de plantas daninhas do banco de sementes foram encontradas até um $\mathrm{cm}$ de profundidade no solo e poucas sementes foram encontradas abaixo de $10 \mathrm{~cm}$ de profundidade (Ball, 1992) . A concentração de sementes de plantas daninhas 
no sistema de plantio direto diminui de forma logarítimica com o aumento da profundidade do solo (Yenish et al., 1992). Cardina et al. (1991), avaliaram o tamanho do banco de sementes em diferentes sistemas de cultivo (plantio direto, cultivo mínimo e cultivo convencional) para a cultura do milho, sendo que o maior número de sementes foi encontrado no sistema de plantio direto. De maneira geral, pode-se dizer que interações entre herbicidas, preparo do solo e práticas culturais alteram o tamanho e a natureza do banco de sementes (Roberts, 1981).

Apesar da grande concentração de sementes nas camadas superficiais do solo, a germinação de várias espécies não ocorre, tanto em sistemas de plantio direto de culturas anuais (Silva, 1997), como no de colheita de cana crua, devido aos efeitos da palha que cobre o solo. No entanto, observa-se, nestes casos, a seleção de espécies que se adaptam ao padrão de distúrbio proporcionado pelo sistema que irão constituir a flora infestante (Radosevich et al., 1997a). Segundo Thiensen \& Vidal (1999), as plantas que sobrevivem às dificuldades iniciais de estabelecimento quando o solo for protegido com camada espessa de resíduos vegetais, geralmente são beneficiadas pela baixa população, cabendo-lhes uma grande porção dos recursos do ambiente, o que favorece o seu desenvolvimento e produção de sementes. Dessa forma, pode-se prever que se nenhuma medida de manejo for aplicada para o controle destas plantas, com o passar dos anos estas espécies de plantas daninhas terão sua proporção no banco de sementes aumentada e se tornarão sérios problemas para a área.

Embora existam diversos fatores que contribuam para o aumento do banco de sementes, Cavers (1983) aponta como principal a chuva de sementes, em função do grande potencial de produção de sementes pelas plantas daninhas. Segundo Deuber (1992), as quantidades máximas de sementes produzidas por algumas espécies de plantas daninhas variam de 500 sem. planta $^{-1}$ para a mostarda (Raphanus raphanistrum), a até 400.000 sem. planta $^{-1}$ para a planta daninha serralha (Sonchus oleraceus). Entretanto, 
em sistemas de plantio direto, uma importante forma de entrada de sementes tem sido o vento, que ao longo do tempo transporta sementes que antes não se encontravam na área, e que em alguns casos se tornam problemáticas (Buhler, 1995).

Desta forma, a não germinação de sementes seria um dos principais pontos de estrangulamento no ciclo de vida das plantas daninhas, que resultaria numa menor infestação e consequentemente menor entrada de sementes. Entretanto, diversas características como dormência e grande longevidade permitem que as sementes presentes no solo não se deteriorem e permaneçam viáveis por longos períodos, a espera de condições ideais para germinação (Hilhorst \& Toorop, 1997).

\subsection{Metodologia para Estudo do Banco de Sementes}

O banco de sementes do solo é utilizado para estudar as relações quantitativas e qualitativas entre a sua população e a da flora infestante (Dessaint et al., 1990). Com essas informações, pode-se elaborar índices de predição e modelos de emergência, permitindo prever infestações futuras e definir medidas de manejo mais adequadas (Barralis et al., 1986; FernándezQuintanilla, 1988).

Entretanto, existem diversos problemas associados com a metodologia de estudo do banco de sementes de plantas daninhas. Dentre eles, destacam-se a amostragem do solo, enumeração das sementes e estimativa da porcentagem de emergência dessas sementes (Cardina \& Sparrow, 1996). Segundo Freckleton \& Watkinson (1998), os modelos de dinâmica populacional de plantas daninhas, que tem como um dos parâmetros o banco de sementes, na maioria das vezes superestimam o crescimento da população pelo fato de utilizarem a média aritmética da população. Segundo estes autores, o mais correto seria a utilização da média geométrica, que leva 
em consideração a variabilidade temporal do banco de sementes, ou seja, depende de amostragens ao longo do tempo.

Além disso, a heterogeneidade de distribuição do banco de sementes seria outro fator que leva ao erro. Para Benoit et al. (1992), dois aspectos são fundamentais para que os estudos com banco de sementes sejam bem sucedidos. O primeiro refere-se ao número de amostras coletadas e o segundo, à metodologia de extração e separação das sementes das amostras do solo.

Nos estudos de biologia das plantas daninhas desenvolvidos até 0 momento, não existe ainda uma conclusão sobre a padronização do número de amostras a serem coletadas em uma determinada área, que caracterize de forma precisa o banco sementes no solo. Entretanto, vários pesquisadores tem estudado técnicas de amostragem que garantam maior acurácia nos dados obtidos. Entre estas, segundo Bigwood \& Inouye (1998), a precisão da estimativa do banco de sementes pode ser melhorada, tomando-se um grande número de sub-amostras, ou aumentando o número de amostras em decréscimo do seu volume.

No entanto, a forma mais reconhecida e correta para se determinar o número ideal de amostras, é através da relação com a variância (Barralis et al., 1986; Benoit et al., 1989). De acordo com Benoit et al. (1989), a análise da variância do número de sementes da amostra é inversamente proporcional ao número de amostras. Portanto, a relação entre variância e o número de sementes por amostras, sugere um padrão exponencial decrescente, sendo que, quando o número de amostras é dobrado, a variância diminui pela metade. Sendo assim, quanto maior for o número de sementes em uma amostra por área, menor será a variância e o número de amostras necessárias para estimar o banco de sementes.

Em função do objetivo da análise do banco de sementes o número de amostras pode ser alterado. Se a proposta de estudo for apenas uma quantificação total de sementes, para se verificar o potencial de infestação de uma área, o número de amostras pode ser menor do que se o objetivo do 
estudo for o de determinar alterações qualitativas e de evolução do banco de sementes em resposta a algum sistema de manejo. Como exemplo Azania (2000) justifica, através da quantificação do banco de sementes em área de cana-de-açúcar, que o baixo potencial de infestação de plantas daninhas na área experimental, foi devido ao pequeno número de sementes encontradas nas amostras coletadas.

Em relação ao diâmetro do amostrador, Benoit et al. (1989) não encontraram diferenças quando compararam amostradores com diâmetros de 1,9; 2,7 e 3,3 centímetros, na avaliação de uma população de Chenopodium spp. no solo. Entretanto, segundo os autores, isto só ocorreu quando os volumes de solo explorado foram iguais, independentemente do diâmetro dos amostradores. De maneira geral, os valores de diâmetro para os amostradores, citados na literatura, encontram-se entre $2,5 \mathrm{~cm}$ (Roberts \& Neilson, 1981) e 4,5 cm (Barralis et al., 1986).

Outro aspecto a ser considerado, é a profundidade de amostragem. A escolha da profundidade está relacionada ao objetivo do estudo e ao tipo da vegetação presente. Desta forma, em solos cultivados, recomenda-se retirar as amostras na profundidade de cultivo, nessas áreas, cerca de $90 \%$ das sementes encontram-se nos primeiros 20 centímetros do perfil do solo (Roberts \& Neilson, 1981; Yenish et al., 1992; Granatos \& Torres, 1993; Bulher et al., 1997).

Após solucionados os problemas com amostragem, inicia-se o processo de quantificação do banco de sementes. Para a quantificação do banco de sementes diferentes metodologias podem ser empregadas (Christoffoleti \& Caetano, 1998). A forma mais primaria para se quantificar o banco de sementes, é através da observação 'in situ' da emergência de plântulas. Entretanto, este método não é preciso, uma vez que sementes podem permanecer viáveis no solo por longo períodos sem germinar e, algumas sementes germinadas não conseguem emergir devido às condições ambientais desfavoráveis (Mortimer, 1990; Cardina \& Sparrow, 1996). 
A forma preferida, utilizada por pesquisadores que trabalham com banco de sementes, tem sido a enumeração da emergência de plantas a partir de amostras do banco de sementes colocas em bandejas em casa de vegetação (Roberts, 1981). Segundo Gross (1990), entre todos os métodos testados em seu trabalho, o de emergência em casa-de-vegetação foi o mais eficaz.

A separação física de sementes, através do peneiramento do solo, também é uma técnica bastante utilizada, apesar de algumas vezes, causar a perda de viabilidade de algumas sementes (Standifer, 1980). Bulher \& Maxwell (1993), aperfeiçoaram o método de separação física, através da utilização de soluções de alta densidade, utilizando o carbonato de potássio $\left(\mathrm{K}_{2} \mathrm{CO}_{3}\right)$, seguido de centrifugação a $10.000 \mathrm{rpm}$, por quinze minutos. Dessa forma, a alta densidade da solução eleva os constituintes orgânicos do solo (matéria orgânica e sementes) que depois da centrifugação são recolhidos, com o uso de uma espátula, para posterior enumeração e identificação. Alguns autores sugerem ainda a utilização de outras substâncias como o sulfato de magnésio $\left(\mathrm{Mg}_{2} \mathrm{SO}_{4}\right)$ (Malone, 1967; Freitas, 1990).

\subsection{Efeitos da Palha de Cana-de-açúcar Sobre o Estabelecimento de Plantas Daninhas}

Deixar resíduos vegetais de colheita na superfície do solo é uma prática agrícola adotada desde há muito tempo, pois apresenta uma série de aspectos positivos, conforme apontam Maldonado et al. (2001), destacando-se conservação de solo e umidade, reciclagem de nutrientes, aumento de matéria orgânica e controle das plantas daninhas, dentre outros. Por outro lado, em locais onde a umidade do solo seria o principal fator limitante à germinação de sementes de plantas daninhas, a maior conservação da umidade no solo 
causada pelos resíduos de colheita, poderiam propiciar um ambiente mais favorável à emergência (Teasdale \& Mohler, 1993).

Em relação à cana-de-açúcar, podem ser observados, em áreas com colheita mecânica sem queima, prejuízos na brotação e crescimento de soqueira de alguns cultivares; excesso de umidade em terrenos baixos, incidência de pragas, etc (Arevalo, 1998).

Quanto aos efeitos positivos da palha de cana sobre a diminuição da infestação de plantas daninhas, Manechini (1998), observou níveis crescentes de controle de plantas daninhas em função da quantidade de palha, na média dos tratamentos, principalmente para gramíneas e espécies de ciclo anual. Espécies de cipós e trepadeiras e algumas espécies de folhas largas tiveram suas populações pouco alteradas, nos ensaios com quantidades intermediárias de palha. A tiririca (Cyperus rotundus) não foi afetada pelos tratamentos em termos de densidade populacional, mas observou-se uma tendência de enraizamento e tuberificação da planta daninha na superfície do solo, quando em presença de palha por anos consecutivos. Esse fato faz com que as plantas de tiririca fiquem debilitadas na época mais seca do ano, facilitando sua erradicação por meios químicos ou mecânicos, na reforma do canavial. Azania \& Rolim (1999), também observaram uma mudança na biodiversidade infestante causada pela cobertura morta vegetal, e destacaram a predominância de espécies perenes em cana crua.

Almeida (1985) destaca que existe uma correlação linear e inversa entre a quantidade de palha deixada na superfície do solo por uma cultura em rotação e a infestação de plantas daninhas na cultura em seqüência. Segundo este autor, a biomassa verde de plantas daninhas passou de aproximadamente $1500 \mathrm{~g} \mathrm{~m}^{-2}$, com a quantidade de palha de adubos verdes no solo de $1 \mathrm{t} \mathrm{ha}^{-1}$ para aproximadamente $250 \mathrm{~g} \mathrm{~m}^{-2}$, quando a quantidade de palha se aproximava de $7 \mathrm{t} \mathrm{ha}^{-1}$. Sendo assim, como a quantidade de palha após a colheita da canade-açúcar pode chegar a mais $15 \mathrm{t} \mathrm{ha}^{-1}$ é possivel fazer algumas generalizações práticas, relacionadas com a matoinfestação, que começa a 
surgir ao redor de 30 a 50 dias após a colheita da cana crua, em função das quantidades de resíduo de colheita (Arevalo, 1998). Com quantidades de resíduos maiores que $15 \mathrm{t} \mathrm{ha}^{-1}$ a matoinfestação é rara. O ideal é conhecer a quantidade de resíduos que produz cada cultivar para poder planejar o manejo mais eficiente.

Desta forma, Martins et al. (1999), avaliaram os efeitos da cobertura do solo com $0,2,4,6,8,10$ e $15 \mathrm{t} \mathrm{ha}^{-1}$ de palha de cana-de-açúcar da variedade RB 825336 sobre a emergência em campo de plântulas de Sida rhombifolia, Euphorbia heterophylla, Bidens pilosa e Ipomoea grandifolia e, concluiram que as espécies estudadas apresentam comportamentos germinativos distintos e a cobertura do solo com quantidades crescentes de palha de cana resultou em padrões de emergência espécie-dependentes. Além disso, neste mesmo trabalho, concluíram que em condições do solo coberto com palha de cana, as espécies infestantes Bidens pilosa, Euphorbia heterophylla e Ipomoea grandifolia, tendem a manter-se como plantas problemas, e Sida rhombifolia deverá diminuir sua agressividade em condições de alta quantidade de palha, igual ou maiores que $6 \mathrm{tha}^{-1}$.

Melendez (1990), avaliando o efeito de diferentes coberturas no desenvolvimento das plantas daninhas Brachiaria plantaginea, Cenchrus echinatus, Bidens pilosa e Ipomoea aristolochiaefolia, concluiu que as coberturas afetaram a comunidade infestante, tanto na predominância das espécies quanto na quantidade, e a palha de cana-de-açúcar (camada de 10 $\mathrm{cm}$ ) inibiu totalmente a germinação das plantas daninhas semeadas, com exceção de Bidens pilosa.

Entretanto, segundo Pitelli (1995), os efeitos da cobertura morta sobre a população de plantas daninhas devem ser analisados sob três aspectos: físicos, químicos e biológicos. Em relação aos efeitos físicos, os resíduos vegetais deixados sobre o solo nos sistemas de plantio direto ou de cultivo mínimo, podem afetar a emergência de plantas daninhas por reduzir a 
alternância de temperatura; impedir que as sementes recebam luz solar ou por obstruir a elongação do hipocótilo (Buhler et al., 1996).

Wesson \& Wareing (1969b), demostraram o papel da luz na quebra de dormência de sementes de plantas daninhas, quando submeteram camadas de solo a diferentes tratamentos de luminosidade com a utilização de diferentes coberturas. Segundo os autores em nenhum dos casos estudados, houve germinação maior que $10 \%$, quando as sementes permaneceram no escuro pelo período total de avaliação. Dessa forma, concluíram que praticamente todas as sementes encontradas numa camada de solo irão germinar, quando submetidas a algum distúrbio e a grande maioria tem a luz como o fator essencial para que a germinação ocorra.

As temperaturas máximas e mínimas para germinação são altamente variáveis entre as espécies de plantas daninhas $e$, influenciadas por diversos fatores (Zimdahl,1999; Holshouser et al., 1996). Entretanto, a alternância de temperatura seria mais atuante pois, segundo Egley \& Duke ${ }^{1}$, citados por Velini \& Negrisoli (2000), a exigência de maior ou menor amplitude térmica constituise no modo mais eficiente, encontrado pelas sementes e propágulos, de controlar a profundidade de germinação no solo. Sendo assim, torna-se possivel que algumas espécies consigam suprimir sua germinação por possuirem reservas insuficientes para emergirem.

Em áreas com cobertura de palha de cana $\left(7,5\right.$ ou $\left.15 \mathrm{tha}^{-1}\right)$, Velini \& Negrisoli (2000) observaram que as duas quantidades de palha estudadas reduziram drasticamente a variação de temperatura a 1 e $5 \mathrm{~cm}$ de profundidades, fato este que pode reduzir a germinação de várias espécies de plantas daninhas, principalmente no caso de sementes de gramíneas forrageiras dos gêneros Brachiaria e Panicum (Velini \& Negrisoli, 2000), entretanto, para sementes de dicotiledôneas, alguns trabalhos apontam a

${ }^{1}$ EGLEY, G.H.; DUKE, S.O. Physiology of seed dormancy and germination. In: DUKE, S.O. (Ed.) Weed Physiology. I. Reproduction and Ecophysiology. Boca Raton: CRC Press, 1985. p.27-64. 
preferência por temperaturas constantes (Maluf,1988; Vasconselos,1984; Ruiz et al.,1990; Dzomeku \& Murdoch, 1999).

O efeito biológico é causado pelo microambiente criado pela palhada, que aumenta a microbiocenose na superfície do solo, principalmente nos primeiros centímetros do perfil, de tal forma que diversas sementes de plantas daninhas podem ser deterioradas (Kremer \& Spencer, 1989) e algumas plântulas predadas. Crawley ${ }^{2}$, citado por Buhler et al. (1997), relata que em sistemas naturais mais que $70 \%$ das sementes podem ser predadas por insetos, pássaros e pequenos mamíferos, entretanto em sistemas agrícolas, tal efeito é menos intenso devido ao alto grau de distúrbio do solo, enterrio de sementes pelo cultivo e falta de habitats para os predadores (Buhler et al., 1997).

Em áreas de plantio direto assim como em outros sistemas conservacionistas, observa-se um acúmulo de sementes de plantas daninhas na superfície do solo. Segundo Silva (1997), isto aparentemente aumenta a emergência de plantas daninhas. No entanto, este mesmo autor relata que muitos pesquisadores têm observado que o acúmulo de sementes na superfície do solo significa maior exposição às condições climáticas e ao ataque de pássaros, roedores e insetos, resultando ao longo do tempo, em redução significativa do banco de sementes.

Em relação aos efeitos alelopáticos, existem duas situações em que poderão apresentar importantes implicações econômicas no caso de cana crua. O primeiros caso refere-se ao potencial de controle de plantas daninhas, e o segundo à possibilidade de que os compostos liberados pela palha de cana cause a intoxicação da própria cultura (Velini \& Negrisoli, 2000).

Existem relatos na literatura de vários casos onde resíduos de culturas levaram ao controle de plantas daninhas devido a possíveis efeitos

${ }^{2}$ CRAWLEY, M.J. Seed predators and plant populations dynamics. In.: FENNER, M. (Ed.). Seeds: the ecology of reneration in plant comunities. Wallingford: CAB International, 1992. p.157-191. 
alelopáticos, como o caso da palha de trigo, centeio e aveia (Almeida, 1988), além de possíveis reduções nas populações de nematóides e até de alguns insetos (Maldonado et al., 2001). De fato, no caso de uso de grandes quantidades de coberturas mortas estes efeitos são visiveis. Uma das possiveis razões seria 0 fato da grande concentração dos compostos alelopáticos nos primeiros centímetros do perfil do solo.

Uma vez que a intensidade dos efeitos alelopáticos depende da concentração dos aleloquímicos, a sua ação será mais pronunciada do que no caso por exemplo do uso de materiais incorporados (Almeida, 1988). Entretanto, Radosevich et al. (1997b) sugerem que outros fatores poderiam levar a mortalidade das plântulas ou impedir a germinação, como modificações no microambiente levando a modificações no pH, por exemplo.

Segundo Gomide (1993), a palhada de cana-de-açúcar, das variedades SP 71-1406 e SP 70-1143, controlam certas espécies de plantas daninhas por liberarem aleloquímicos e impedirem a incidência de luz nas sementes de plantas daninhas no solo, inibindo assim a emergência.

A grande quantidade de resíduos, e por consequência de lixiviados da palha de cana, pode causar redução na brotação de perfilhos da cana. Este fenômeno é conhecido como autoalelopatia, de modo que em áreas com o cultivo da mesma cultura durante vários anos pode ocorrer um decréscimo no rendimento. Este fato foi observado nas culturas do trigo e arroz (Almeida, 1988) e daí a denominação popular do termo "terras cansadas". Em áreas com cana crua observa-se em alguns casos, a ocorrência de rebrota desuniforme, após a colheita sem a queima.

\subsection{Manejo de Plantas Daninhas em Cana Crua}

Se algumas plantas daninhas conseguem germinar através da camada de palha de cana deixada na superfície após a colheita, conforme já descrito, é evidente que há necessidade de controle destas plantas, o que 
normalmente é feito através do uso de herbicidas aplicados em condições de pré ou pós-emergência, em área total. Entretanto, segundo Velini \& Negrisoli (2000) atualmente, o controle de plantas daninhas em cana crua vem sendo feito principalmente através da aplicação de herbicidas em uma operação chamada de "catação". Esta operação, pode significar em menor custo, quando comparada com aplicação em área total, pois são controlados apenas as plantas daninhas escapes, com aplicação localizada de herbicidas. No entanto, necessita de maior disponibilidade de mão de obra, que pode ser um problema, principalmente nas regiões produtoras próximas à grandes centros urbanos, onde existe grande escacez de mão de obra, dada a competição com a oferta de empregos nestes centros.

De fato, o controle realizado em catação tem sido suficiente para o manejo de plantas daninhas destas áreas, entretanto, existem casos onde o controle em área total deve ser utilizado, principalmente em áreas com menor quantidade de palha, além disso, com o passar dos anos a comunidade infestante é alterada em função da pressão de seleção exercida por uma medida de manejo, permitindo o aumento populacional de determinadas espécies. Existem na literatura diversos trabalhos que evidenciam o efeito das práticas agronômicas na dinâmica populacional das plantas daninhas (Clements et al.,1996; Cardina et al., 1991; Roberts, 1981; Buhler et al.,1997). Dessa forma, o controle das plantas daninhas com herbicidas em área total ainda é altamente utilizado e possivelmente continuara sendo, mesmo nas áreas de colheita mecanizada de cana-de-açúcar.

Entre os herbicidas utilizados em cana-de-açúcar, os aplicados em pré-emergência são os mais empregados. Porém, a palhada presente na superfície do solo intercepta uma quantidade considerável de herbicida aplicado em condições de pré-emergência, o qual não atinge o solo (Banks \& Robinson, 1986; Mills \& Witt, 1989). Desta forma, a aplicação de herbicidas préemergentes, em áreas de colheita de cana crua, é restrita aos produtos herbicida que conseguem atingir o solo, atravessando a palhada deixada na superfície. 
Segundo Velini \& Negrisoli (2000), é consenso, entre os técnicos que trabalham com controle de plantas daninhas em cana-de-açúcar, que os herbicidas tradicionalmente utilizados em pré-emergência não conseguem atravessar a camada de palha deixada pela cultura e atingir o solo. Com a finalidade de avaliar este efeito, os autores conduziram um experimento utilizando um corante (FDC-1), simulando um herbicida, procurando avaliar a quantidade do mesmo interceptado por camadas de palha de cana de $0,1,2,4$, $6,8,10$ e $15 \mathrm{tha}^{-1}$, com volume de calda aplicado de $195 \mathrm{~L} \mathrm{ha}^{-1}$. Quando a camada de palha foi de 10 e 15 tha $^{-1}$, as quantidades de corante retido foram de 99,4 e $99,5 \%$, respectivamente.

Quando um herbicida é aplicado, seu destino no ambiente e suas interações com o solo são governadas por fatores químicos, físicos e biológicos. Dessa forma, o conhecimento dos fatores que influenciam a atividade $e$ estabilidade dos herbicidas no solo é fundamental pois, através dele, é que se pode explicar o sucesso ou o fracasso no controle de plantas daninhas, a tolerância das culturas e a persistência dos mesmos no ambiente (Hurle \& Wacker, 1980).

Neste sentido, Mills \& Witt (1989) concluiram que, para o herbicida imazaquin, a interceptação pela cobertura vegetal poderia aumentar sua dissipação e reduzir sua efetividade em sistemas conservacionistas, já o mesmo não foi relatado em relação ao herbicida imazethapyr. Segundo Basham et al. (1987), a principal forma de degradação da molécula de imazaquin é pela fotodegradação, o que justifica a hipótese de Mills \& Witt (1989), de que sistemas conservacionistas aumentariam sua dissipação devido ao fato de que sobre a palhada, o produto ficaria mais exposto a luz solar, e se dissiparia mais rápido.

Sabe-se que a luz solar é filtrada pela folhagem de uma cultura. Desta forma, em uma cultura densa, a intensidade relativa de radiação no comprimento de onda do vermelho distante $(710 \mathrm{~nm})$ para a radiação no vermelho $(660 \mathrm{~nm})$ aumenta rapidamente entre o topo do dossel e a superfície do solo (Bernardes, 1987). Esse mesmo fato ocorre em folhas mortas. 
Segundo Velini \& Negrisoli (2000), praticamente toda luz de comprimentos de onda entre 190 e $700 \mathrm{~nm}$ é retida quando incide sobre uma única folha seca de cana-de-açúcar. Como explicação prática, o autor utilizou como exemplo o herbicida oxyfluorfen que possui meia vida no solo de 5 a 55 dias, na presença da luz, entretanto, na ausência da luz tem sua meia vida aumentada para 292 dias. Velini \& Negrisoli (2000) afirmam que a degradação deste produto ocorre quase que exclusivamente pela ação da luz e conclui que, como quantidades mínimas de palha podem praticamente extinguir a luz vermelha, que atinge o solo, tanto a desintoxicação do solo, quanto a persistência do controle de plantas daninhas poderiam ser drasticamente modificados pela presença da palha, em áreas com colheita de cana crua. Dessa forma, nota-se que são vários os fatores que determinam a eficiência e persistência de herbicidas quando aplicados sobre coberturas mortas.

Mills \& Witt (1989), também observaram diferentes interações entre alguns herbicidas e a cobertura morta, sendo que produtos com características químicas semelhantes, que eram usados para as mesmas situações no controle de plantas daninhas tiveram seu comportamento modificado quando a aplicação foi feita sobre a cobertura morta. Para Pereira (1999), as áreas com plantio direto sempre apresentaram menor número total de plantas daninhas, sobretudo gramíneas, entretanto em experimento conduzido pelo autor, o controle da planta daninha Euphorbia heterophylla foi insatisfatório no tratamento com herbicida pré-emergente. $O$ autor justifica que durante a fase inicial do ensaio as chuvas foram escassas, o que pode ter causado uma rápida degradação pela luz solar, uma vez que penetrou no solo.

Dessa forma, pode-se observar que a eficácia na utilização de um herbicida aplicado sobre cobertura morta depende de vários fatores, ligados não somente ao produto e sua formulação, mas também ao tipo de palhada, e principalmente à fatores ambientais. Dentre os fatores ambientais, o que participa decisivamente na capacidade de um herbicida aplicado em pré- 
emergência atuar no controle de plantas daninhas, atingindo o solo, é a precipitação pluvial (Watts \& Hall, 1996).

Rodrigues et al. (2000a), avaliaram e eficiência dos herbicidas atrazine, simazine, trifluralin, acetochlor, metolachlor, alachlor, imazaquin, pendimethalin, metribuzin, clomazone e sulfentrazone, aplicados sobre cobertura de aveia-preta. Após 24 horas da aplicação foi feita a simulação de chuva de $20 \mathrm{~mm}$, após então os autores realizaram análises cromatográficas de resíduo em amostras de solo. Os resultados mostraram que antes da irrigação houve retenção de todos os produtos, entretanto, após a irrigação observou-se que os herbicidas atrazine e sulfentrazone atravessaram facilmente a camada de palha com recuperação de até $90 \%$. O autor classificou como mediamente lixiviáveis os produtos imazaquin, simazine, clomazone, metribuzin e isoxaflutole, com recuperação de 30 a $50 \%$, e como menos lixiviáveis, os produtos metolachlor, alachlor, acetochlor e trifluralin.

Segundo Banks \& Robinson (1986), a palha de trigo interceptou $50 \%$ ou mais da quantidade inicialmente aplicada dos herbicidas acetochlor, alachlor e metolachlor. Entretanto, esta quantidade pode ser variável em função não apenas da quantidade de chuva mas também em função da quantidade de palha presente na superfície do solo. Dessa forma, estes autores observaram que com quantidades de palha superiores a $4480 \mathrm{~kg} \mathrm{ha}^{-1}$, menos que $10 \%$ dos produtos alachlor e acetochlor inicialmente aplicado atingiram o solo, já para o herbicida metolachlor foram encontradas quantidades superiores à $30 \%$. Em relação a chuva, a partir de aproximadamente $70 \mathrm{~mm}$ não houve diferenças nas quantidades de herbicida recuperadas, que aumentaram em torno de 15 a $20 \%$ após o tratamento.

No que se refere a palha de cana-de-açúcar, existem poucos relatos na literatura entretanto, devido a grande importância do tema o interesse tem sido crescente. Hernandez et al. (2000), avaliaram em casa-de-vegetação a eficiência dos herbicidas imazapic e imazapic + pendimenthalin, aplicados sobre a palha de cana no controle das planta daninhas Cyperus rotundus, 
Panicum maximum, Brachiaria plantaginea, Digitaria horizontalis, Amaranthus viridis e Ipomoea purpurea, onde também foram feitas simulações de chuvas de 30,60 e $90 \mathrm{~mm}$. Os autores concluíram que ambos os herbicidas apresentam características adequadas de solubilidade e percolação, pois foram carregados para o solo proporcionando o controle das plantas daninhas, portanto indicam boas perspectivas para a utilização em áreas de colheita mecanizada de cana crua.

Segundo Rodrigues et al. (2000b), em trabalhos anteriores, foi verificado que alguns herbicidas são retidos na palha, mesmo ocorrendo chuvas logo após a aplicação. Entre os trabalhos citados pelo autor, existem os casos do metribuzin (Banks \& Robinson, 1982), oryzalin (Banks \& Robinson, 1984) e das acetanilidas, alachlor, acetolachlor e metolachlor (Banks \& Robinson, 1986) e trifluralin (Rodrigues et al., 1998). Entretanto, outros são lixiviados para o solo com chuvas que ocorram 24 horas após a aplicação como é o caso da atrazine (Fornarolli, 1997). Rodrigues et al. (2000b), salientam entretanto, que os resultados já mencionados nesta revisão foram obtidos apenas com os produtos isolados e não em misturas. Dessa forma, o autor encontrou, no solo, após irrigação de $20 \mathrm{~mm}$ + chuva de $28 \mathrm{~mm}, 24$ horas a pós a aplicação das misturas metolachlor + atrazine e atrazine + isoxaflutole, aplicados em préemergência no sistema de plantio direto de milho, sobre palha de aveia preta (Avena strigosa), metade das doses aplicadas da mistura metolachlor/atrazine; $10 \%$ de atrazine e $30 \%$ do isoxaflutole no caso da mistura atrazine/isoxaflutole.

Outro aspecto que deve ser considerado, além das misturas de herbicidas e quantidade de palha, é o tipo de palhada utilizada como cobertura morta no solo e seu estado de decomposição, uma vez que esta diretamente relacionado ao teor de matéria orgânica do solo, principalmente nos primeiros centímetros do perfil do solo. Segundo Graveel \& Turco (1997) a fração de pesticidas sorvidos é inversamente proporcional a profundidade do solo, em função da maior concentração de matéria orgânica na superfície do solo. Desta forma, Fadayomi (1988) justifica uma redução no controle de plantas daninhas 
em uma área experimental com cana-de-açúcar, pelo herbicida hexazinone isolado ou em misturas (no tanque e comercial) com diuron, em função da maior quantidade de matéria orgânica no solo, em relação às outras áreas testadas. 


\section{EFEITOS DA PALHA DE CANA-DE-AÇÚCAR NA INFESTAÇÃO DE PLANTAS DANINHAS E NA EFICÁCIA DO CONTROLE QUIMICO}

\section{Resumo}

A eficiência dos herbicidas diuron + hexazinone no controle das plantas daninhas Brachiaria decumbens Stapf; Brachiaria plantaginea (Link) Hitchc; Digitaria horizontalis Willd; Euphorbia heterophylla L.; Panicum maximum Jacq.; Ipomoea grandifolia (Dammer) O'Donell e a infestação natural da área experimental foi avaliada em dois locais, comparando tratamentos sem a palhada de cana resultante da colheita (sem palha) $x$ com a palhada resultante da colheita (com palha). O primeiro experimento foi instalado em janeiro de 1999, na Usina Santa Luiza em soqueira de cana-de-açúcar de terceiro corte, onde o tratamento com palha apresentava uma quantidade sobre o solo equivalente a $14 \mathrm{tha}^{-1}$. O segundo foi instalado em dezembro de 1999, na Usina Iracema em soqueira de terceiro corte, onde o tratamento com palha apresentava uma quantidade sobre o solo equivalente a $16 \mathrm{t} \mathrm{ha}^{-1}$. Após o corte da cana-de-açúcar as plantas daninhas foram semeadas em parcelas cobertas ou não por palha de cana, sob delineamento experimental de blocos ao acaso com parcelas sub-sub-divididas. Em seguida os herbicidas diuron + hexazinone foram aplicados nas doses de $0,0+0,0 ; 0,936+0,264 ; 1,117+$ 0,330 e $1,404+0,396 \mathrm{~kg}$ i.a. $\mathrm{ha}^{-1}$, respectivamente. Foram avaliadas as porcentagens de controle e de cobertura do solo pelas plantas daninhas, aos 15,40 e 80 dias após os tratamentos com herbicida (DAT). Os resultados 
foram submetidos a análise de variância com aplicação do teste $F$, de Tukey $e$ contrastes do teste $\mathrm{F}$. Conclui-se que a infestação das espécies de plantas daninhas E. heterophylla e I. grandifolia não foi afetada pela camada de palha deixada na superfície do solo. Além disso, o controle químico das plantas daninhas não foi significativamente afetado pela palha de cana-de-açúcar, comparativamente à área sem a presença de palha na superfície do solo.

\section{THE EFFECTS OF SUGARCANE CROP RESIDUE ON WEED ESTABLISHEMENT AND ON THE EFFICACY OF CHEMICAL WEED CONTROL}

\section{Summary}

The efficacy of the herbicides diuron + hexazinone on the control of the weeds Brachiaria decumbens Stapf; Brachiaria plantaginea (Link) Hitchc; Digitaria horizontalis Willd; Euphorbia heterophylla L.; Panicum maximum Jacq.; Ipomoea grandifolia (Dammer) O'Donell and the natural weed infestation in the experimental area was evaluated in two sites, comparing treatments without sugarcane trash residue left on the soil after harvest $x$ treatment with all sugarcane trash residue left on the soil surface after harvest. The first experiment was set in January of 1999 in a sugarcane raton of third harvest located in areas of the sugar mill Santa Luiza, where the treatment with sugarcane harvest trash residue left on the soil surface was $14 \mathrm{tha}^{-1}$ of crop residue. The second experiment was installed in December of 1999 in a raton of third harvest located in areas of the sugar mill Iracema, where the treatment with sugarcane harvest trash residue left on the soil surface was $16 \mathrm{tha}^{-1}$ of crop residue. The weeds were seeded right after sugarcane harvest in the plots with and without sugarcane trash residue, in an experimental design of randomized completely blocks with sub-sub-plots. After that, it was sprayed the herbicide 
treatments with the herbicides diuron + hexazinone at the rates of $0.0+0.0$; $0.936+0.264 ; 1.117+0.330$ and $1.404+0.396 \mathrm{~kg}$ a.i. ha ${ }^{-1}$, respectively. It was evaluated the weed control percentage and soil cover by the weeds at 15, 40 and 80 days after herbicide treatments (DAT). The results were submitted to analysis of variance with application of $F$ test, Tukey test and contrasts of the $F$ test. It was concluded that the infestation of the weeds $E$. heterophylla and $I$. Grandifolia were not affected by the sugarcane crop residue left on the soil surface. Furthermore, the trash residue, when compared to the treatments without the residue did not affect the chemical weed control of the weeds.

\subsection{Introdução}

A quantidade de palha de cana-de-açúcar que permanece na superficie do solo após o corte sem queima, pode chegar a $20 \mathrm{t} \mathrm{ha}^{-1} \mathrm{e}$ assim provocar alterações no sistema de produção e no agroecossitema da cultura. Dentre estas alterações destaca-se a mudança na flora daninha que é observada nas áreas onde este sistema de colheita tem sido adotado. Dessa forma, algumas das principais espécies que fazem parte da flora infestante dos canaviais que são colhidos após a queima deixam de ser importantes e são substituídas por outras que melhor se adaptam a este novo sistema.

Desde o início da utilização do sistema de colheita de cana crua (nome dado para as áreas onde a cana é colhida sem queima), observou-se um alto grau de controle de plantas daninhas pela palha de cana-de-açúcar. Em certos casos, o nível de controle atingido é maior que $90 \%$, sendo portanto, superior a determinadas aplicações de herbicidas (Manechini, 2000). Entretanto, observa-se também que existem várias espécies que escapam ao controle da palhada e tornam-se problemáticas nestas áreas (Martins et al., 1999). Além disso, o nível de controle é altamente dependente da quantidade de palha deixada no solo, sua distribuição, etc. Desta forma a utilização de 
herbicidas em cana crua continua sendo uma das principais medidas de manejo de plantas daninhas, principalmente em culturas com pequena produção de palha.

Até 0 momento, poucos trabalhos de pesquisa foram feitos com o objetivo de avaliar o comportamento de herbicidas aplicados sobre a palha de cana, entretanto, sabe-se que a palhada presente na superfície do solo intercepta uma quantidade considerável de herbicida aplicado em condições de pré-emergência, o qual não atinge o solo (Banks \& Robinson, 1986; Mills \& Witt, 1989). Desta forma, a aplicação de herbicidas pré-emergentes em áreas de colheita de cana crua é restrita aos produtos herbicida que conseguem atingir o solo, atravessando a palhada deixada na superfície.

Dentre os herbicidas utilizados em cana-de-açúcar, apresentam destaque os de aplicação em pré-emergência e pós-emergência inicial (Rodrigues \& Almeida, 1998; Lorenzi, 2000). Dentre estes, o herbicida diuron isolado ou em mistura com o herbicida hexazinone é extensivamente utilizado em pré-emergência, tanto em áreas de cana planta, como em cana soca por apresentarem amplo espectro de controle de plantas daninhas (Fadayomi, 1988), e também seletividade à cultura da cana-de-açúcar.

Desta forma, foi conduzido este trabalho com o objetivo de avaliar a eficiência da palha de cana deixada na superfície do solo após a colheita e da mistura comercial dos herbicidas diuron $\left(468 \mathrm{~g} \mathrm{~kg}^{-1}\right)$ + hexazinone $\left(132 \mathrm{~g} \mathrm{~kg}^{-1}\right)$, aplicado em condições de campo em pré-emergência, no controle das plantas daninhas $B$. decumbens; $B$. plantaginea ; $D$. horizontalis; $E$. heterophylla; $P$. maximum; I. grandifolia, e sobre a infestação natural da área experimental, aplicado em parcelas com e sem palha de cana deixada na superfície do solo. 


\subsection{Material e Métodos}

\subsubsection{Usina Santa Luiza}

Em janeiro de 1999 foi instalado um experimento na Usina Santa Luiza, localizado no município de Matão-SP, em área de cana soca de terceiro corte, plantada com a variedade SP79-2233, em solo tipo Podsólico vermelho amarelo (Tabela 1). As plantas daninhas estudadas foram: $B$. decumbens; $B$. plantaginea; $D$. horizontalis; $P$. maximum; I. grandifolia e infestação natural; e o herbicida aplicado foi a mistura comercial de diuron + hexazinone em préemergência nas doses de $0,0+0,0 ; 0,936+0,264 ; 1,117+0,330 ; 1,404+$ $0,396 \mathrm{~kg}$ i.a. $\mathrm{ha}^{-1}$ respectivamente, em parcelas com palha de cana deixada na superfície do solo após a colheita sem queima $x$ parcelas cuja palha foi retirada. O produto comercial utilizado foi o Velpar $\mathrm{K}$, que contém $468 \mathrm{~g}$ de diuron +132 $\mathrm{g}$ de hexazinone $\mathrm{kg}^{-1}$, em formulação do tipo grânulos autodispersiveis em água (GRDA), produzido pela Du Pont do Brasil.

Tabela 1. Análises química e física do solo da área experimental, a partir de amostras retiradas das parcelas com cana crua, da Usina Santa Luiza.

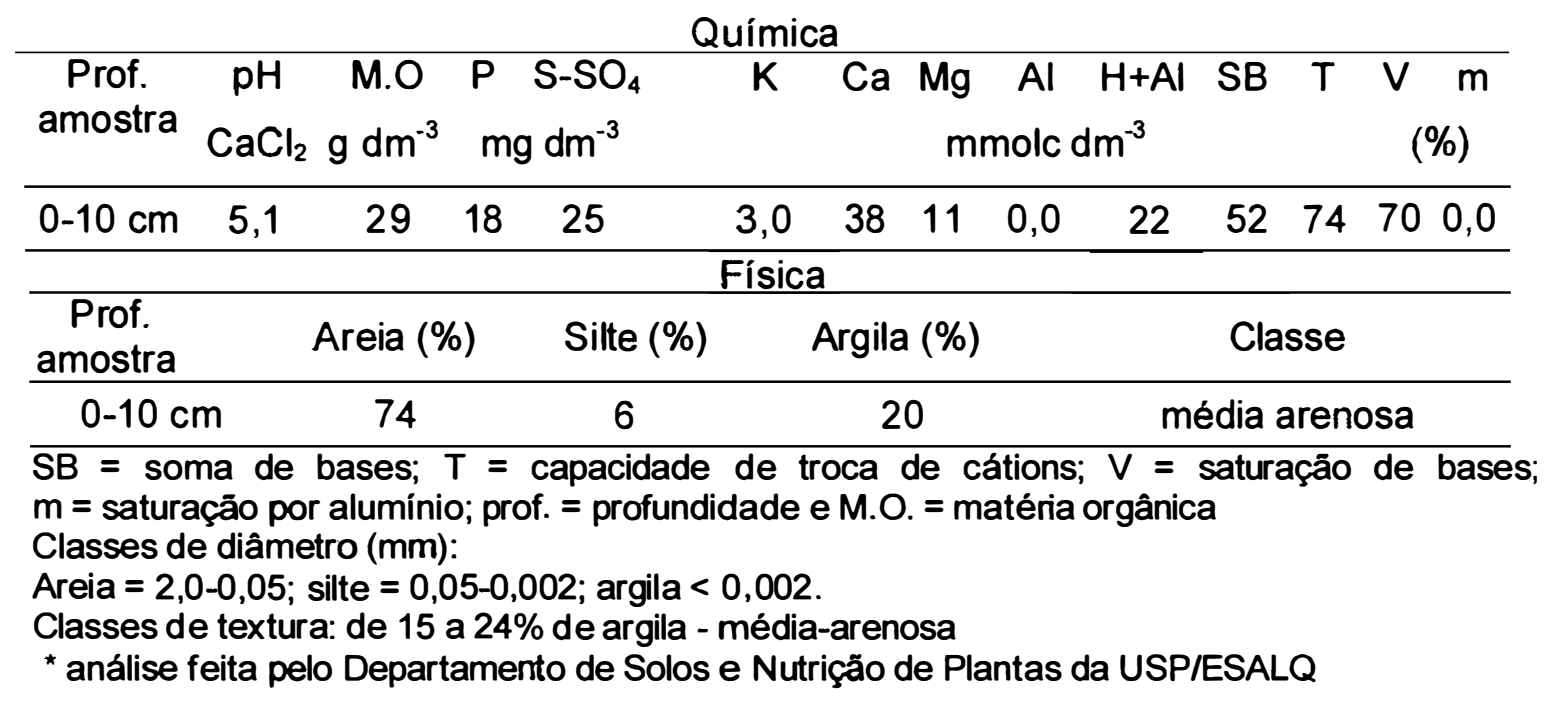


O delineamento experimental utilizado foi o de blocos ao acaso com parcelas sub-sub-divididas, utilizando 3 fatores de estudo ou seja: palha (2 com e sem) $x$ planta daninha ( 5 espécies + infestação natural) $x$ herbicida ( 3 doses + testemunha sem herbicida), totalizando 192 sub-sub-parcelas, pois foram utilizadas quatro repetições.

As sub-sub-parcelas eram constituídas de uma entrelinha de canade-açúcar, de $5 \mathrm{~m}$ de comprimento e 1,4 $\mathrm{m}$ de largura, totalizando uma área de $7,0 \mathrm{~m}^{2}$. Em cada parcela onde foi aplicado o herbicida, deixou-se uma faixa de 1 metro sem aplicação do herbicida como testemunha e as avaliações de controle (\%) foram feitas baseadas nesta faixa testemunha. Nestas avaliações zero representou ausência de controle e 100 controle total das plantas daninhas sendo os valores intermediários proporcionais ao controle.

A instalação foi feita logo após o corte da cana na área, na primeira quinzena do mês de Janeiro de 1999, sendo que a quantidade média de palha na superfície do solo após o corte era de $14 \mathrm{t} \mathrm{ha}^{-1}$. Para a semeadura das plantas daninhas na sub-sub-parcela com palha foi retirada inicialmente a palha, com posterior semeadura e logo após a mesma palha foi retornada. Para a área sem palha, o solo foi descoberto e em seguida foi feita a semeadura das plantas. Em cada parcela foi feita a semeadura a lanço da planta daninha correspondente, em quantidade de 100 sementes $\mathrm{m}^{2} \mathrm{com}$ incorporação ao solo através de rastelo. Em seguida foi aplicado o herbicida com pulverizador costal de pressão constante, com $\mathrm{CO}_{2}$, em volume de calda de aproximadamente $300 \mathrm{~L} \mathrm{ha}^{-1} \mathrm{em}$ sentido longitudinal às linhas de cana. As condições climáticas no dia da instalação do experimento (10/01/1999) estavam adequadas para a pulverização (ausência de ventos, a aplicação iniciou-se as 11:00 horas com céu nublado, temperatura de $28^{\circ} \mathrm{C}$, solo úmido, umidade relativa do ar de $80 \%$ ).

Foram realizadas avaliações aos 15, 40 e 80 dias após o tratamento (DAT), através da porcentagem de controle e de cobertura do solo. No entanto, em função das fortes chuvas no período, que excederam às médias mensais 
históricas mais elevadas (Tabela 2), as avaliações do efeito de interação palha $x$ herbicida foram prejudicadas, devido ao fato do herbicida ter sido lixiviado em excesso, resultando em padrões de controle não condizentes com o produto.

A planta daninha $P$. maximum não germinou, sendo desconsiderada de todas as avaliações, o mesmo ocorreu com a infestação natural, em função do aparecimento apenas de tiririca ( $C$. rotundus) além da perda de algumas parcelas em função do excesso de umidade.

Tabela 2. Médias de precipitação pluvial mensal no município de Matão/SP.

\begin{tabular}{|c|c|c|c|}
\hline \multirow{2}{*}{ Mês } & \multicolumn{3}{|c|}{$\begin{array}{l}\text { Precipitação pluvial (mm) } \\
\text { Ano }\end{array}$} \\
\hline & 98 & 99 & $(1941-1970)$ \\
\hline Janeiro & 94 & 394 & 251 \\
\hline Fevereiro & 255 & 227 & 232 \\
\hline Março & 181 & 194 & 153 \\
\hline Abril & 63 & 76 & 51 \\
\hline Maio & 94 & 25 & 41 \\
\hline Junho & 1 & 37 & 26 \\
\hline Julho & 6 & 2 & 22 \\
\hline Agosto & 35 & 0 & 15 \\
\hline Setembro & 42 & 83 & 40 \\
\hline Outubro & 239 & 42 & 112 \\
\hline Novembro & 71 & 98 & 149 \\
\hline Dezembro & 320 & 263 & 216 \\
\hline
\end{tabular}

Fonte: Copersucar, 1998; Copersucar, 1999; Escola Superior de Agricultura "Luiz de Queiroz" (2001).

Os resultados provenientes do campo foram analisados através de análise de variância, com aplicação do teste $F$, sendo que as interações significativas tiveram suas médias comparadas ente si através do teste de Tukey $(P<0,05)$ e contrastes do teste $F$. Para análise dos resultados de porcentagem, estes foram transformados para arco seno da raiz quadrada da 
porcentagem divido por 100 , com o objetivo de normalização dos dados cujos valores originais não obedeciam a distribuição normal.

\subsubsection{Usina Iracema}

Em dezembro de 1999 foi instalado o experimento na Usina Iracema, localizada no município de Iracemápolis-SP, em área de cana soca de terceiro corte, plantada com a variedade SP79-2233, em solo Latosolo vermelho escuro (Tabela 3). As plantas daninhas estudadas foram: $B$. decumbens; $B$. plantaginea; D. horizontalis; E. heterophylla; P. maximum; I. grandifolia e infestação natural; e o herbicida aplicado foi a mistura comercial dos herbicidas diuron e hexazinone em pré-emergência nas doses de $0,0+0,0 ; 0,936+0,264$; $1,117+0,330$ e $1,404+0,396 \mathrm{~kg}$ i.a. $\mathrm{ha}^{-1}$, respectivamente, em parcelas com palha de cana deixada na superfície do solo após a colheita sem queima $x$ parcelas cuja palha foi retirada. O produto comercial utilizado foi o Velpar $K$, que contém $468 \mathrm{~g}$ de diuron $+132 \mathrm{~g}$ de hexazinone $\mathrm{kg}^{-1}$, em formulação do tipo grânulos autodispersiveis em água (GRDA) produzido pela Du Pont do Brasil.

Tabela 3. Análises química e física do solo da área experimental, a partir de amostras retiradas das parcelas com cana crua, da Usina Iracema.

Química

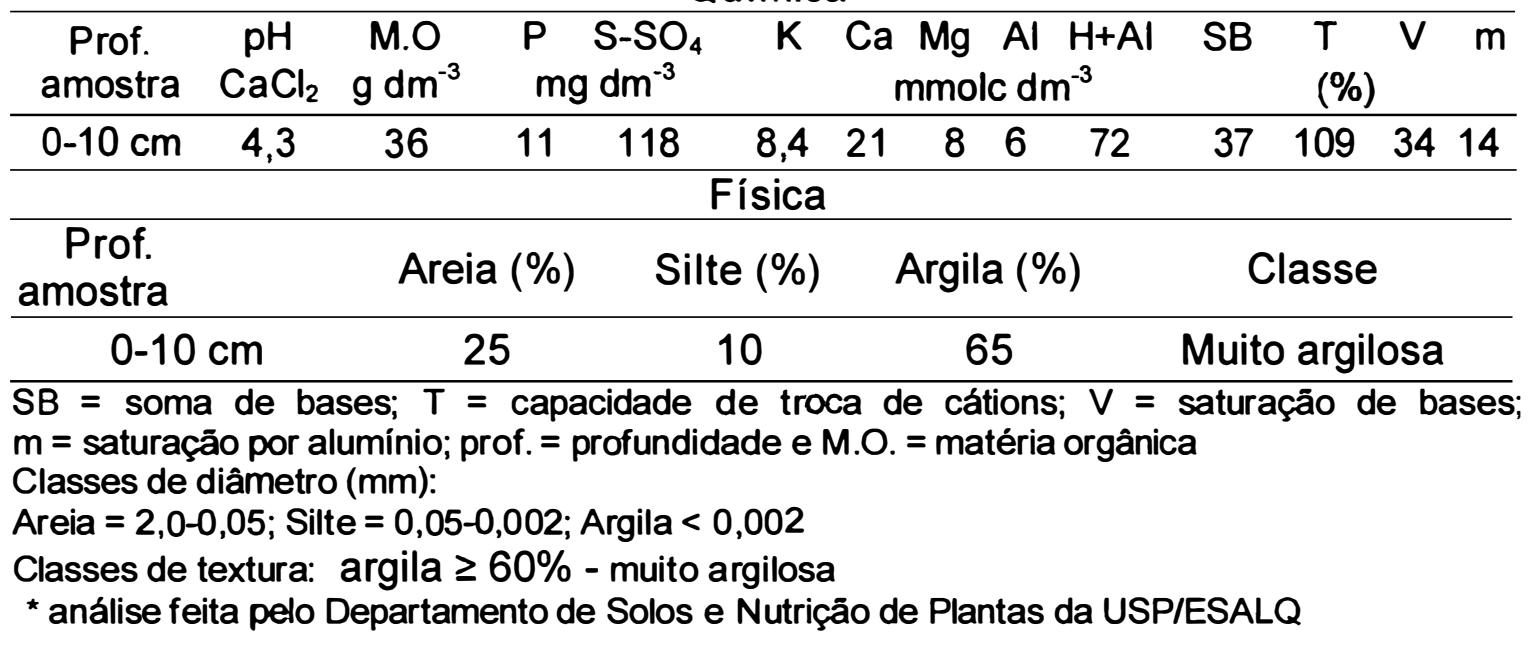


O delineamento experimental utilizado foi o de blocos ao acaso com parcelas sub-sub-divididas, utilizando 3 fatores de estudo ou seja: palha (2 com e sem) $\times$ planta daninha (6 espécies + infestação natural) $\times$ herbicida ( 3 doses + testemunha sem herbicida), totalizando 224 sub-sub-parcelas, pois foram utilizadas quatro repetições.

As sub-sub-parcelas constituíram-se de uma entrelinha de cana-deaçúcar de $5 \mathrm{~m}$ de comprimento e 1,4 $\mathrm{m}$ de largura, totalizando uma área de 7,0 $\mathrm{m}^{2}$. Em cada parcela onde foi aplicado o herbicida deixou-se uma faixa de 1 metro sem aplicação do herbicida como testemunha, e as avaliações de controle (\%) foram feitas baseadas nesta faixa testemunha. Nestas condições zero representou ausência de controle e 100 controle total das plantas daninhas, sendo os valores intermediários proporcionais ao contorle.

A instalação teve início logo após o corte da cana na área, na primeira quinzena de Dezembro de 1999, sendo que a quantidade média de palha na superfície do solo após o corte era de $16 \mathrm{t} \mathrm{ha}^{-1}$. Para a semeadura das plantas daninhas na sub-sub-parcela com palha foi retirada inicialmente a palha, com posterior semeadura e logo após a mesma palha foi retornada. Para a área sem palha, o solo foi descoberto e em seguida foi feita a semeadura das plantas. Neste experimento, foram semeadas duas espécies de plantas daninhas por parcela, na quantidade de 100 sementes por metro, através de uma sulcação seguido da semeadura e cobrimento superficial com solo. Em seguida foi aplicado o herbicida com pulverizador costal de pressão constante com $\mathrm{CO}_{2}$, em volume de calda de $300 \mathrm{~L} \mathrm{ha}^{-1}$ longitudinalmente as linhas de cana. As condições climáticas no dia da instalação do experimento (10/12/1999) estavam adequadas para a pulverização (ausência de ventos, aplicação iniciou-se as 18:00 horas com temperatura de $27^{\circ} \mathrm{C}$, solo úmido e umidade relativa do ar de $85 \%$ ). No momento da aplicação, a palha apresentava baixa umidade; entretanto, durante o período de condução do experimento, as médias de precipitação pluvial foram satisfatórias (Tabela 4). 
Foram realizadas avaliações aos 15, 40 e 80 dias após a semeadura das plantas daninhas e aplicação do herbicida (DAT), através da porcentagem de controle e de cobertura do solo. Os dados provenientes do campo foram analisados através de análise de variância, com aplicação do teste $F$, sendo que as interações significativas tiveram suas médias comparadas ente si através do teste de Tukey $(P<0,05)$, e contrastes do teste $F$. Para análise, os resultados de porcentagem foram transformados para arco seno da raiz quadrada da porcentagem divido por 100 , com o objetivo de normalização dos dados cujos valores originais não obedeciam a distribuição normal.

Tabela 4. Médias de precipitaçāo pluvial mensal no municipio de Piracicaba/SP*.

\begin{tabular}{lccc}
\hline \multirow{2}{*}{\multicolumn{1}{c}{ Mês }} & \multicolumn{3}{c}{$\begin{array}{c}\text { Precipitação pluvial }(\mathrm{mm}) \\
\text { Ano }\end{array}$} \\
\cline { 2 - 4 } & 99 & 2000 & $(1917-1998)$ \\
\hline Janeiro & 382 & 236 & 241 \\
Fevereiro & 198 & 124 & 190 \\
Março & 211 & 185 & 131 \\
Abril & 89 & 0,8 & 52 \\
Maio & 51 & 5,3 & 38 \\
Junho & 68 & 5,2 & 44 \\
Julho & 2,7 & 60 & 23 \\
Agosto & 0,0 & 84 & 25 \\
Setembro & 86 & 91 & 50 \\
Outubro & 28 & 114 & 122 \\
Novembro & 52 & 239 & 126 \\
Dezembro & 270 & 196 & 192
\end{tabular}

Fonte: Escola Superior de Agricultura "Luiz de Queiroz" (2001); Sentelhas et al. (2001). "posto meteorológico a $15 \mathrm{~km}$ da área experimental.

\subsection{Resultados e Discussão}

\subsubsection{Usina Santa Luiza}

As médias da porcentagem de controle das 4 espécies de plantas daninhas estudadas nos diversos tratamentos encontram-se nas Tabelas 5 a 8 . 
O efeito da palha de cana sobre o desenvolvimento das espécies daninhas nas parcelas sem aplicação do herbicida pode ser observado nas Figuras 1 a 4, através do parâmetro de cobertura do solo (\%).

Tabela 5. Porcentagem de controle da planta daninha corda de viola ( $I$. grandifolia), Usina Santa Luiza.

\begin{tabular}{ccccccc}
\hline $\begin{array}{c}\text { Dose } \\
\left.(\mathrm{kg} \mathrm{i.a} \mathrm{ha})^{-1}\right)^{1}\end{array}$ & \multicolumn{2}{c}{ 15 DAT } & \multicolumn{2}{c}{40 DAT } & \multicolumn{2}{c}{80 DAT } \\
diuron + hexazinone & $\begin{array}{c}\text { sem } \\
\text { palha }\end{array}$ & $\begin{array}{c}\text { com } \\
\text { palha }\end{array}$ & $\begin{array}{c}\text { sem } \\
\text { palha }\end{array}$ & $\begin{array}{c}\text { com } \\
\text { palha }\end{array}$ & $\begin{array}{c}\text { sem } \\
\text { palha }\end{array}$ & $\begin{array}{c}\text { com } \\
\text { palha }\end{array}$ \\
\hline $0,0+0,0^{3}$ & $0 \mathrm{a}^{2}$ & $0 \mathrm{a}$ & $0 \mathrm{a}$ & $0 \mathrm{a}$ & $0 \mathrm{a}$ & $0 \mathrm{a}$ \\
$0,936+0,264$ & $98 \mathrm{~b}$ & $100 \mathrm{~b}$ & $98 \mathrm{~b}$ & $99 \mathrm{~b}$ & $85 \mathrm{~b}$ & $86 \mathrm{~b}$ \\
$1,117+0,330$ & $96 \mathrm{~b}$ & $100 \mathrm{~b}$ & $99 \mathrm{~b}$ & $98 \mathrm{~b}$ & $80 \mathrm{~b}$ & $91 \mathrm{~b}$ \\
$1,404+0,396$ & $100 \mathrm{~b}$ & $100 \mathrm{~b}$ & $100 \mathrm{~b}$ & $100 \mathrm{~b}$ & $83 \mathrm{~b}$ & $89 \mathrm{~b}$ \\
\hline
\end{tabular}

${ }^{1}$ Herbicida contendo $468 \mathrm{~g} \mathrm{~kg}^{-1}$ de diuron $+132 \mathrm{~g} \mathrm{~kg}^{-1}$ de hexazinone, na formulação comercial.

${ }^{2}$ Médias nas colunas seguidas por letras distintas, são diferentes entre si $(P<0,05)$; médias nas linhas dentro de cada fator época (15, 40 e 80 DAT), seguidas por asteristico ( $\left.{ }^{*}\right)$, diferem entre si dentro da variável palha (com ou sem) $(P<0,05 ; C V=15 \%)$. ${ }^{3}$ Controle na faixa testemunha sem aplicação de herbicida.

Tabela 6. Porcentagem de controle da planta daninha capim marmelada ( $B$. plantaginea), Usina Santa Luiza.

\begin{tabular}{ccccccc}
\hline $\begin{array}{c}\text { Dose } \\
\left.(\mathrm{kg} \mathrm{i.a} \mathrm{ha})^{-1}\right)^{1}\end{array}$ & \multicolumn{2}{c}{ 15 DAT } & \multicolumn{2}{c}{40 DAT } & \multicolumn{2}{c}{80 DAT } \\
diuron + hexazinone & sem & com & sem & com & sem & com \\
& palha & palha & palha & palha & palha & palha \\
\hline $0,0+0,0^{3}$ & $0 a^{2}$ & $0 a$ & $0 a$ & $0 a$ & $0 a$ & $0 a$ \\
$0,936+0,264$ & $60 b^{*}$ & $100 b^{*}$ & $28 b^{*}$ & $96 b^{*}$ & $36 b^{*}$ & $100 b^{*}$ \\
$1,117+0,330$ & $85 b^{*}$ & $100 b^{*}$ & $77 \mathrm{~cd}^{*}$ & $100 b^{*}$ & $50 b^{*}$ & $100 b^{*}$ \\
$1,404+0,396$ & $67 b^{*}$ & $100 b^{*}$ & $53 d^{*}$ & $99 b^{*}$ & $50 b^{*}$ & $100 b^{*}$ \\
\hline
\end{tabular}

${ }^{1}$ Herbicida contendo $468 \mathrm{~g} \mathrm{~kg}^{-1}$ de diuron $+132 \mathrm{~g} \mathrm{~kg}^{-1}$ de hexazinone, na formulação comercial.

${ }^{2}$ Médias nas colunas seguidas por letras distintas, são diferentes entre si $(P<0,05)$; médias nas linhas dentro de cada fator época (15, 40 e 80 DAT), seguidas por asterístico ( $\left.{ }^{*}\right)$, diferem entre si dentro da variável palha (com ou sem) $(P<0,05 ; C V=15 \%) .{ }^{3}$ Controle na faixa testemunha sem aplicação de herbicida. 
Tabela 7. Porcentagem de controle da planta daninha capim colchão ( $D$. horizontalis), Usina Santa Luiza.

\begin{tabular}{ccccccc}
\hline $\begin{array}{c}\text { Dose } \\
(\mathrm{kg} \mathrm{i.a} \mathrm{ha})^{-1}\end{array}$ & \multicolumn{2}{c}{$15 \mathrm{DAT}$} & \multicolumn{2}{c}{$40 \mathrm{DAT}$} & \multicolumn{2}{c}{$80 \mathrm{DAT}$} \\
diuron + hexazinone & $\begin{array}{c}\text { sem } \\
\text { palha }\end{array}$ & $\begin{array}{c}\text { Com } \\
\text { palha }\end{array}$ & $\begin{array}{c}\text { sem } \\
\text { palha }\end{array}$ & $\begin{array}{c}\text { com sem } \\
\text { palha }\end{array}$ palha palha \\
\hline $0,0+0,0^{3}$ & $0 \mathrm{a}^{2}$ & $0 \mathrm{a}$ & $0 \mathrm{a}$ & $0 \mathrm{a}$ & $0 \mathrm{a}$ & $0 \mathrm{a}$ \\
$0,936+0,264$ & $83 \mathrm{~b}$ & $100 \mathrm{~b}^{*}$ & $28 \mathrm{~b}^{*}$ & $98 \mathrm{~b}^{*}$ & $23 \mathrm{~b}^{*}$ & $100 \mathrm{~b}^{*}$ \\
$1,117+0,330$ & $94 \mathrm{bc}$ & $100 \mathrm{~b}$ & $66 \mathrm{c}^{*}$ & $100 \mathrm{~b}^{*}$ & $43 \mathrm{~b}^{*}$ & $100 \mathrm{~b}^{*}$ \\
$1,404+0,396$ & $100 \mathrm{c}$ & $100 \mathrm{~b}$ & $80 \mathrm{c}^{*}$ & $100 \mathrm{~b}^{*}$ & $45 \mathrm{~b}^{*}$ & $100 \mathrm{~b}^{*}$ \\
\hline
\end{tabular}

1 Herbicida contendo $468 \mathrm{~g} \mathrm{~kg}^{-1}$ de diuron $+132 \mathrm{~g} \mathrm{~kg}^{-1}$ de hexazinone, na formulação comercial. ${ }^{2}$ Médias nas colunas seguidas por letras distintas, são diferentes entre si $(P<0,05)$; médias nas linhas dentro de cada fator época (15, 40 e $80 \mathrm{DAT}$ ), seguidas por asterístico ( $\left.{ }^{\star}\right)$, diferem entre si dentro da variável palha (com ou sem) $(P<0,05 ; C V=15 \%)$. ${ }^{3}$ Controle na faixa testemunha sem aplicação de herbicida.

Tabela 8. Porcentagem de controle da planta daninha capim braquiária ( $B$. decumbens), Usina Santa Luiza.

\begin{tabular}{ccccccc}
\hline $\begin{array}{c}\text { Dose } \\
\left.(\mathrm{kg} \mathrm{i.a} \mathrm{ha})^{-1}\right)^{1}\end{array}$ & \multicolumn{2}{c}{$15 \mathrm{DAT}$} & \multicolumn{2}{c}{$40 \mathrm{DAT}$} & \multicolumn{2}{c}{$80 \mathrm{DAT}$} \\
diuron + hexazinone & $\begin{array}{c}\text { sem } \\
\text { palha }\end{array}$ & $\begin{array}{c}\text { com } \\
\text { palha }\end{array}$ & $\begin{array}{c}\text { Sem } \\
\text { palha }\end{array}$ & $\begin{array}{c}\text { com } \\
\text { palha }\end{array}$ & $\begin{array}{c}\text { sem } \\
\text { palha }\end{array}$ & $\begin{array}{c}\text { com } \\
\text { palha }\end{array}$ \\
\hline $0,0+0,0^{3}$ & $0 \mathrm{a}^{2}$ & $0 \mathrm{a}$ & $0 \mathrm{a}$ & $0 \mathrm{a}$ & $0 \mathrm{a}$ & $0 \mathrm{a}$ \\
$0,936+0,264$ & $53 \mathrm{~b}^{*}$ & $100 \mathrm{~b}^{*}$ & $35 \mathrm{~b}^{*}$ & $98 \mathrm{~b}^{*}$ & $30 \mathrm{~b}^{*}$ & $100 \mathrm{~b}^{*}$ \\
$1,117+0,330$ & $57 \mathrm{~b}^{*}$ & $100 \mathrm{~b}^{*}$ & $43 \mathrm{~b}^{*}$ & $98 \mathrm{~b}^{*}$ & $32 \mathrm{~b}^{*}$ & $100 \mathrm{~b}^{*}$ \\
$1,404+0,396$ & $71 \mathrm{~b}^{*}$ & $100 \mathrm{~b}^{*}$ & $54 \mathrm{~b}^{*}$ & $100 \mathrm{~b}^{*}$ & $43 \mathrm{~b}^{*}$ & $100 \mathrm{~b}^{*}$ \\
\hline
\end{tabular}

${ }^{1}$ Herbicida contendo $468 \mathrm{~g} \mathrm{~kg}^{-1}$ de diuron $+132 \mathrm{~g} \mathrm{~kg}^{-1}$ de hexazinone, na formulação comercial. ${ }^{2}$ Médias nas colunas seguidas por letras distintas, são diferentes entre si $(P<0,05)$; médias nas linhas dentro de cada fator época (15, 40 e $80 \mathrm{DAT}$ ), seguidas por asterístico ( $\left.{ }^{*}\right)$, diferem entre si dentro da variável palha (com ou sem) $(P<0,05 ; C V=15 \%)$. ${ }^{3}$ Controle na faixa testemunha sem aplicação de herbicida. 
Nas tabelas 5 a 8 pode-se observar que a eficácia do herbicida no controle das plantas daninhas principalmente nas áreas sem palha foi pequeno. No caso das parcelas com palha, o controle das plantas daninhas foi elevado, pois além do efeito herbicida, existe o efeito físico da palha de cana. Embora haja possibilidade do efeito alelopático, o que não deve ser descartado, fica mais evidente que as plantas não germinaram em função da ausência da luz, já que os efeitos alelopáticos seriam menos seletivos (Almeida, 1988; Veline \& Negrisoli, 2000). Nas parcelas sem palha, com exceção da espécie I. grandifolia o controle foi abaixo do que normalmente ocorre em condições normais. Isto pode ser explicado em função da grande quantidade de chuva no período, cerca de duas vezes maior que o normal.

Observando os valores de porcentagem de controle nota-se que ao longo do tempo ocorre um decréscimo no controle das espécies, principalmente no tratamento com palha. Este fato pode ser explicado por uma maior lixiviação de herbicidas no sistema de cana crua. Segundo Watts \& Hall (1996) áreas com cobertura vegetal morta tendem a apresentar maiores perdas de herbicidas por lixiviação, já em sistemas convencionais, a forma principal de perda de herbicidas seria por escorrimento superficial.

Em relação ao efeito da palha sobre o desenvolvimento das plantas daninhas, observa-se na Figura 3, que I. grandifolia conseguiu superar a camada de palha e aos 80 dias cobria cerca de $19 \%$ da área. Aos 40 dias notase uma cobertura de solo pela $B$. decumbens de $8 \%$ devido a emergência através da camada de palha (Figura 4). No entanto, quanto à $D$. horizontalis (Figura 1) e B. plantaginea (Figura 2), praticamente houve uma supressão total da emergência destas plantas daninhas, pela palha de cana-de-açúcar. 


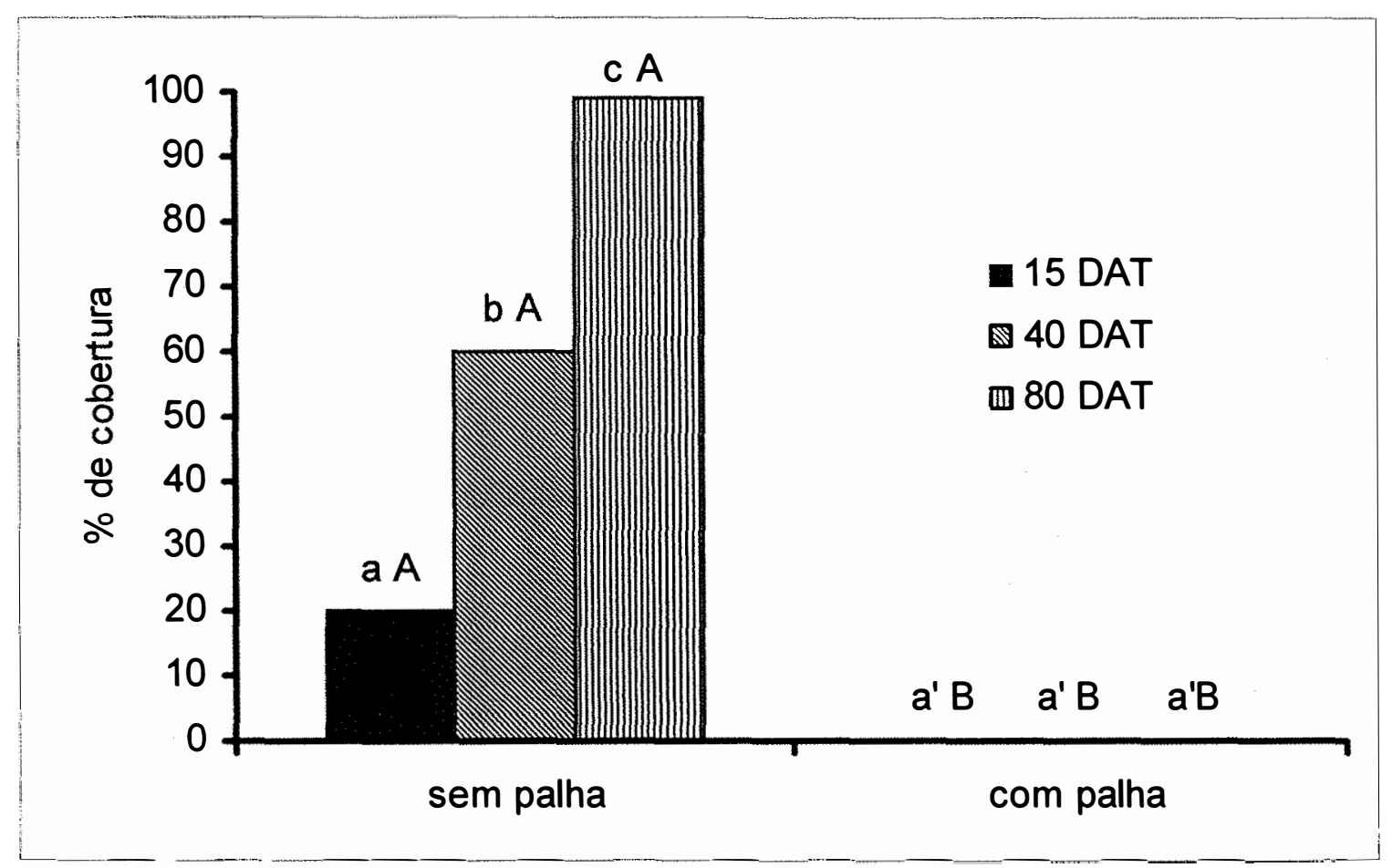

Figura 1- Área do solo coberto pela espécie $D$. horizontalis (15, 40 e 80 DAT), nas parcelas que não receberam herbicida, Usina Santa Luiza. (Letras minúsculas iguais dentro do fator época para os níveis do fator palha, não diferem entre si $(P<0,05)$ pelo contraste do teste $F$. Letras maiúsculas iguais dentro do fator palha, para os níveis do fator época, não diferem entre si $(P<0,05)$ pelo contraste do teste $F)$. 


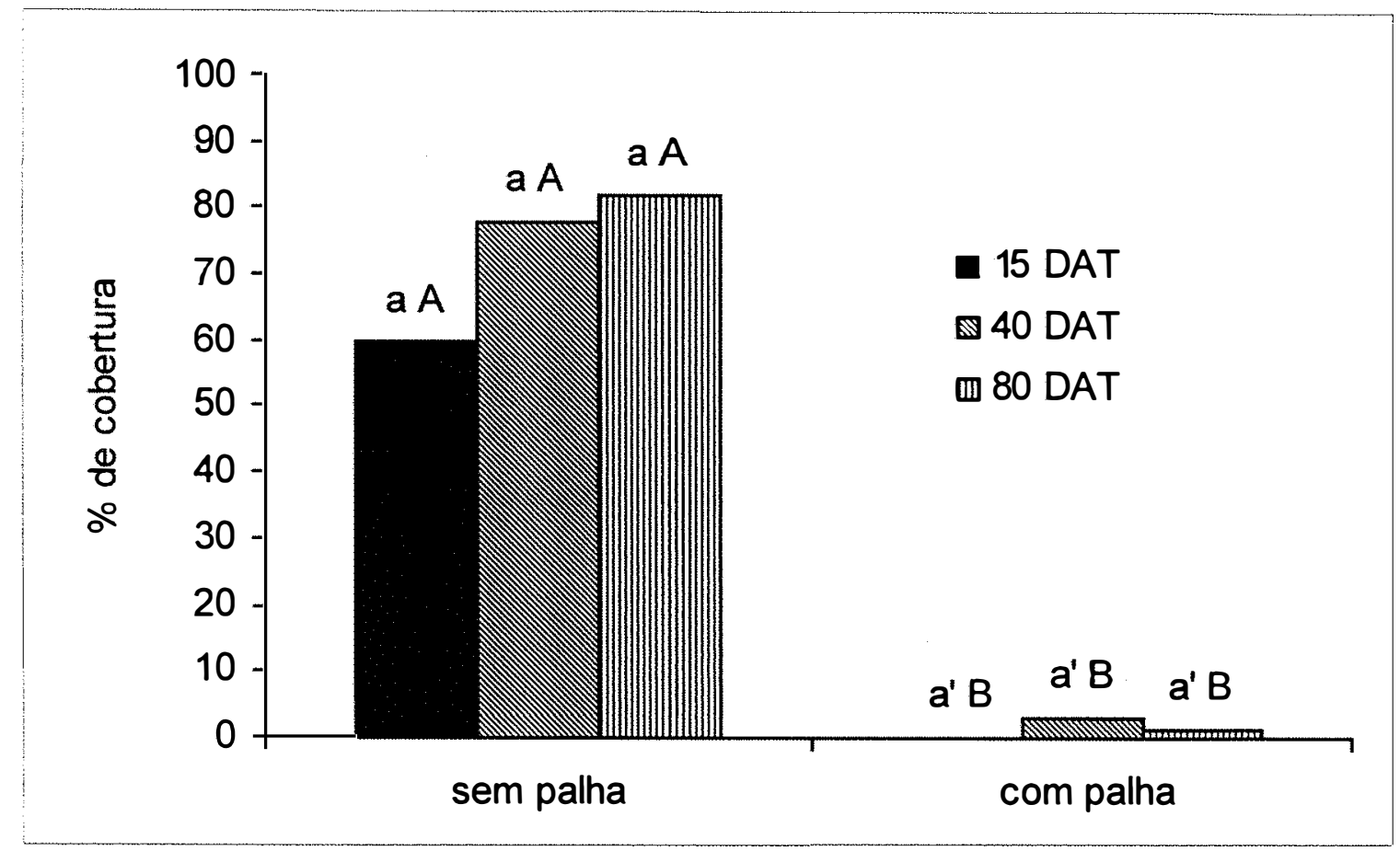

Figura 2 - Área do solo coberto pela espécie B. plantaginea (15, 40 e 80 DAT), nas parcelas que não receberam herbicida, Usina Santa Luiza. (Letras minúsculas iguais dentro do fator época para os níveis do fator palha, não diferem entre si $(P<0,05)$ pelo contraste do teste $F$. Letras maiúsculas iguais dentro do fator palha, para os níveis do fator época, não diferem entre si $(P<0,05)$ pelo contraste do teste $F)$. 


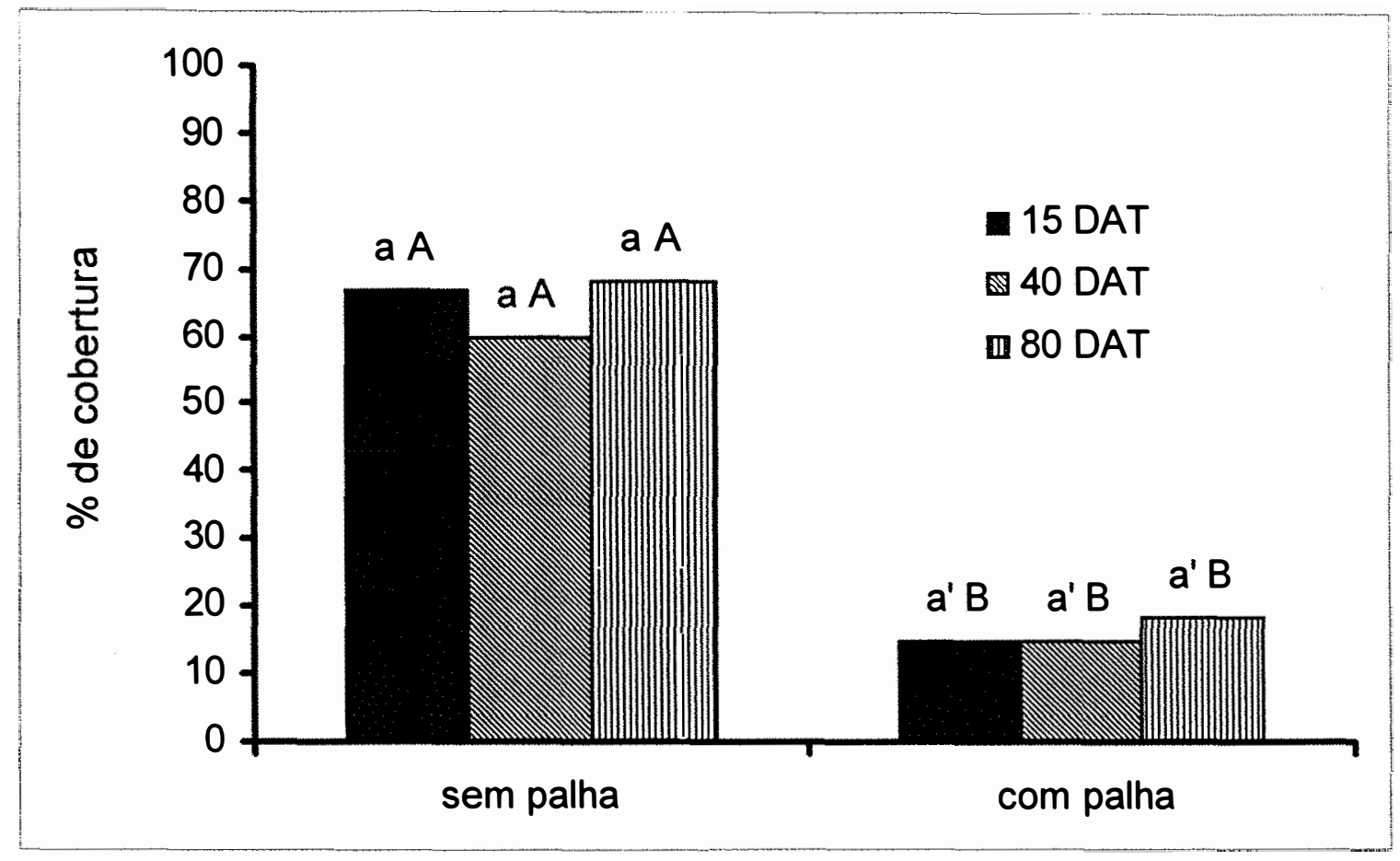

Figura 3 - Área do solo coberto pela espécie I. grandifolia (15, 40 e 80 DAT), nas parcelas que não receberam herbicida, Usina Santa Luiza. (Letras minúsculas iguais dentro do fator época para os níveis do fator palha, não diferem entre si $(P<0,05)$ pelo contraste do teste $F$. Letras maiúsculas iguais dentro do fator palha, para os níveis do fator época, não diferem entre si $(P<0,05)$ pelo contraste do teste $F)$. 


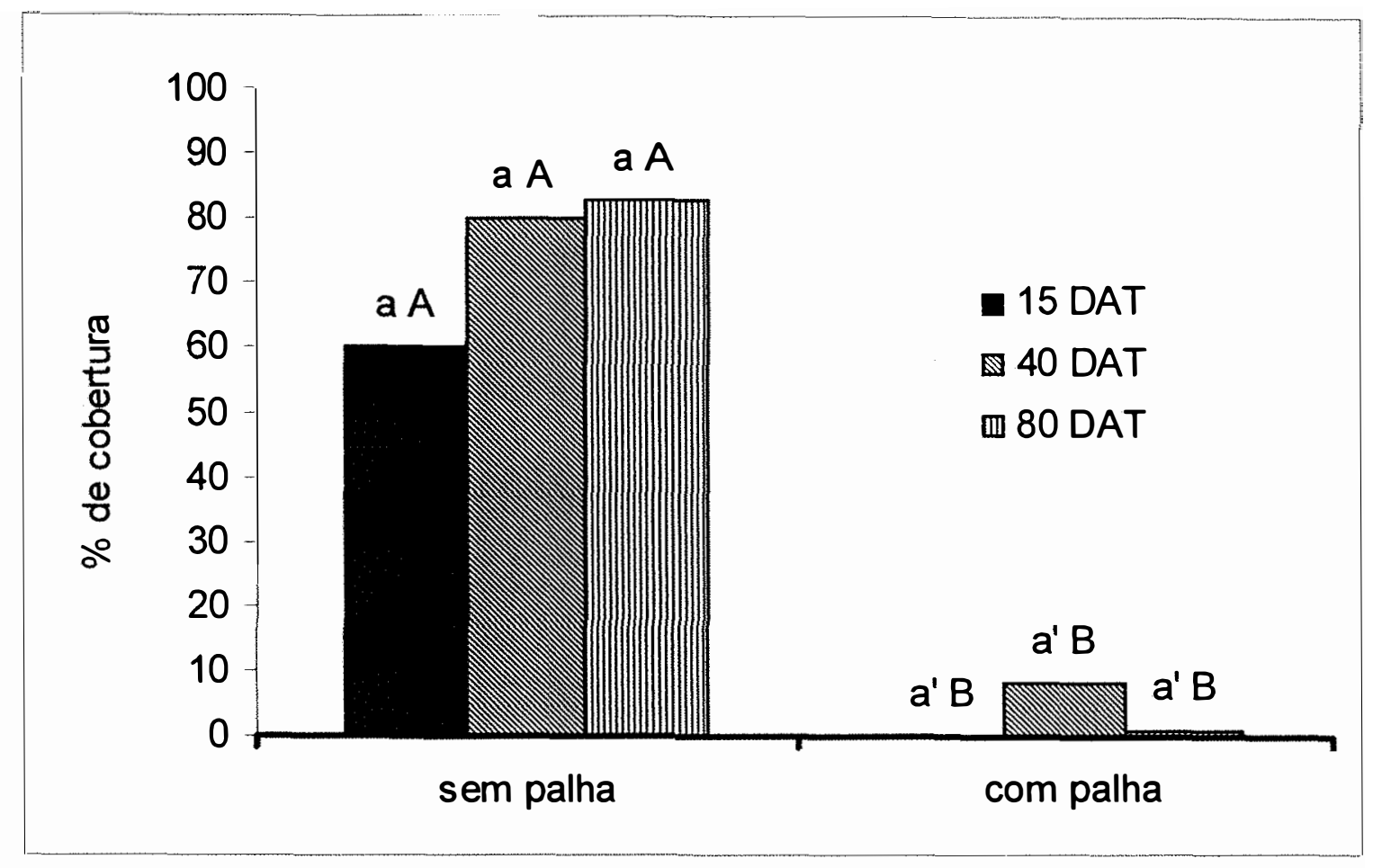

Figura 4 - Área do solo coberto pela espécie B.decumbens (15, 40 e 80 DAT), nas parcelas que não receberam herbicida, Usina Santa Luiza. (Letras minúsculas iguais dentro do fator época para os niveis do fator palha, não diferem entre si $(P<0,05)$ pelo contraste do teste $F$. Letras maiúsculas iguais dentro do fator palha, para os niveis do fator época, não diferem entre si $(P<0,05)$ pelo contraste do teste $F)$. 
$\mathrm{Na}$ Tabela 9 é apresentado o quadro com os valores de significância dos contrastes do teste $F$, referente às Figuras 1 a 4 . A interpretação deste quadro baseia-se no fato do fator época, que apresenta 3 níveis $(15,40$ e 80 DAT), assim, optou-se por aplicar o contraste do teste $F$, comparando as épocas 15 vs 80 e 15 vs $(40,80)$. Desta forma, entende-se que se a época 15 difere da época 80 , e difere da média entre as épocas 40 e 80 , então ela é diferente também da época 40 , que por sua vez é diferente da época 80 . Este fenômeno ocorreu apenas para a planta daninha $D$. horizontalis no tratamento sem palha. Observando a Figura 1 verifica-se realmente que a porcentagem de cobertura foi estatisticamente diferente entre si nas três épocas avaliadas. Para as demais plantas daninhas, observa-se que os resultados nas três avaliações foram semelhantes (Figura 2 a 4 e Tabela 9).

Tabela 9. Valores do contraste do teste $F$, para os níveis de época do fator palha $(P<0,05)$, Usina Santa Luiza.

\begin{tabular}{lcccc}
\hline \multicolumn{1}{c}{ Contrastes } & \multicolumn{2}{c}{ Sem palha } & Prob > F & \multicolumn{2}{c}{ Com palha } \\
Espécies & 15 vs 80 & 15 vs $(40,80)$ & 15 vs 80 & 15 vs $(40,80)$ \\
\hline I. grandifolia & $0,8^{1}$ & 0,8 & 0,8 & 0,9 \\
D. horizontalis & $0,01^{*}$ & $0,01^{*}$ & 1,0 & 0,3 \\
B. plantaginea & 0,2 & 0,2 & 0,7 & 0,6 \\
B. decumbens & 0,2 & 0,2 & 0,7 & 0,3 \\
\hline
\end{tabular}

${ }^{1}$ valores de Prob $>F$, dentro das colunas seguidos de ${ }^{*}$, representa que o contraste é significativo $(P<0,05)$

\subsubsection{Usina Iracema}

As médias dos tratamentos sobre a porcentagem de controle das seis espécies estudadas e da infestação natural da área (principais plantas daninhas: capim marmelada (B. plantaginea), amendoim bravo ( $E$. hetophylla), soja perene (Glycine. Wightii (Graham ex wight \& Arn.) Verdc.) e corda de viola (I. grandifolia), encontram-se nas Tabelas 10 a 16. Nas Figuras 5 a 11 pode-se 
observar o efeito da palha de cana sobre o desenvolvimento das espécies através do parâmetro de cobertura do solo (\%).

Tabela 10. Porcentagem de controle do capim colonião ( $P$. maximum), no experimento instalado na Usina Iracema.

\begin{tabular}{|c|c|c|c|c|c|c|}
\hline \multirow{2}{*}{$\begin{array}{c}\text { Dose } \\
\left(\mathrm{kg} \mathrm{i.a} \mathrm{ha}^{-1}\right)^{1} \\
\text { diuron + hexazinone }\end{array}$} & \multicolumn{2}{|c|}{15 DAT } & \multicolumn{2}{|c|}{40 DAT } & \multicolumn{2}{|c|}{80 DAT } \\
\hline & $\begin{array}{c}\text { sem } \\
\text { palha }\end{array}$ & $\begin{array}{c}\text { com } \\
\text { palha }\end{array}$ & $\begin{array}{l}\text { sem } \\
\text { palha }\end{array}$ & $\begin{array}{l}\text { com } \\
\text { palha }\end{array}$ & $\begin{array}{l}\text { sem } \\
\text { palha }\end{array}$ & $\begin{array}{l}\text { com } \\
\text { palha }\end{array}$ \\
\hline $\begin{array}{l}0,0+0,0^{3} \\
0,936+0,264 \\
1,117+0,330 \\
1,404+0,396\end{array}$ & $\begin{array}{l}0 a^{2} \\
99 b \\
100 b \\
100 b\end{array}$ & $\begin{array}{r}0 a \\
100 b \\
100 b \\
100 b\end{array}$ & $\begin{array}{l}0 a \\
98 b \text { * } \\
99 b c \\
99 c\end{array}$ & $\begin{array}{c}0 a \\
100 b^{*} \\
100 b \\
100 b\end{array}$ & $\begin{array}{ll}0 & a \\
82 & b^{\star} \\
86 & b c \\
88 & c\end{array}$ & $\begin{array}{l}0 \mathrm{a} \\
90 \mathrm{~b} \text { * } \\
87 \mathrm{c} \\
90 \mathrm{c}\end{array}$ \\
\hline
\end{tabular}

1 Herbicida contendo $468 \mathrm{~g} \mathrm{~kg}^{-1}$ de diuron $+132 \mathrm{~g} \mathrm{~kg}^{-1}$ de hexazinone, na formulação comercial. ${ }^{2}$ Médias nas colunas seguidas por letras distintas, são diferentes entre si $(P<0,05)$; médias nas linhas dentro de cada fator época (15, 40 e 80 DAT), seguidas por asterístico $\left(^{*}\right)$, diferem entre si dentro da variável palha (com ou sem) $(P<0,05 ; C V=4 \%){ }^{3}$ Controle na faixa testemunha sem aplicação de herbicida.

Tabela 11. Porcentagem de controle do capim colchão ( $D$. horizontalis), no experimento instalado na Usina Iracema.

\begin{tabular}{ccccccc}
\hline $\begin{array}{c}\text { Dose } \\
\left.(\mathrm{kg} \mathrm{i} . \mathrm{a} \mathrm{ha})^{-1}\right)^{1}\end{array}$ & \multicolumn{2}{c}{$15 \mathrm{DAT}$} & \multicolumn{2}{c}{$40 \mathrm{DAT}$} & \multicolumn{2}{c}{$80 \mathrm{DAT}$} \\
diuron + hexazinone & $\begin{array}{c}\text { sem } \\
\text { palha }\end{array}$ & $\begin{array}{c}\text { com } \\
\text { palha }\end{array}$ & $\begin{array}{c}\text { sem } \\
\text { palha }\end{array}$ & $\begin{array}{c}\text { com } \\
\text { palha }\end{array}$ & $\begin{array}{c}\text { sem } \\
\text { palha }\end{array}$ & $\begin{array}{c}\text { com } \\
\text { palha }\end{array}$ \\
\hline $0,0+0,0^{3}$ & $0 \mathrm{a}^{2}$ & $0 \mathrm{a}$ & $0 \mathrm{a}$ & $0 \mathrm{a}$ & $0 \mathrm{a}$ & $0 \mathrm{a}$ \\
$0,936+0,264$ & $100 \mathrm{~b}$ & $100 \mathrm{~b}$ & $98 \mathrm{~b}$ & $100 \mathrm{~b}^{*}$ & $98 \mathrm{~b}$ & $100 \mathrm{~b}^{*}$ \\
$1,117+0,330$ & $100 \mathrm{~b}$ & $100 \mathrm{~b}$ & $99 \mathrm{bc}$ & $100 \mathrm{~b}$ & $99 \mathrm{bc}$ & $90 \mathrm{~b}$ \\
$1,404+0,396$ & $100 \mathrm{~b}$ & $100 \mathrm{~b}$ & $100 \mathrm{c}$ & $100 \mathrm{~b}$ & $100 \mathrm{c}$ & $90 \mathrm{~b}$ \\
\hline
\end{tabular}

${ }^{1}$ Herbicida contendo $468 \mathrm{~g} \cdot \mathrm{kg}^{-1}$ de diuron $+132 \mathrm{~g} \cdot \mathrm{kg}^{-1}$ de hexazinone, na formulação comercial. ${ }^{2}$ Médias nas colunas seguidas por letras distintas, são diferentes entre si $(P<0,05)$; médias nas linhas dentro de cada fator época (15, 40 e 80 DAT), seguidas por asterístico (*), diferem entre si dentro da variável palha (com ou sem) $(P<0,05 ; C V=4 \%)$. ${ }^{3}$ Controle na faixa testemunha sem aplicação de herbicida. 
Tabela 12. Porcentagem de controle do capim braquiária (B. decumbens), no experimento instalado na U sina Iracema.

\begin{tabular}{|c|c|c|c|c|c|c|}
\hline \multirow{2}{*}{$\begin{array}{c}\text { Dose } \\
\left(\mathrm{kg} \mathrm{i.a} \mathrm{ha}{ }^{-1}\right)^{1} \\
\text { diuron + hexazinone }\end{array}$} & \multicolumn{2}{|c|}{$15 \mathrm{DAT}$} & \multicolumn{2}{|c|}{40 DAT } & \multicolumn{2}{|c|}{80 DAT } \\
\hline & $\begin{array}{l}\text { sem } \\
\text { palha }\end{array}$ & $\begin{array}{l}\text { com } \\
\text { palha }\end{array}$ & $\begin{array}{l}\text { sem } \\
\text { palha }\end{array}$ & $\begin{array}{l}\text { com } \\
\text { palha }\end{array}$ & $\begin{array}{l}\text { sem } \\
\text { palha }\end{array}$ & $\begin{array}{l}\text { com } \\
\text { palha }\end{array}$ \\
\hline $\begin{array}{l}0,0+0,0^{3} \\
0,936+0,264 \\
1,117+0,330 \\
1,404+0,396\end{array}$ & $\begin{array}{l}0 a^{2} \\
97 b^{*} \\
98 b^{*} \\
98 b^{*}\end{array}$ & $\begin{array}{l}0 a \\
100 b^{*} \\
100 b^{*} \\
100 b^{*}\end{array}$ & $\begin{array}{l}0 a \\
98 b \text { * } \\
99 b \\
99 b\end{array}$ & $\begin{array}{l}0 a \\
100 b^{*} \\
100 b \\
100 b\end{array}$ & $\begin{array}{c}0 \mathrm{a} \\
99 \mathrm{~b} \\
99 \mathrm{~b} \\
100 \mathrm{~b}\end{array}$ & $\begin{array}{c}0 \mathrm{a} \\
100 \mathrm{~b} \\
99 \mathrm{~b} \\
100 \mathrm{~b}\end{array}$ \\
\hline
\end{tabular}

${ }^{1}$ Herbicida contendo $468 \mathrm{~g} \mathrm{~kg}^{-1}$ de diuron $+132 \mathrm{~g} \mathrm{~kg}^{-1}$ de hexazinone, na formulação comercial. ${ }^{2}$ Médias nas colunas seguidas por letras distintas, são diferentes entre si $(P<0,05)$; médias nas linhas dentro de cada fator época (15, 40 e 80 DAT), seguidas por asterístico (*), diferem entre si dentro da variável palha (com ou sem) $(P<0,05 ; C V=4 \%)$. ${ }^{3}$ Controle na faixa testemunha sem aplicação de herbicida.

Tabela 13. Porcentagem de controle do capim marmelada (B. plantaginea), no experimento instalado na Usina Iracema.

\begin{tabular}{ccccccc}
\hline $\begin{array}{c}\text { Dose } \\
(\mathrm{kg} \mathrm{i.a} \mathrm{ha-1})^{1}\end{array}$ & \multicolumn{2}{c}{ 15 DAT } & \multicolumn{2}{c}{40 DAT } & \multicolumn{2}{c}{$80 \mathrm{DAT}$} \\
diuron + hexazinone & sem & com & sem & com & sem & com \\
palha & palha & palha & palha & palha & palha \\
\hline $0,0+0,0^{3}$ & $0 \mathrm{a}^{2}$ & $0 \mathrm{a}$ & $0 \mathrm{a}$ & $0 \mathrm{a}$ & $0 \mathrm{a}$ & $0 \mathrm{a}$ \\
$0,936+0,264$ & $85 \mathrm{~b}^{*}$ & $100 \mathrm{~b}$ * & $100 \mathrm{~b}$ & $100 \mathrm{~b}$ & $100 \mathrm{~b}$ & $100 \mathrm{~b}$ \\
$1,117+0,330$ & $85 \mathrm{~b}^{*}$ & $100 \mathrm{~b}^{*}$ & $100 \mathrm{~b}$ & $100 \mathrm{~b}$ & $100 \mathrm{~b}$ & $100 \mathrm{~b}$ \\
$1,404+0,396$ & $90 \mathrm{~b}^{*}$ & $100 \mathrm{~b}^{*}$ & $100 \mathrm{~b}$ & $100 \mathrm{~b}$ & $100 \mathrm{~b}$ & $100 \mathrm{~b}$ \\
\hline
\end{tabular}

${ }^{1}$ Herbicida contendo $468 \mathrm{~g} \mathrm{~kg}^{-1}$ de diuron $+132 \mathrm{~g} \mathrm{~kg}^{-1}$ de hexazinone, na formulação comercial; ${ }^{2}$ Médias nas colunas seguidas por letras distintas, são diferentes entre si $(P<0,05)$; médias nas linhas dentro de cada fator época (15, 40 e $80 \mathrm{DAT})$, seguidas por asterístico ( $\left.{ }^{*}\right)$, diferem entre si dentro da variável palha (com ou sem) $(P<0,05 ; C V=4 \%)$. ${ }^{3}$ Controle na faixa testemunha sem aplicação de herbicida. 
Tabela 14. Porcentagem de controle da corda de viola (I. grandifolia), no experimento instalado na Usina Iracema.

\begin{tabular}{ccccccc}
\hline $\begin{array}{c}\text { Dose } \\
(\mathrm{kg} \mathrm{i.a} \mathrm{ha-1})^{1}\end{array}$ & \multicolumn{2}{c}{ 15 DAT } & \multicolumn{2}{c}{40 DAT } & \multicolumn{2}{c}{80 DAT } \\
diuron + hexazinone & sem & Com & sem & com & sem & com \\
palha & palha & palha & palha & palha & palha \\
\hline $0,0+0,0^{3}$ & $0 \mathrm{a}^{2}$ & $0 \mathrm{a}$ & $0 \mathrm{a}$ & $0 \mathrm{a}$ & $0 \mathrm{a}$ & $0 \mathrm{a}$ \\
$0,936+0,264$ & $85 \mathrm{~b}^{*}$ & $99 \mathrm{~b}^{*}$ & $97 \mathrm{~b}$ & $93 \mathrm{~b}$ & $97 \mathrm{~b}$ & $97 \mathrm{~b}$ \\
$1,117+0,330$ & $82 \mathrm{~b}^{*}$ & $99 \mathrm{~b}^{*}$ & $98 \mathrm{~b}$ & $97 \mathrm{~b}$ & $99 \mathrm{c}$ & $99 \mathrm{c}$ \\
$1,404+0,396$ & $87 \mathrm{~b}^{*}$ & $99 \mathrm{~b}^{*}$ & $98 \mathrm{~b}$ & $99 \mathrm{c}$ & $100 \mathrm{c}$ & $99 \mathrm{c}$ \\
\hline
\end{tabular}

${ }^{1}$ Herbicida contendo $468 \mathrm{~g} \mathrm{~kg}^{-1}$ de diuron $+132 \mathrm{~g} \mathrm{~kg}^{-1}$ de hexazinone, na formulação comercial; ${ }^{2}$ Médias nas colunas seguidas por letras distintas, são diferentes entre si $(P<0,05)$; médias nas linhas dentro de cada fator época (15, 40 e 80 DAT), seguidas por asterístico ( $\left.{ }^{\star}\right)$, diferem entre si dentro da variável palha (com ou sem) $(P<0,05 ; C V=4 \%)$. ${ }^{3}$ Controle na faixa testemunha sem aplicação de herbicida.

Tabela 15. Porcentagem de controle do amendoim bravo (E. heterophylla), no experimento instalado na Usina Iracema.

\begin{tabular}{ccccccc}
\hline $\begin{array}{c}\text { Dose } \\
(\mathrm{kg} \mathrm{i.a} \mathrm{ha-1})^{1}\end{array}$ & \multicolumn{2}{c}{$15 \mathrm{DAT}$} & \multicolumn{2}{c}{$40 \mathrm{DAT}$} & \multicolumn{2}{c}{$80 \mathrm{DAT}$} \\
diuron + hexazinone & sem & com & sem & com & sem & com \\
palha & palha & palha & palha & palha & palha \\
\hline $0,0+0,0^{3}$ & $0 \mathrm{a}^{2}$ & $0 \mathrm{a}$ & $0 \mathrm{a}$ & $0 \mathrm{a}$ & $0 \mathrm{a}$ & $0 \mathrm{a}$ \\
$0,936+0,264$ & $85 \mathrm{~b}^{*}$ & $99 \mathrm{~b}^{*}$ & $96 \mathrm{~b}$ & $99 \mathrm{~b}$ & $96 \mathrm{~b}$ * & $99 \mathrm{~b}$ \\
$1,117+0,330$ & $85 \mathrm{~b}^{*}$ & $99 \mathrm{~b}^{*}$ & $98 \mathrm{c}$ & $99 \mathrm{~b}$ & $99 \mathrm{c}$ & $99 \mathrm{~b}$ \\
$1,404+0,396$ & $90 \mathrm{~b}^{*}$ & $100 \mathrm{~b}^{*}$ & $97 \mathrm{bc}$ & $99 \mathrm{~b}$ & $98 \mathrm{c}$ & $99 \mathrm{~b}$ \\
\hline
\end{tabular}

${ }^{1}$ Herbicida contendo $468 \mathrm{~g} \mathrm{~kg}^{-1}$ de diuron $+132 \mathrm{~g} \mathrm{~kg}^{-1}$ de hexazinone, na formulação comercial; ${ }^{2}$ Médias nas colunas seguidas por letras distintas, são diferentes entre si $(P<0,05)$; médias nas linhas dentro de cada fator época (15, 40 e $80 \mathrm{DAT})$, seguidas por asterístico $\left(^{*}\right)$, diferem entre si dentro da variável palha (com ou sem)(P<0,05; $C V=4 \%)$. ${ }^{3}$ Controle na faixa testemunha sem aplicação de herbicida. 
Tabela 16. Porcentagem de controle da infestação natural (capim marmelada, soja perene, amendoim bravo e corda de viola), no experimento instalado na Usina Iracema.

\begin{tabular}{ccccccc}
\hline $\begin{array}{c}\text { Dose } \\
(k g \text { i.a ha })^{-1}\end{array}$ & \multicolumn{2}{c}{15 DAT } & \multicolumn{2}{c}{40 DAT } & \multicolumn{2}{c}{80 DAT } \\
diuron + hexazinone & sem & com & sem & com & sem & com \\
palha & palha & palha & palha & palha & palha \\
\hline $0,0+0,0^{3}$ & $0 \mathrm{a}^{2}$ & $0 \mathrm{a}$ & $0 \mathrm{a}$ & $0 \mathrm{a}$ & $0 \mathrm{a}$ & $0 \mathrm{a}$ \\
$0,936+0,264$ & $96 \mathrm{~b}$ & $93 \mathrm{~b}$ & $96 \mathrm{~b}$ & $97 \mathrm{~b}$ & $93 \mathrm{~b}$ & $93 \mathrm{~b}$ \\
$1,117+0,330$ & $98 \mathrm{~b}^{*}$ & $92 \mathrm{~b}$ & $98 \mathrm{c}$ & $97 \mathrm{~b}$ & $96 \mathrm{~b}$ & $94 \mathrm{~b}$ \\
$1,404+0,396$ & $98 \mathrm{~b}$ & $99 \mathrm{c}$ & $99 \mathrm{c}$ & $96 \mathrm{~b}$ & $96 \mathrm{~b}$ & $96 \mathrm{~b}$ \\
\hline
\end{tabular}

1 Herbicida contendo $468 \mathrm{~g} \mathrm{~kg}^{-1}$ de diuron $+132 \mathrm{~g} \mathrm{~kg}^{-1}$ de hexazinone, na formulação comercial. ${ }^{2}$ Médias nas colunas seguidas por letras distintas, são diferentes entre si $(P<0,05)$; médias nas linhas dentro de cada fator época (15, 40 e 80 DAT), seguidas por asterístico (*), diferem entre si dentro da variável palha (com ou sem) $(P<0,05 ; C V=4 \%)$. ${ }^{3}$ Controle na faixa testemunha sem aplicação de herbicida.

Nas Tabelas 10 e 11, nota-se que houve um excelente controle das plantas daninhas $P$. maximum e $D$. horizontalis nas áreas com e sem palha. Em relação às doses de herbicida, só ocorreram diferenças dentro do fator palha, aos 80 DAT, e na menor dose de herbicida testado $\left(0,0936+0,264 \mathrm{~kg}^{\text {i.a. }} \mathrm{ha}^{-1}\right)$. Todavia, os níveis de controle nestes casos, são considerados satisfatórios.

$O$ controle de $B$. decumbens (Tabela 12), foi crescente dentro do fator época, onde o maior controle ocorre aos 80 DAT. Aos 15 DAT, são encontrados os menores valores de controle, independente da dose de herbicida. Para $B$. plantaginea (Tabela 13), só são observados falhas de controle aos 15 DAT, no tratamento sem palha. Aos 40 e 80 DAT, o controle desta planta daninha foi excelente.

Nas Tabelas 14 e 15, referentes às plantas daninhas folhas larga, observa-se que na menor dose de herbicida $\left(0,936+0,264 \mathrm{~kg}\right.$ i.a. ha $\left.{ }^{-1}\right)$ houve decréscimo no efeito residual do herbicida, nas parcelas com a presença da palha de cana na superfície do solo. Nas doses de $1,117+0,330 \mathrm{~kg}$ i.a. ha ${ }^{-1} \mathrm{e}$ $1,404+0,396 \mathrm{~kg}$ i.a. $\mathrm{ha}^{-1}$, a I. grandofolia apresentou a menor porcentagem de controle aos 15 DAT, nas parcelas sem a presença da palha, ocorrendo o mesmo para $E$. heterophylla. Entretanto, no tratamento com a presença da 
palha de cana-de-açúcar, os níveis de controle destas espécies de plantas daninhas são mantidos ao longo do tempo em valores satisfatórios. A infestação natural (Tabela 16), apresentou um bom nivel de controle em todas as épocas e em todos os tratamentos.

O efeito da palha de cana-de-açúcar na eficiência do herbicida, foi observado principalmente aos 15 DAT. Após esta época, só são encontradas diferenças dentro dos níveis de palha, na menor dose de herbicida $(0,936+$ $0,264 \mathrm{~kg}$ i.a. $\mathrm{ha}^{-1}$ ).

Os efeitos da palha sobre o estabelecimento e desenvolvimento das espécies estudas são apresentados nas Figuras 5 a 11. Nas Figuras 9 e 10, pode-se observar que as plantas daninhas corda de viola e amendoim bravo, tiveram seu desenvolvimento inicial ligeiramente afetado pela camada de palha de cana. O efeito deste retardamento inicial pode ser mais visualizado nas Figuras 9 e 10, onde aos 60 dias, as áreas cobertas nos tratamentos sem palha e com palha são de aproximadamente $95 \%$ e $45 \%$, respectivamente, para ambas às espécies.

Da mesma forma que Martins et al. (1999), foi observado que o desenvolvimento das espécies corda de viola ( $I$. aristolochiaefolia) e amendoim bravo ( $E$. heterophylla) foi inibido pela palha de cana com menor intensidade que outras plantas daninhas (Figuras 9 e 10), entretanto, o herbicida foi eficiente em todos os tratamentos (Tabelas 10 a 16).

Sabe-se que o período de competição entre plantas daninhas e a cultura da cana-de-açúcar é variável entre diferentes regiões e condições da cultura (Kuva, 2000). Desta forma, trabalhos na literatura apontam para um período de matocompetição entre 60 e 120 dias (Arévalo et al., 1977), 18 e 66 dias (Blanco et al., 1979), 30 e 90 (Rolim \& Christoffoleti, 1982). Tratando-se de cana crua, é possivel no entanto, que exista outro período de matocompetição, pois as espécies que se adaptam ao sistema de colheita da cana crua apresentam o desenvolvimento inicial retardado. 


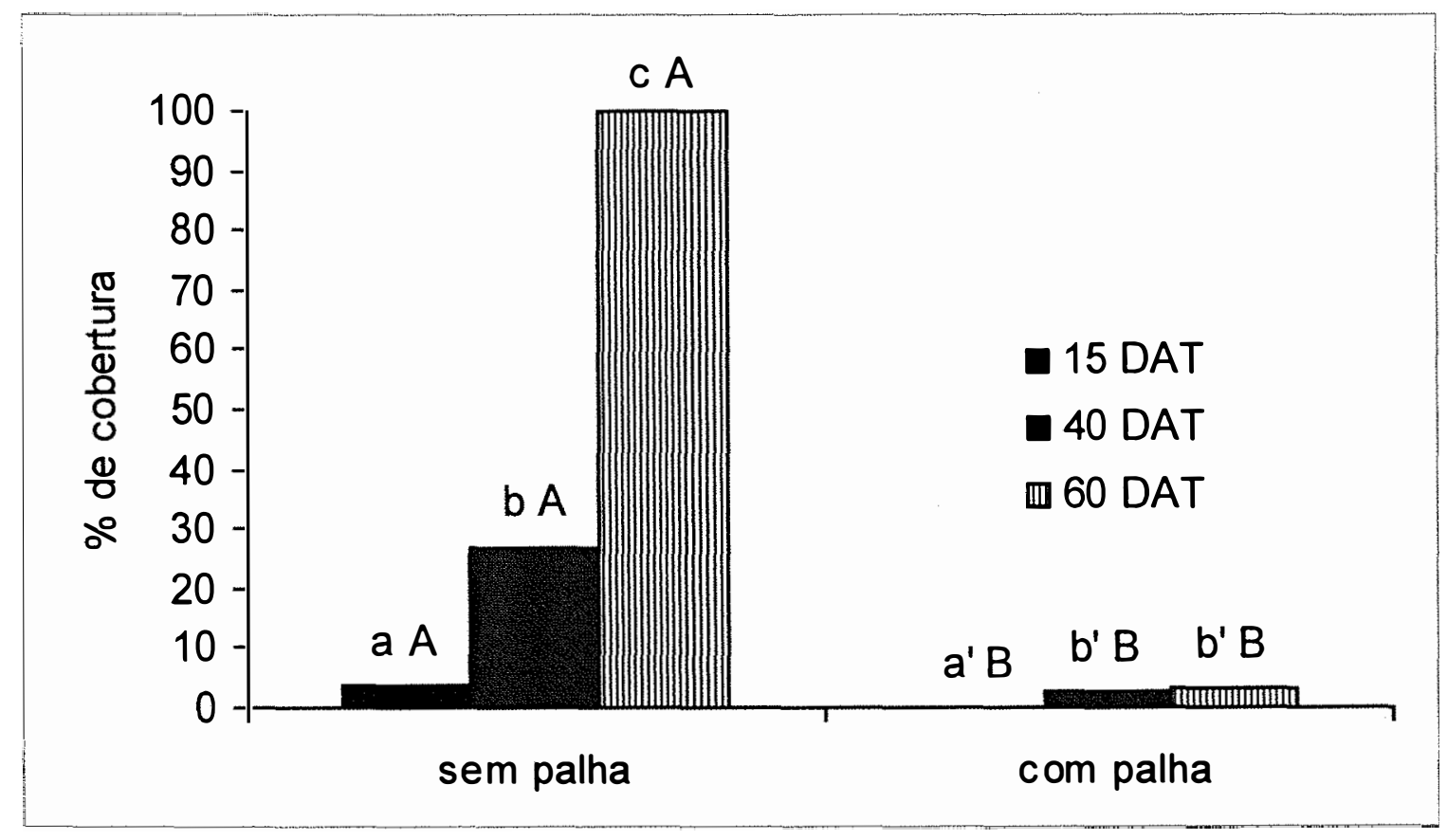

Figura 5 - Área do solo coberto pela espécie $D$. horizontalis (15, 40 e 80 DAT), nas parcelas que não receberam herbicida, Usina Iracema. (Letras minúsculas iguais dentro do fator época para os niveis do fator palha, não diferem entre si $(P<0,05)$ pelo contraste do teste $F$. Letras maiúsculas iguais dentro do fator palha, para os niveis do fator época, não diferem entre si $(P<0,05)$ pelo contraste do teste $F)$. 


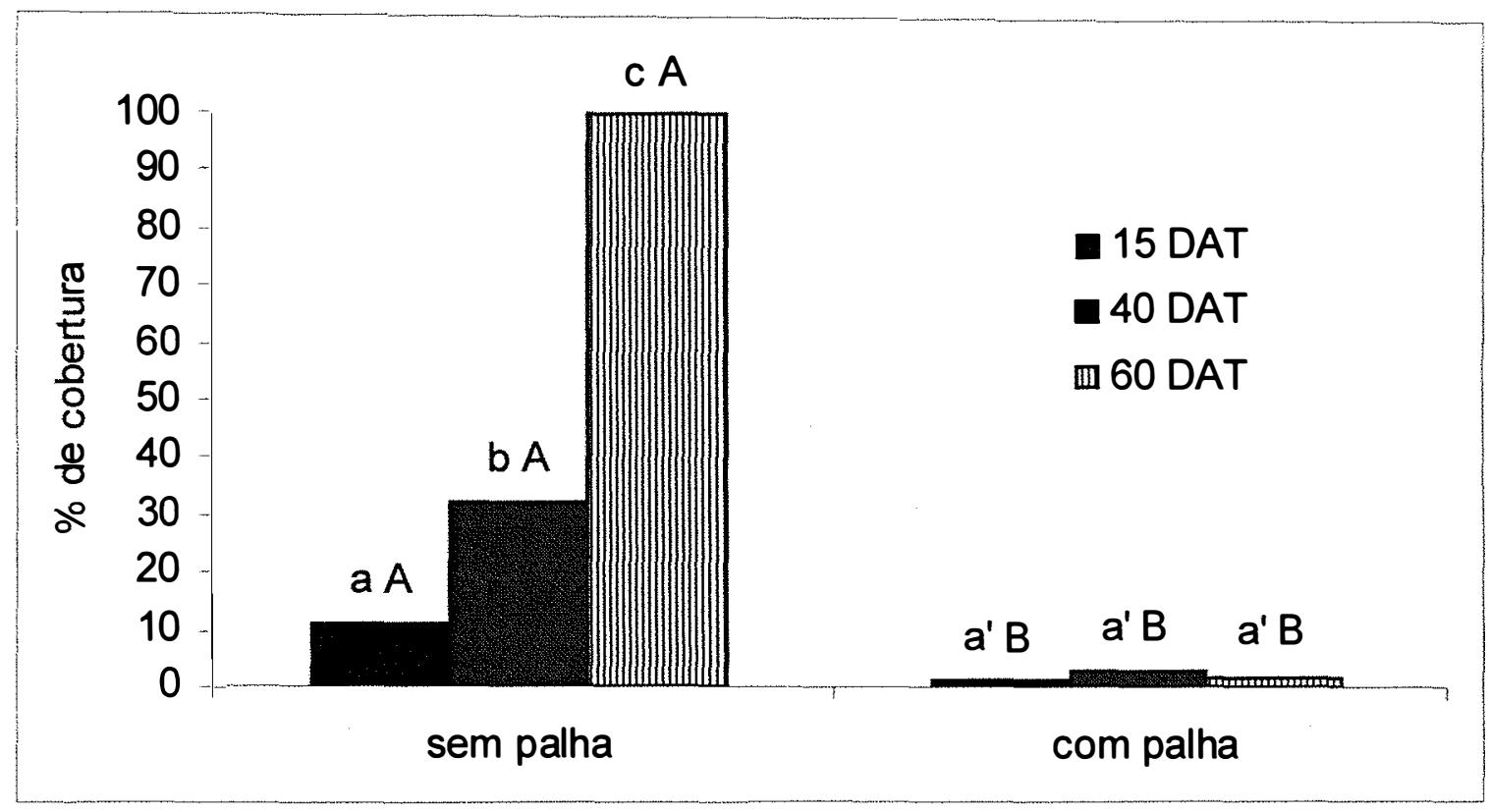

Figura 6 - Área do solo coberto pela espécie P. maximum (15, 40 e 80 DAT), nas parcelas que não receberam herbicida, Usina Iracema. (Letras minúsculas iguais dentro do fator época para os niveis do fator palha, não diferem entre si $(P<0,05)$ pelo contraste do teste $F$. Letras maiúsculas iguais dentro do fator palha, para os níveis do fator época, não diferem entre si $(P<0,05)$ pelo contraste do teste $F)$. 


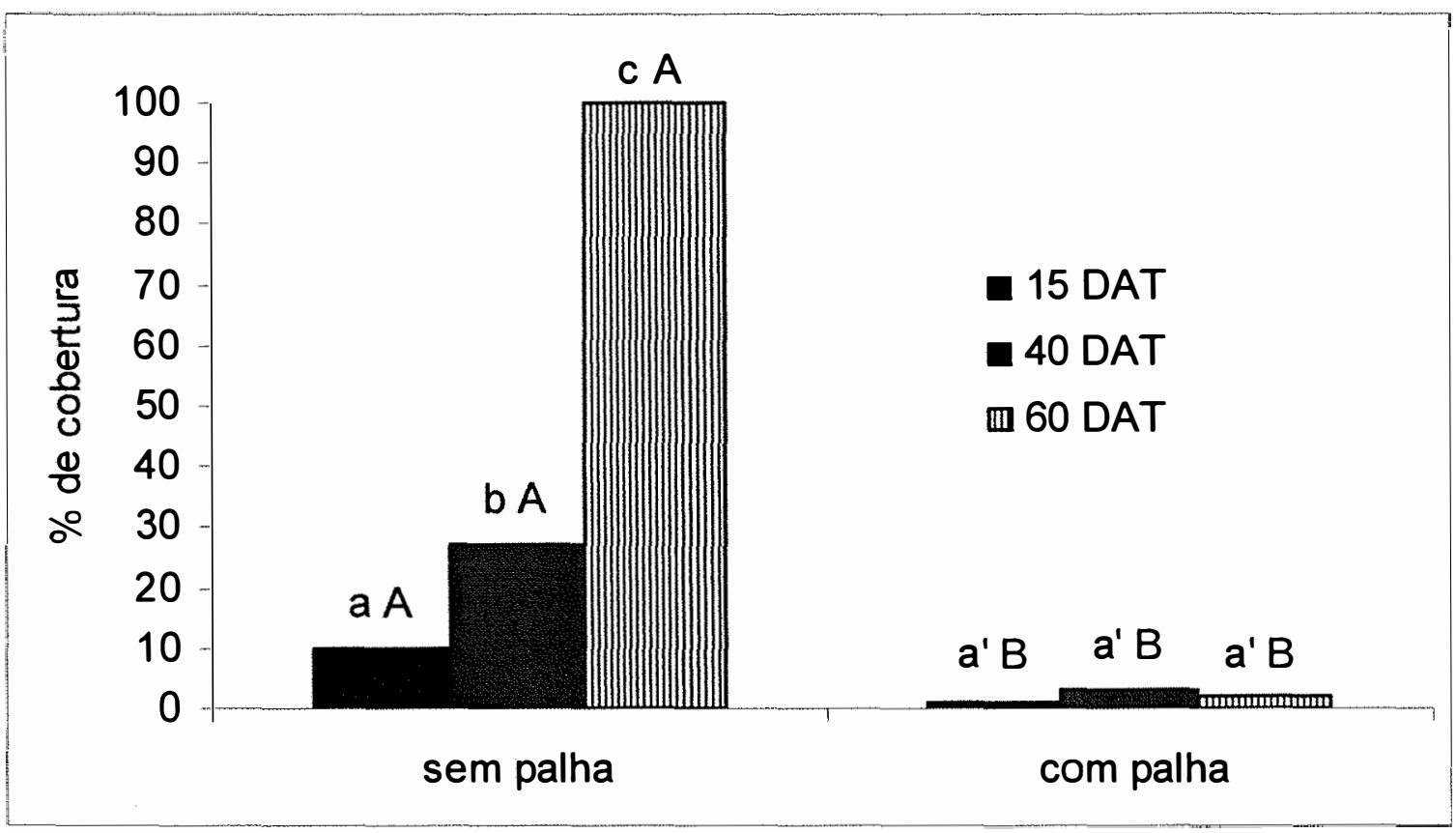

Figura 7 - Área do solo coberto pela espécie $B$. decumbens (15, 40 e 80 DAT), nas parcelas que não receberam herbicida, Usina Iracema. (Letras minúsculas iguais dentro do fator época para os niveis do fator palha, não diferem entre si $(P<0,05)$ pelo contraste do teste $F$. Letras maiúsculas iguais dentro do fator palha, para os niveis do fator época, não diferem entre si $(P<0,05)$ pelo contraste do teste $F)$. 


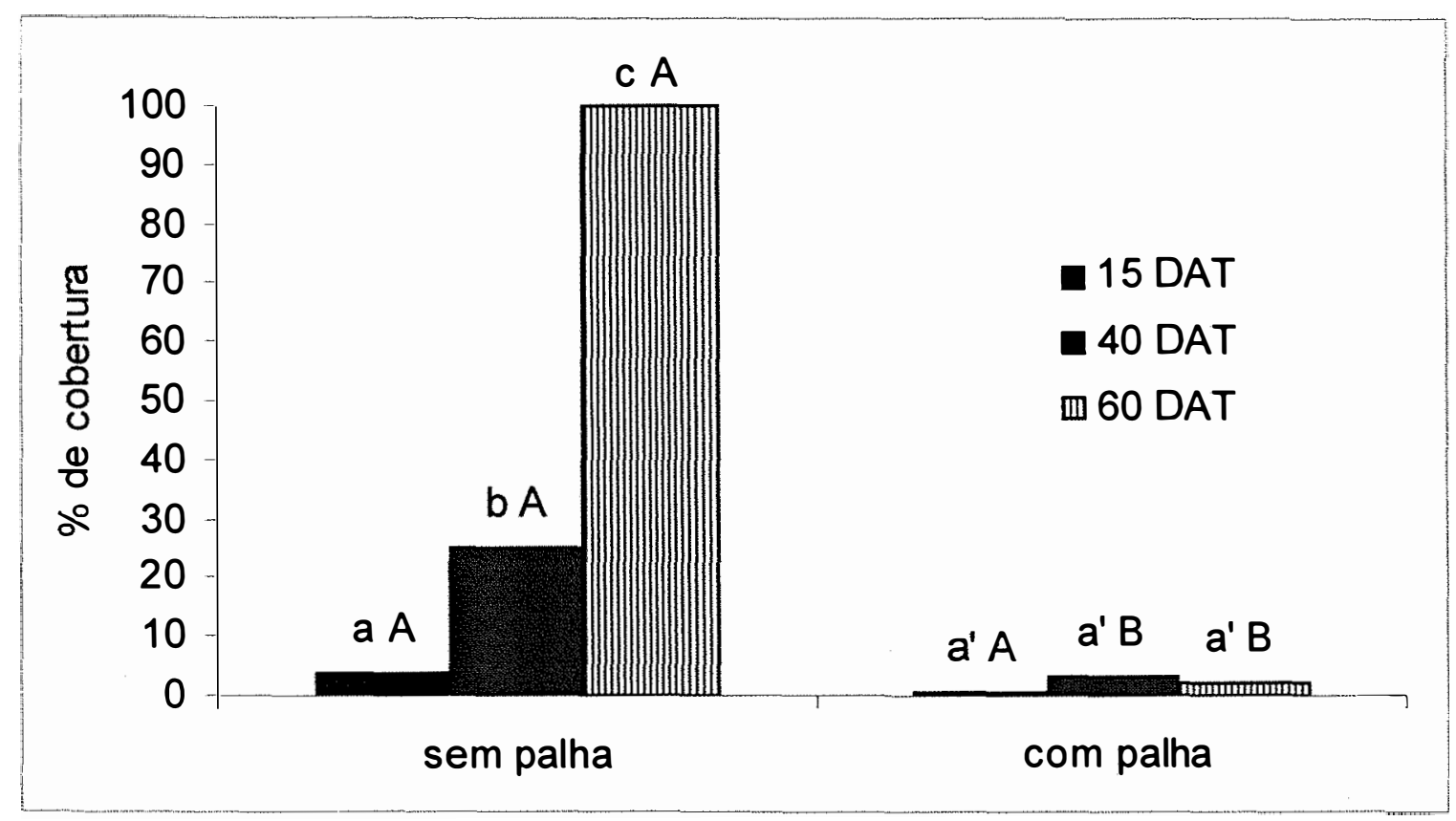

Figura 8 - Área do solo coberto pela espécie B. plantaginea (15, 40 e 80 DAT), nas parcelas que não receberam herbicida, Usina Iracema. (Letras minúsculas iguais dentro do fator época para os niveis do fator palha, não diferem entre si $(P<0,05)$ pelo contraste do teste $F$. Letras maiúsculas iguais dentro do fator palha, para os niveis do fator época, não diferem entre si $(P<0,05)$ pelo contraste do teste $F)$. 


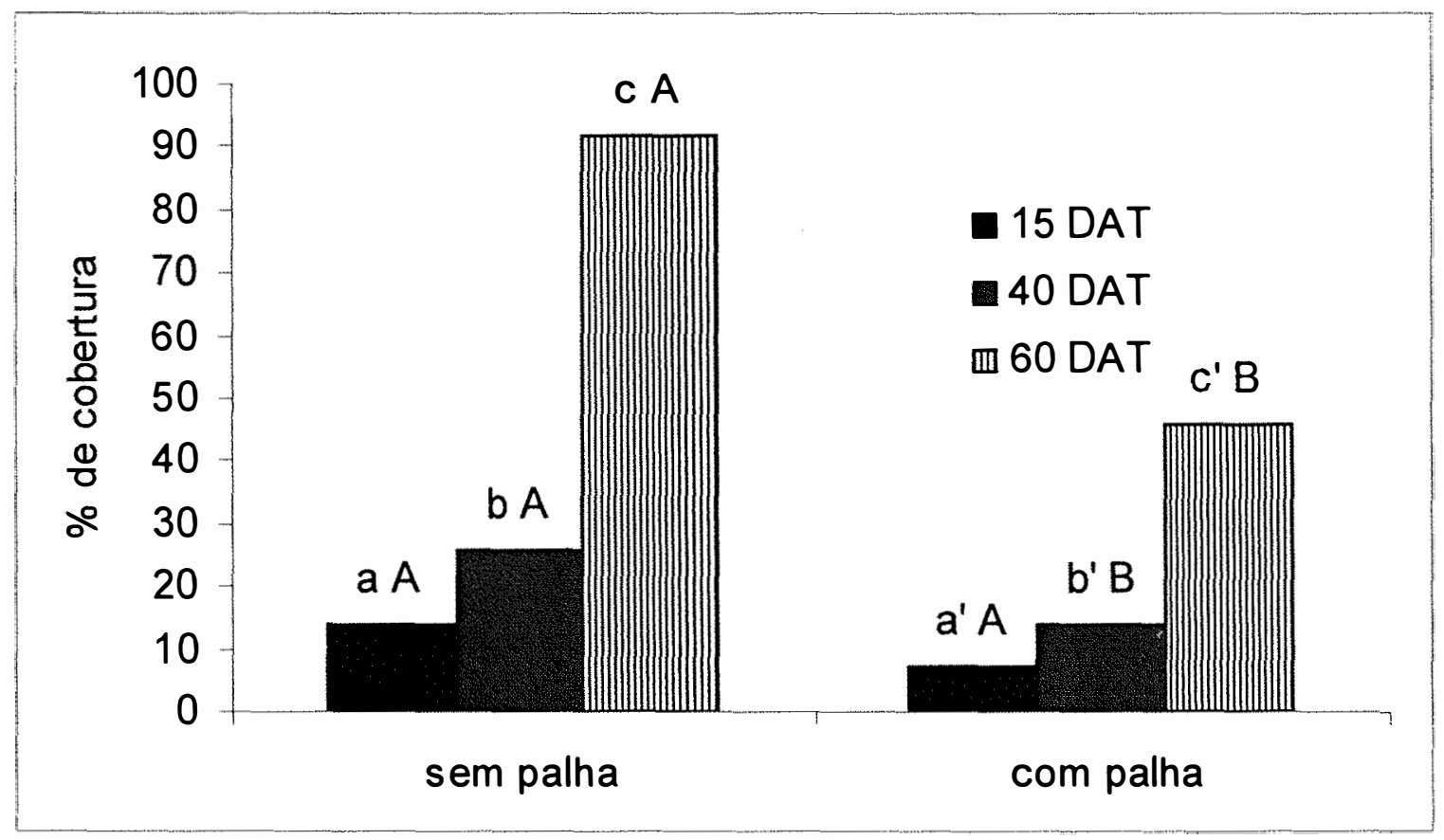

Figura 9 - Área do solo coberto pela espécie I. grandifolia (15, 40 e 80 DAT), nas parcelas que não receberam herbicida, Usina Iracema. (Letras minúsculas iguais dentro do fator época para os niveis do fator palha, não diferem entre si $(P<0,05)$ pelo contraste do teste $F$. Letras maiúsculas iguais dentro do fator palha, para os níveis do fator época, não diferem entre si $(P<0,05)$ pelo contraste do teste $F)$. 


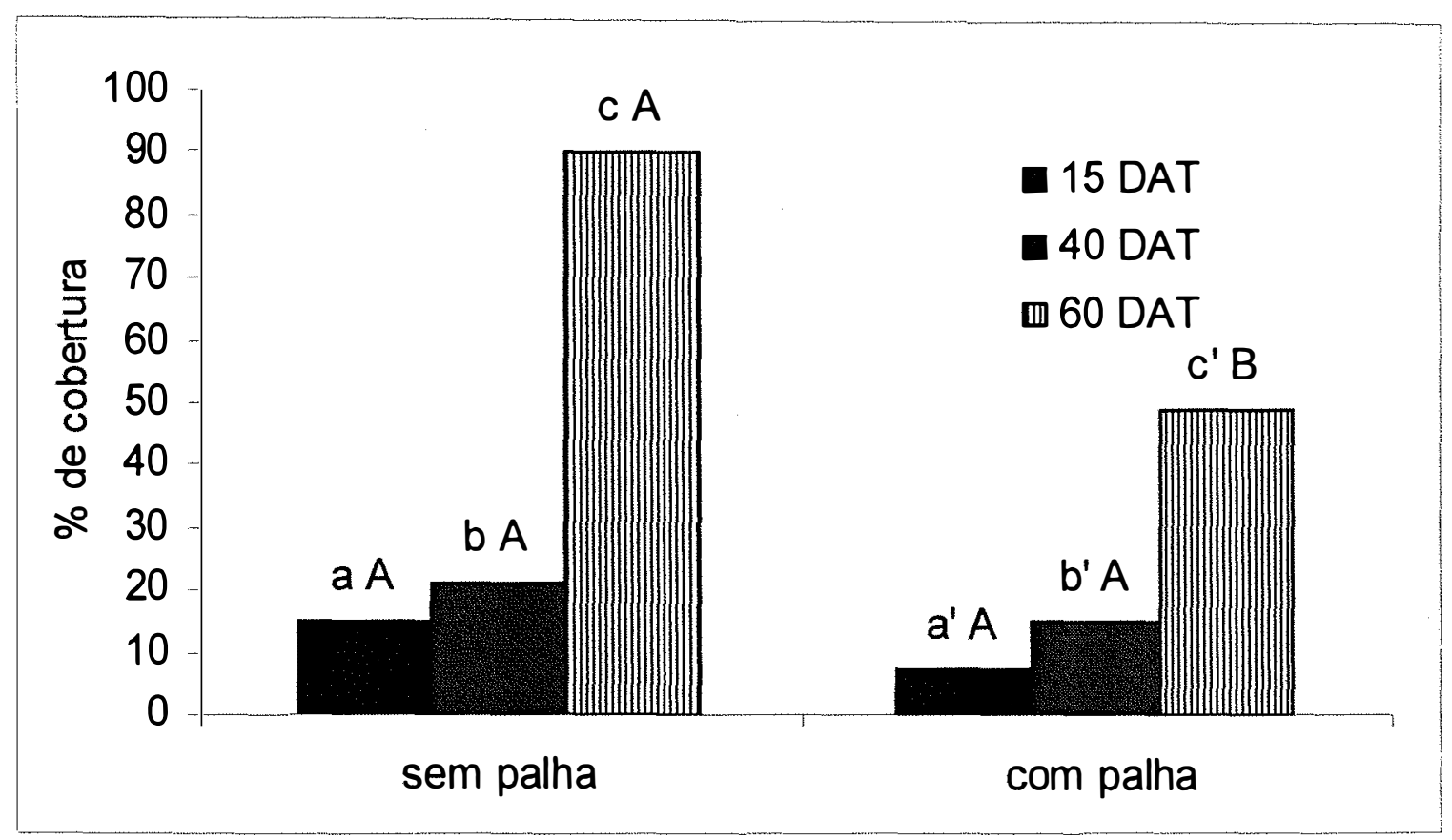

Figura 10 - Área do solo coberto pela espécie E. heterophylla (15, 40 e 80 DAT), nas parcelas que não receberam herbicida, Usina Iracema. (Letras minúsculas iguais dentro do fator época para os niveis do fator palha, não diferem entre si $(P<0,05)$ pelo contraste do teste $F$. Letras maiúsculas iguais dentro do fator palha, para os niveis do fator época, não diferem entre si $(P<0,05)$ pelo contraste do teste F). 


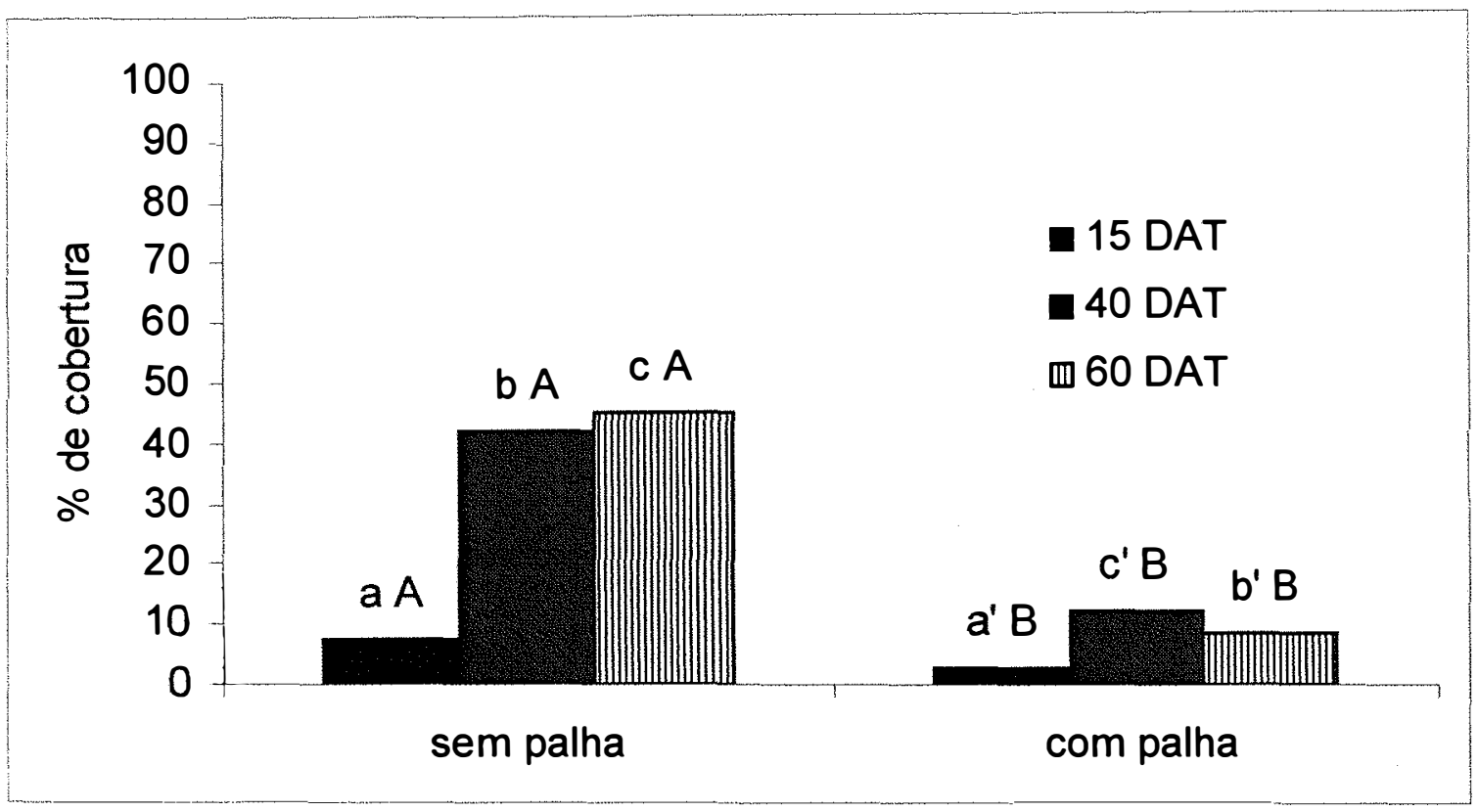

Figura 11 - Área do solo coberto pela infestação natural de plantas daninhas (15, 40 e 80 DAT), nas parcelas que não receberam herbicida, Usina Iracema. (Letras minúsculas iguais dentro do fator época para os niveis do fator palha, não diferem entre si $(P<0,05)$ pelo contraste do teste $F$. Letras maiúsculas iguais dentro do fator palha, para os niveis do fator época, não diferem entre si $(P<0,05)$ pelo contraste do teste $F$ ). 
$\mathrm{Na}$ Tabela 17, é apresentado o quadro com os valores da porcentagem dos contrastes do teste $F$, referente às Figuras 5 a 11. A interpretação deste quadro baseia-se no fato de como o fator época apresenta 3 niveis $(15,40$ e 80 DAT), optou-se por aplicar o contraste do teste $F$, comparando as épocas 15 vs 80 e 15 vs $(40,80)$. Desta forma, entende-se que se a época 15 difere da época 80 , e difere da média entre as épocas 40 e 80 , então ela é diferente também da época 40 , que por sua vez é diferente da época 80 . Observando-se a Figura 11 no fator palha (com) nota-se diferença entre as épocas 15 e 80, pelo segundo contraste. De acordo com a Tabela 19, é possivel entender, que dentro de uma margem de erro de $5 \%$, existe a probabilidade de 0,03 para que esta diferença não exista.

Tabela 17. Valores do contraste do teste $F$, para os níveis de época do fator palha $(P<0,05)$, Usina Iracema.

\begin{tabular}{|c|c|c|c|c|}
\hline \multirow{2}{*}{$\begin{array}{c}\text { Contrastes } \\
\text { Espécies }\end{array}$} & \multicolumn{2}{|c|}{ Sem palha } & \multicolumn{2}{|c|}{ Com palha } \\
\hline & 15 vs 80 & 15 vs $(40,80)$ & 15 vs 80 & 15 vs $(40,80)$ \\
\hline I. grandifolia & $1.10^{-5} \star 1$ & $1.10^{-5}$ * & $2.10^{-5}$ * & $1,6.10^{-5}$ * \\
\hline D. horizontalis & $1.10^{-5}$ * & $1.10^{-5}$ * & $3.10^{-2}$ & $2.10^{-2}$ \\
\hline B. plantaginea & $1.10^{-5}$ * & $1.10^{-5}$ * & $5.10^{-1}$ & $2.10^{-1}$ \\
\hline B. decumbens & $1.10^{-5}$ * & $1.10^{-5}$ * & $5.10^{-1}$ & $5.10^{-1}$ \\
\hline P. maximum & $1.10^{-5}$ * & $1.10^{-5}$ * & $5.10^{-1}$ & $3.10^{-1}$ \\
\hline E. heterophylla & $1.10^{-5} \star$ & $1.10^{-5}$ * & $1.10^{-5}$ * & $1.10^{-5}$ * \\
\hline Inf. Natural & $1.10^{-5}$ * & $1.10^{-5}$ * & $3.10^{-2}$ & $5.10^{-3} \star$ \\
\hline
\end{tabular}

${ }^{1}$ valores de Prob $>F$, dentro das colunas seguidos de ${ }^{*}$, representa que o contraste é significativo $(P<0,05)$.

Os resultados de porcentagem de área coberta pelas plantas daninhas obtidos na Usina Iracema, para as espécies $B$. decumbens, B. plantaginea, $D$. horizontalis e I. grandifolia, são semelhantes aos da Usina Santa Luiza. A espécie $P$. maximum apresenta comportamento semelhante ao das outras gramíneas estudadas. Em relação a espécie E. heterophylla, observa-se padrão de crescimento muito semelhante ao de I. grandifolia, em ambos os niveis do fator palha. 


\subsection{Conclusões}

As espécies I. grandifolia e $E$. heterophyla não tem sua emergência inibidas pela camada de palha de cana-de-açúcar deixada na superfície do solo após a colheita. Entretanto, o controle das plantas daninhas estudadas é eficiente pelo herbicida, o que sugere que a mistura comercial de diuron + hexazinone pode atravessar camadas de $15 \mathrm{t} \mathrm{ha}^{-1}$ de palha de cana. No entanto, esta passagem esta condicionada à vários fatores, entre eles a quantidade de palha, distribuição da palha e condições climáticas adequadas.

Em áreas de cana-de-açúcar colhida mecânica sem queima, com infestação predominante pelas gramíneas $B$. decumbens, $B$. plantaginea, $P$. maximum, $D$. horizontalis, onde a camada de palha após a colheita for de aproximadamente $15 \mathrm{t} \mathrm{ha}^{-1}$ ou maior, há uma grande redução na necessidade do uso de herbicidas pré-emergentes, sendo mais indicado a aplicação localizada de herbicidas pós-emergentes, na operação tradicionalmente chamada de catação. 


\section{EFEITO RESIDUAL DA MISTURA FORMULADA DOS HERBICIDAS DIURON + HEXAZINONE EM ÁREAS COM COLHEITA MECANIZADA DE CANA-DE-AÇÚCAR SEM QUEIMA}

Resumo

Em área de produção de cana-de-açúcar, pertencente à Usina Iracema, instalou-se um experimento com a aplicação dos herbicidas diuron + hexazinone, nas doses de $0,0+0,0 ; 0,936+0,264 ; 1,117+0,330 ; 1,404+$ $0,396 \mathrm{~kg}$ i.a. ha- ${ }^{-1}$ respectivamente, em parcelas de soqueira de cana-de-açúcar cobertas ou não com palha resultante da colheita da cana-de-açúcar (16 tha-1). Aos 30 e 60 dias após a aplicação dos herbicidas (DAT), coletou-se amostras de $1 \mathrm{~kg}$ de solo dos cinco centímetros superficiais de cada parcela, as quais foram condicionadas em vasos, em casa-de-vegetação, sob delineamento experimental de blocos ao acaso com quatro repetições. Cada vaso foi semeado com pepino que serviu como planta teste (bioensaio) para deteç̧ão dos resíduos do herbicida. Após 21 dias da instalação em casa-de-vegetação foram feitas pesagens da biomassa da parte aérea da planta teste. Os resultados foram submetidos a análise de variância com aplicação do teste $F$, seguidos pelo teste de Tukey. Com o objetivo de comparação dos resultados com doses conhecidas dos herbicidas no solo, construiu-se uma curva de doseresposta com a formulação comercial do mesmo herbicida, nas doses de $0,0+$ 0,$0 ; 0,0932+0,0264 ; 0,1872+0,0528 ; 0,2808+0,0792 ; 0,3744+0,1056 ;$ $0,4680+0,1320$ e $0,936+0,264 \mathrm{~kg}$ i.a. $\mathrm{ha}^{-1}$ de diuron + hexazinone, 
respectivamente. Conclui-se que o efeito residual da mistura de diuron + hexazinone foi reduzido para um período de $30 \mathrm{DAT}$, e que embora a palha de cana-de-açúcar deixada na superfície retenha boa parte do herbicida aplicado sobre ela, uma parcela deste herbicida pode atingir o solo e proporcionar efeito residual e controle de plantas daninhas, dependendo da quantidade de chuva que ocorre dentro dos primeiros dias após a aplicação do herbicida.

\section{RESIDUAL EFFECTS OF THE COMMERCIAL MIXTURE OF DIURON + HEXAZINONE IN SUGARCANE AREAS UNDER MECHANICAL HARVEST OF SUGARCANE WITHOUT PRIOR TO BURNING}

\section{Summary}

In area of sugarcane production of the sugar mill Iracema it was installed an experiment with the application of the herbicides diuron + hexazinone at the rates of $0.0+0.0 ; 0.936+0.264 ; 1.117+0.330$ and $1.404+$ $0.396 \mathrm{~kg}$ a.i. $\mathrm{ha}^{-1}$ respectively, in a raton of sugarcane, which soil surface was covered or not with sugarcane trash debris from harvest without burning (16 t $\mathrm{ha}^{-1}$ ). At 30 and 60 days after herbicide application (DAT), it was collected soil samples of $1 \mathrm{~kg}$ from the top $5 \mathrm{~cm}$ of the soil profile of each plot, and placed in pots in the greenhouse, in a completely randomized experimental design, with four replications. In each pot it was seeded cucumber that was used as test plant (bioassay) for the detection of the herbicide residue. After 21 days of the experiment installation in the greenhouse it was weighted the cucumber shoot biomass. The results were submitted to an analysis of variance with application of the F test, followed by the Tukey test. With the objective of comparission of the results with known rates of the herbicides in the soil a dose response curve was built with the rates of diuron + hexazinone of $0.0+0.0 ; 0.0932+0.0264$; $0.1872+0.0528 ; 0.2808+0.0792 ; 0.3744+0.1056 ; 0.4680+0.1320$ and 0.936 
$+0.264 \mathrm{~kg}$ a.i. ha ${ }^{-1}$, respectively. It was concluded that the residual effect of the mixture of diuron + hexazinone was reduced to a period of $30 \mathrm{DAT}$, and that even though the sugarcane harvest trash debris residue left on the soil surface retain great amount of the herbicide sprayed, a portion of the rate sprayed can reach the soil and give some residual effect in the control of the susceptible weeds; however, the intensity of control and residual effects is a function of the amount of rainfall in the next few days after herbicide application.

\subsection{Introdução}

Tradicionalmente, na cultura da cana-de-açúcar, grande parte das aplicações de herbicidas são feitas em condições de pré-emergência. Dentre as 55 formulações registradas até a presente data para a cultura da cana, uma esta registrada para aplicação em pré-plantio incorporado (PPI), duas para aplicação em PPI ou pré-emergência (PRE), 18 para aplicação em PRE, 17 para aplicação em PRE ou pós-emergência (POS) e 17 para aplicação em POS (Lorenzi, 2000).

A quantidade de resíduos deixados na superfície do solo após a colheita de cana mecanizada sem queima, sistema chamado de cana crua, pode chegar a $20 \mathrm{t} \mathrm{ha}^{-1}$. Esta quantidade de palha deixada na superfície do solo resulta tanto em mudanças no sistema de condução da cultura, como no manejo de plantas daninhas.

Segundo Rodrigues et al. (2000b), apesar das coberturas vegetais mortas reduzirem a população de plantas daninhas, elas podem interceptar os herbicidas quando aplicados sobre a palhada. De maneira geral, Rodrigues et al. (2000a), citam que existem herbicidas que são facilmente lixiviados para o solo, com chuvas da ordem de $20 \mathrm{~mm}$ que ocorram até 24 horas após a aplicação e outros que mesmo após as chuvas, continuam retidos na palhada. 
Desta forma, em função da presença da palha no solo, a aplicação de herbicidas em pré-emergência fica limitada aos produtos que conseguem atingir o solo, atravessando a camada de palha. Pode-se entender portanto, que os herbicidas aplicados em pré-emergência em cana crua devem apresentar características adequadas de solubilidade e percolação. Segundo Hernandez et al. (2000) os herbicidas imazapic e imazapic + pendimhetalin apresentam características favoráveis que possibilitam a aplicação sobre a palha de cana.

Existem moléculas que após atravessarem a camada de palha, podem apresentar comportamento distinto, como o herbicida oxyfluorfen que segundo Veline \& Negrisoli (2000), tem sua meia vida no solo de 55 dias na presença de luz, e de 292 dias, na ausência de luz. Entretanto, não existem relatos como este, para a maioria dos herbicidas utilizados em cana-de-açúcar em pré-emergência. Todavia, como o oxyfluorfen é degradado principalmente por fotólise (Rodrigues \& Almeida, 1998), pode-se inferir que herbicidas aplicados em cana-de-açúcar, em pré-emergência e que tiverem a luz como principal forma de degradação poderão apresentar o mesmo comportamento. Porém, se não atravessarem a palhada, podem ser degradados mais rapidamente.

No caso dos herbicidas que sofrem degradação microbiana, como o diuron (Rodrigues \& Almeida, 1998), é possivel que a fração que atinge o solo tenha um período residual maior. Isto pode ocorrer por que os microorganismos do solo são altamente dependente da temperatura e umidade para atuarem na degradação de pesticidas. Sendo assim, quanto maior a umidade do solo, menor será a atividade dos microorganismo decompositores (aeróbicos) e maior será o período de permanência do produto no solo (Turco, 1997). É sabido que uma das vantagens do uso de coberturas vegetais morta, é a conservação da umidade do solo.

Os objetivos deste trabalho foram: a) avaliar o efeito residual da mistura formulada de diuron + hexazinone, aplicado em área de cana crua, através de bioensaio com planta teste e b) determinar, através de bioensaio, 
concentração aproximada do herbicida no solo, através de comparação com curva de dose-resposta aplicado em planta teste.

\subsection{Materiais e Métodos}

\subsubsection{Período Residual da Mistura Formulada dos Herbicidas Diuron + Hexazinone em Áreas de Cana Crua Determinado através de Bioensaio}

No mês de dezembro de 1999 foi instalado um experimento em área pertencente à Usina Iracema no município de Iracemápolis-SP, em solo Latosolo vermelho escuro (Tabela 18), em soqueira de cana-de-açúcar, da variedade SP79-2233, colhida sem queima no terceiro corte. Os tratamentos constaram da mistura comercial dos herbicidas diuron + hexazinone aplicado em pré-emergência, em parcelas com palha e sem palha, resultante da colheita, nas doses de $0,0+0,0 ; 0,936+0,264 ; 1,117+0,330 ; 1,404+0,396 \mathrm{~kg}$ i.a. ha-1 ${ }^{-1}$. $\mathrm{O}$ produto comercial utilizado foi o Velpar $\mathrm{K}$, que contém $468 \mathrm{~g}$ de diuron +132 $\mathrm{g}$ de hexazinone por quilograma de sua formulação, produzido pela Du Pont do Brasil, sendo apresentado na formulação de grânulos autodispersíveis em água (GRDA). 
Tabela 18. Análise química e física do solo da área experimental, a partir de amostras retiradas das parcelas de cana crua, da Usina Iracema

Química

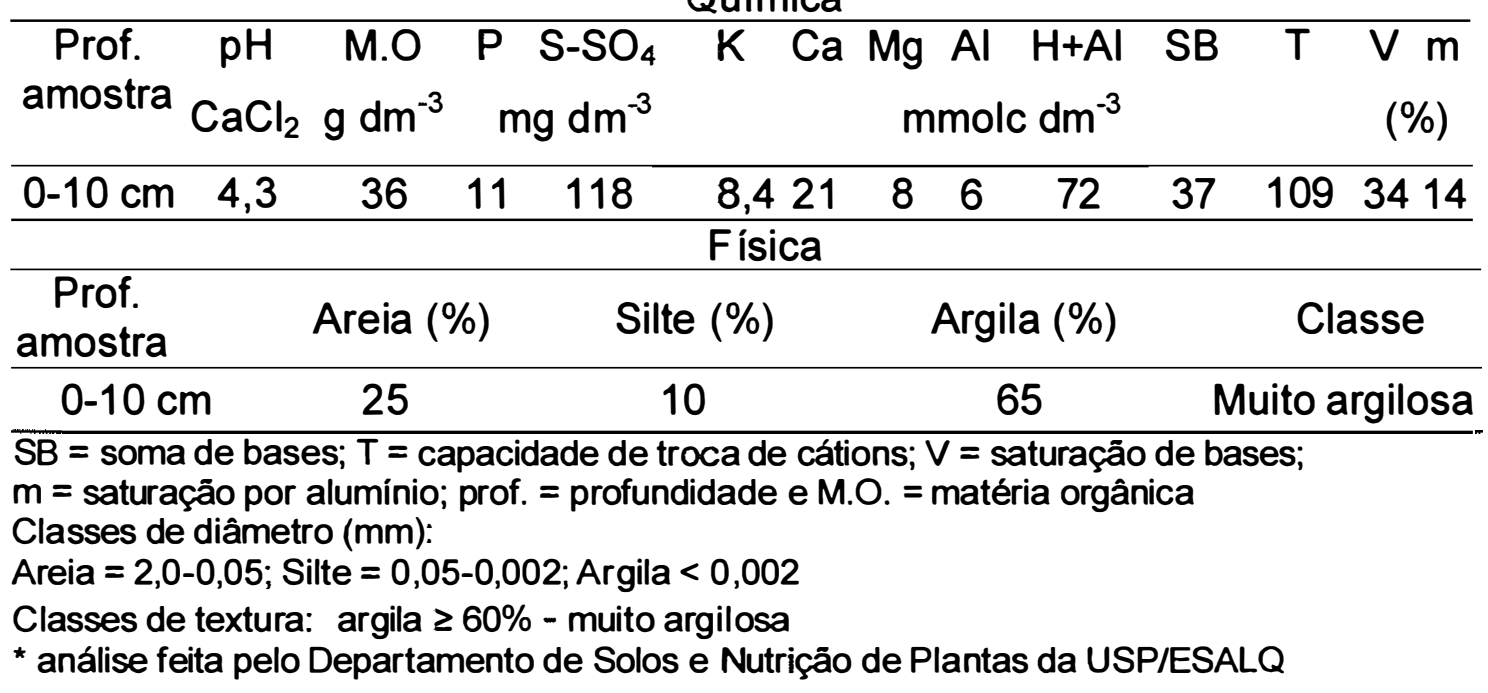

Aos 30 e 60 dias após a aplicação (DAT) das doses dos herbicidas no campo, foram coletadas amostras de $1 \mathrm{~kg}$ de solo nas parcelas tratadas e na testemunha. A Tabela 19 apresenta os valores de precipitação pluvial durante o período de coleta do material, onde observa-se que no dia seguinte a aplicação do herbicida (9/12/99) houve uma chuva de aproximadamente 40 $\mathrm{mm}$. Essas amostras foram colocadas em vasos, com capacidade para 700 $\mathrm{cm}^{3}$, condicionados em casa-de-vegetação, onde foi semeada a planta teste pepino, na quantidade de seis sementes por vaso, incorporadas na superfície do solo. $O$ delineamento experimental adotado foi o de blocos ao acaso, com quatro repetições. Após 21 dias, as plantas de pepino tiveram sua parte aérea cortada e a biomassa seca foi medida.

Os dados provenientes do experimento foram submetidos a análise de variância, com aplicação do teste $F$, sendo que as interações significativas tiveram suas médias comparadas ente si pelo teste de Tukey $(P<0,05)$. 
Tabela 19. Precipitação pluvial ocorrida no período de condução do experimento no campo (5 de Dezembro de 1999 a 10 de Fevereiro de 2000).

\begin{tabular}{|c|c|c|c|c|c|c|c|}
\hline Dia & Mes & Ano & $\begin{array}{l}\text { Precipitação } \\
(\mathrm{mm})\end{array}$ & Dia & Mes & Ano & $\begin{array}{l}\text { Precipitação } \\
(\mathrm{mm})\end{array}$ \\
\hline 5 & Dez & 1999 & 0,0 & ${ }^{2} 8$ & Jan & 2000 & 0,0 \\
\hline 6 & Dez & 1999 & 10,5 & 9 & Jan & 2000 & 0,0 \\
\hline 7 & Dez & 1999 & 48,2 & 10 & Jan & 2000 & 0,0 \\
\hline 8 & Dez & 1999 & 8,9 & 11 & Jan & 2000 & 21,6 \\
\hline${ }^{1} 9$ & Dez & 1999 & 0,0 & 12 & Jan & 2000 & 0,2 \\
\hline 10 & Dez & 1999 & 39,6 & 13 & Jan & 2000 & 4,9 \\
\hline 11 & Dez & 1999 & 0,0 & 14 & Jan & 2000 & 10,4 \\
\hline 12 & Dez & 1999 & 0,0 & 15 & Jan & 2000 & 0,7 \\
\hline 13 & Dez & 1999 & 44,7 & 16 & Jan & 2000 & 4,8 \\
\hline 14 & Dez & 1999 & 2,3 & 17 & Jan & 2000 & 0,5 \\
\hline 15 & Dez & 1999 & 0,0 & 18 & Jan & 2000 & 0,0 \\
\hline 16 & Dez & 1999 & 0,0 & 19 & Jan & 2000 & 0,0 \\
\hline 17 & Dez & 1999 & 0,0 & 20 & Jan & 2000 & 0,0 \\
\hline 18 & Dez & 1999 & 0,0 & 21 & Jan & 2000 & 0,0 \\
\hline 19 & Dez & 1999 & 0,3 & 22 & Jan & 2000 & 0,0 \\
\hline 20 & Dez & 1999 & 0,0 & 23 & Jan & 2000 & 0,0 \\
\hline 21 & Dez & 1999 & 0,0 & 24 & Jan & 2000 & 0,0 \\
\hline 22 & Dez & 1999 & 45,5 & 25 & Jan & 2000 & 17,0 \\
\hline 23 & Dez & 1999 & 0,0 & 26 & Jan & 2000 & 19,8 \\
\hline 24 & Dez & 1999 & 12,7 & 27 & Jan & 2000 & 0,0 \\
\hline 25 & Dez & 1999 & 0,8 & 28 & Jan & 2000 & 0,0 \\
\hline 26 & Dez & 1999 & 0,0 & 29 & Jan & 2000 & 0,0 \\
\hline 27 & Dez & 1999 & 28,2 & 30 & Jan & 2000 & 0,0 \\
\hline 28 & $\mathrm{Dez}$ & 1999 & 0,0 & 31 & Jan & 2000 & 14,7 \\
\hline 29 & Dez & 1999 & 0,0 & 1 & Fev & 2000 & 13,1 \\
\hline 30 & Dez & 1999 & 0,0 & 2 & Fev & 2000 & 0,0 \\
\hline 31 & Dez & 1999 & 7,9 & 3 & Fev & 2000 & 0,0 \\
\hline 1 & Jan & 2000 & 21,9 & 4 & Fev & 2000 & 5,0 \\
\hline 2 & Jan & 2000 & 31,1 & 5 & Fev & 2000 & 0,0 \\
\hline 3 & Jan & 2000 & 6,6 & 6 & Fev & 2000 & 0,0 \\
\hline 4 & Jan & 2000 & 3,0 & 37 & Fev & 2000 & 0,0 \\
\hline 5 & Jan & 2000 & 0,9 & 8 & Fev & 2000 & 0,0 \\
\hline 6 & Jan & 2000 & 6,2 & 9 & Fev & 2000 & 2,3 \\
\hline 7 & Jan & 2000 & 71,6 & 10 & Fev & 2000 & 26,1 \\
\hline
\end{tabular}

Total no período: $532 \mathrm{~mm}$

'Data da instalação do experimento no campo; ${ }^{2}$ Primeira coleta (30 DAT);

${ }^{3}$ Segunda coleta (60 DAT)

Fonte: Escola Superior de Agricultura "Luiz de Queiroz" (2001). 


\subsubsection{Curva de Dose Resposta da Mistura Formulada dos Herbicida Diuron + Hexazinone, Sobre Plantas de Pepino.}

Foram coletadas amostras ao acaso, nas parcelas testemunhas do campo. O solo onde foram coletadas as amostras não tinha histórico da aplicação de herbicidas nos últimos anos, portanto assume-se que não havia qualquer resíduo de herbicida no solo. O solo coletado apresentava a mesma classe textural (muito argilosa) utilizada no experimento de campo. Logo após, as amostras foram colocadas em vasos com capacidade de $500 \mathrm{~g}$, e em seguida foi feito a semeadura da planta pepino na quantidade de seis sementes por vaso, seguido da aplicação em pré-emergência do herbicida diuron + hexazinone nas doses de $0,0+0,0 ; 0,0932+0,0264 ; 0,1872+0,0528 ; 0,2808+$ 0,$0792 ; 0,3744+0,1056$ e $0,4680+0,1320 \mathrm{~kg}^{\text {i.a. }}$ ha $^{-1}$ (doses correspondentes as do produto comercial Velpar $K$ de 0,$\left.0 ; 0,2 ; 0,4 ; 0,6 ; 0,8 ; 1,0 \mathrm{~kg} \mathrm{ha}^{-1}\right) . \quad A$ aplicação foi feita em câmara de aspersão, no Departamento de Produção Vegetal da ESALQ/USP, utilizando-se bico Teejet 8002E, com um consumo de calda de $300 \mathrm{~L} \mathrm{ha}^{-1}$, pressão de trabalho de $30 \mathrm{lb} \mathrm{pol}^{-2}$.

Após a aplicação os vasos foram condicionados em casa-devegetação, onde aos 21 DAT houve o corte das planta e pesagem de biomassa da seca parte aérea. Os dados de biomassa foram submetidos à análise de variância com aplicação do teste $F$, sendo que as interações significativas, foram submetidas a análise de regressão $(P<0,01)$. 


\subsection{Resultados e Discussão}

\subsubsection{Período Residual da Mistura Formulada dos Herbicidas Diuron + Hexazinone em Áreas de Cana Crua Determinado através de Bioensaio}

Os valores apresentados na Tabela 20 , evidenciam a presença do herbicida por até 30 dias após a aplicação do herbicida nas parcelas com palha, pois aos 60 DAT não houve diferença da biomassa de pepino entre a testemunha e os tratamentos herbicidas Já os tratamentos sem palha mostraram diferenças até os $60 \mathrm{DAT}$. Em relação as doses, no tratamento sem palha, aos 30 DAT, a medida que estas vão aumentando, a matéria seca do pepino diminui gradualmente. No tratamento com palha, foram constatadas diferenças apenas entre a testemunha e os demais tratamentos (Figura 12). Entretanto, os valores de biomassa dos tratamentos com e sem palha, somente diferem na maior dose (Tabela 20). Já aos 60 DAT, no tratamento com palha, não são observadas diferenças entre os tratamentos herbicida, o que se observa, no entanto, nos tratamentos sem palha, onde as doses mais elevadas do produto proporcionaram uma menor biomassa da planta teste.

Tabela 20. Biomassa seca $(\mathrm{g})$ das plantas de pepino em amostras coletadas nas parcelas tratadas com herbicida aos 30 e 60 DAT no experimento de campo da Usina Iracema.

\begin{tabular}{|c|c|c|c|c|c|c|c|c|}
\hline \multirow[b]{2}{*}{ Tratamentos } & \multicolumn{4}{|c|}{$\begin{array}{c}30 \text { dias } \\
\operatorname{Doses}^{1}\left(\mathrm{~kg} \mathrm{i} \text {.a. } \mathrm{ha}^{-1}\right)\end{array}$} & \multicolumn{4}{|c|}{$\begin{array}{c}60 \text { dias } \\
\left.\text { Doses (kg i.a. } \mathrm{ha}^{-1}\right)\end{array}$} \\
\hline & 0 & 1 & 2 & $3^{4}$ & 0 & 1 & 2 & $3^{5}$ \\
\hline Com palha ${ }^{2}$ & $0,90 \mathrm{aA}$ & $0,54 \mathrm{bA}$ & $0,62 \mathrm{bA}$ & $0,62 \mathrm{bA}$ & $1,23 \mathrm{aA}$ & $1,40 \mathrm{aA}$ & $1,50 \mathrm{aA}$ & $1,45 a A$ \\
\hline Sem palha ${ }^{3}$ & $0,90 \mathrm{aA}$ & $0,48 \mathrm{bA}$ & $0,37 \mathrm{bA}$ & $0,20 b B$ & $1,35 \mathrm{aA}$ & $1,07 \mathrm{bB}$ & $0,84 c B$ & $0,66 \mathrm{~dB}$ \\
\hline
\end{tabular}

TDiuron + hexazinone: 0 - testemunha; 1 - 0,936 + 0,264; 2 -1,117+0,330; $3-1,404+0,396$ ( $\mathrm{kg}$ i.a. ha ${ }^{-1}$ de diuron e hexazinone, respectivamente). Médias seguidas pelas mesmas letras minúsculas na linha e maiúsculas na coluna, não diferem entre si pelo teste Tukey $(P<0,05)$. ${ }^{2} \mathrm{DMS}$ (linha; 30 e $\left.60 \mathrm{DAT}\right)=0,28 ;{ }^{3} \mathrm{DMS}$ (linha; $\left.30 \mathrm{DAT}\right)=0,3 ;{ }^{3} \mathrm{DMS}($ linha; 60 DAT) = 0,17; ${ }^{4} \mathrm{DMS}$ (coluna; 30 DAT) $=0,42 ;{ }^{5} \mathrm{DMS}$ (coluna; $\left.60 \mathrm{DAT}\right)=0,31$. 
Segundo Rodrigues \& Almeida (1998), os herbicidas diuron (468 g $\left.\mathrm{kg}^{-1}\right)$ + hexazinone $\left(132 \mathrm{~g} \mathrm{~kg}^{-1}\right.$ ) apresentam em condições de solo sem cobertura por palha e nas doses recomendadas, uma persistência de até 150 dias. Entretanto, Banks \& Robinson (1986) e Mills \& Witt (1989), mostraram que a palhada presente na superfície do solo intercepta uma quantidade considerável de herbicida aplicado em condições de pré-emergência, o qual não atinge o solo.

Desta forma, no presente caso foi observado, através das análises indiretas pela biomassa seca do pepino, que o efeito residual do herbicida foi reduzido. De acordo com a Tabela 20, observa-se que o efeito residual do herbicida vai até aos 30 dias após aplicação na palha. Já aos 60 dias, não há efeito residual, nas parcelas coletadas em área sobre a palha. Entretanto, nas amostras retiradas das parcelas onde a aplicação foi feita diretamente no solo, constata-se que aos 60 DAT ainda existe efeito residual do herbicida.

Turco (1997), demostrou que com maior umidade do solo ocorre diminuição na quantidade de microorganismos aeróbicos que decompõem pesticidas. Tal fato resultaria, nas condições da presente pesquisa, em maior período residual, uma vez que conforme Fernandes (2001) a umidade do solo em áreas de cana coberta com palha é bem maior do que em áreas de solo descoberto. Entretanto, acredita-se que o efeito residual da mistura comercial de diuron + hexazinone é reduzido principalmente pela retenção de parte do herbicida pela palhada. Todavia, não se sabe o comportamento da fração do herbicida que atingiu o solo.

Outro aspecto a ser considerado, é que aos 30 DAT (Figura 12), somente são observadas diferenças entre as doses nas parcelas sem palha. Nos tratamentos com a presença da palha, tal efeito não foi observado, tal fato pode ser explicado pela alta sensibilidade ao herbicida da planta utilizada no teste (pepino) (Figura 12). 


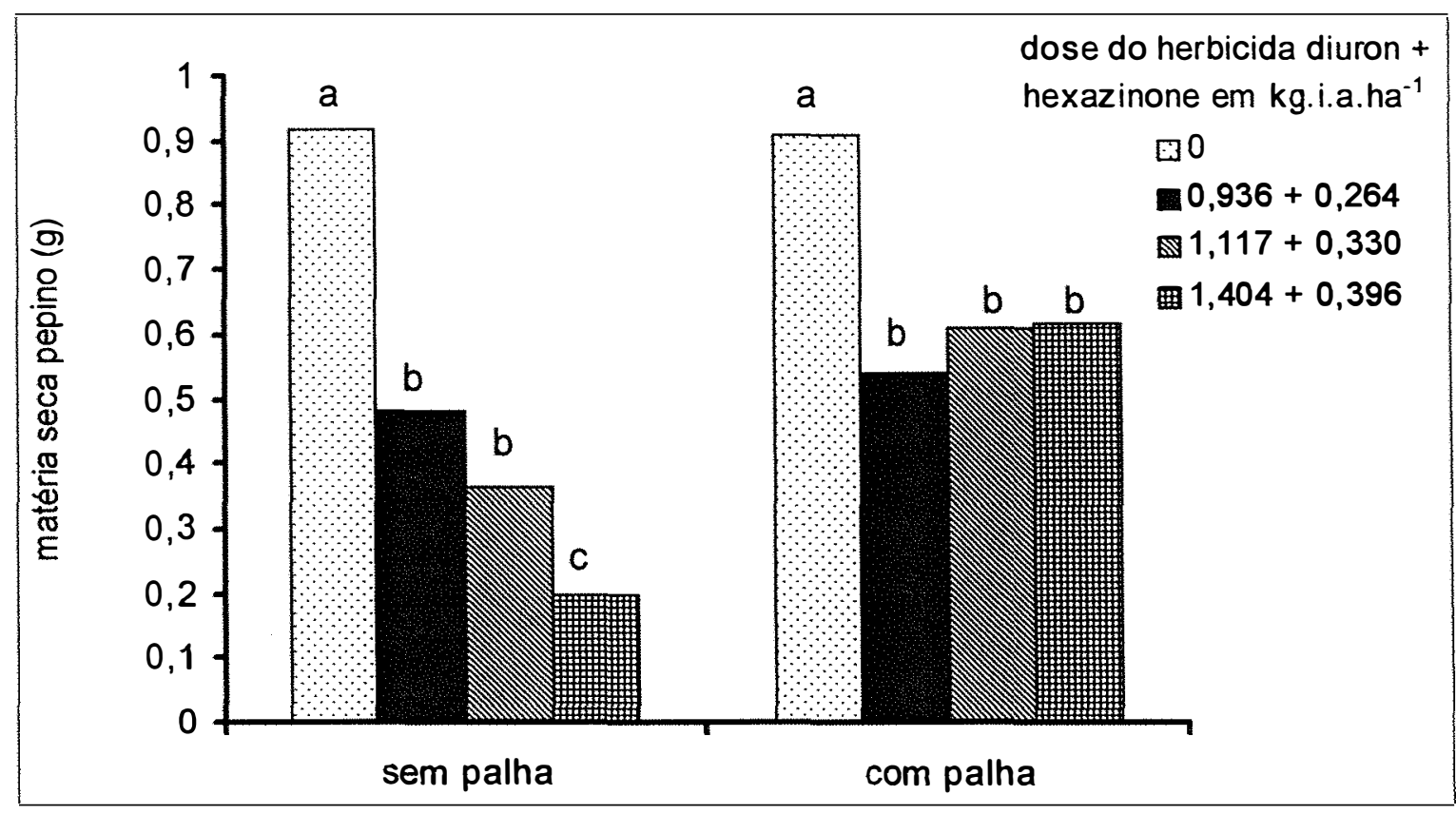

Figura 12 - Efeito residual do herbicida, através da biomassa seca da planta teste pepino, aos 30 DAT (letras iguais, dentro dos níveis do fator palha, não diferem pelo teste de Tukey $(P<0,05))$.

\subsubsection{Curva de Dose Resposta da Mistura Formulada dos Herbicidas Diuron + Hexazinone, Sobre Plantas de Pepino.}

$\mathrm{Na}$ Figura 13, é apresentada a resposta de plantas de pepino ao herbicida diuron + hexazinone, em termos de biomassa seca, segundo às doses de $0,0+0,0 ; 0,0932+0,0264 ; 0,1872+0,0528 ; 0,2808+0,0792 ; 0,3744$ $+0,1056 ; 0,4680+0,1320$ e $0,936+0,264 \mathrm{~kg}$ i.a. $\mathrm{ha}^{-1}$, representados pelas doses do produto comercial de 0,$0 ; 0,2 ; 0,4 ; 0,6 ; 0,8 ; 1,0 ;$ e $2,0 \mathrm{~kg} \mathrm{ha}^{-1}$. 


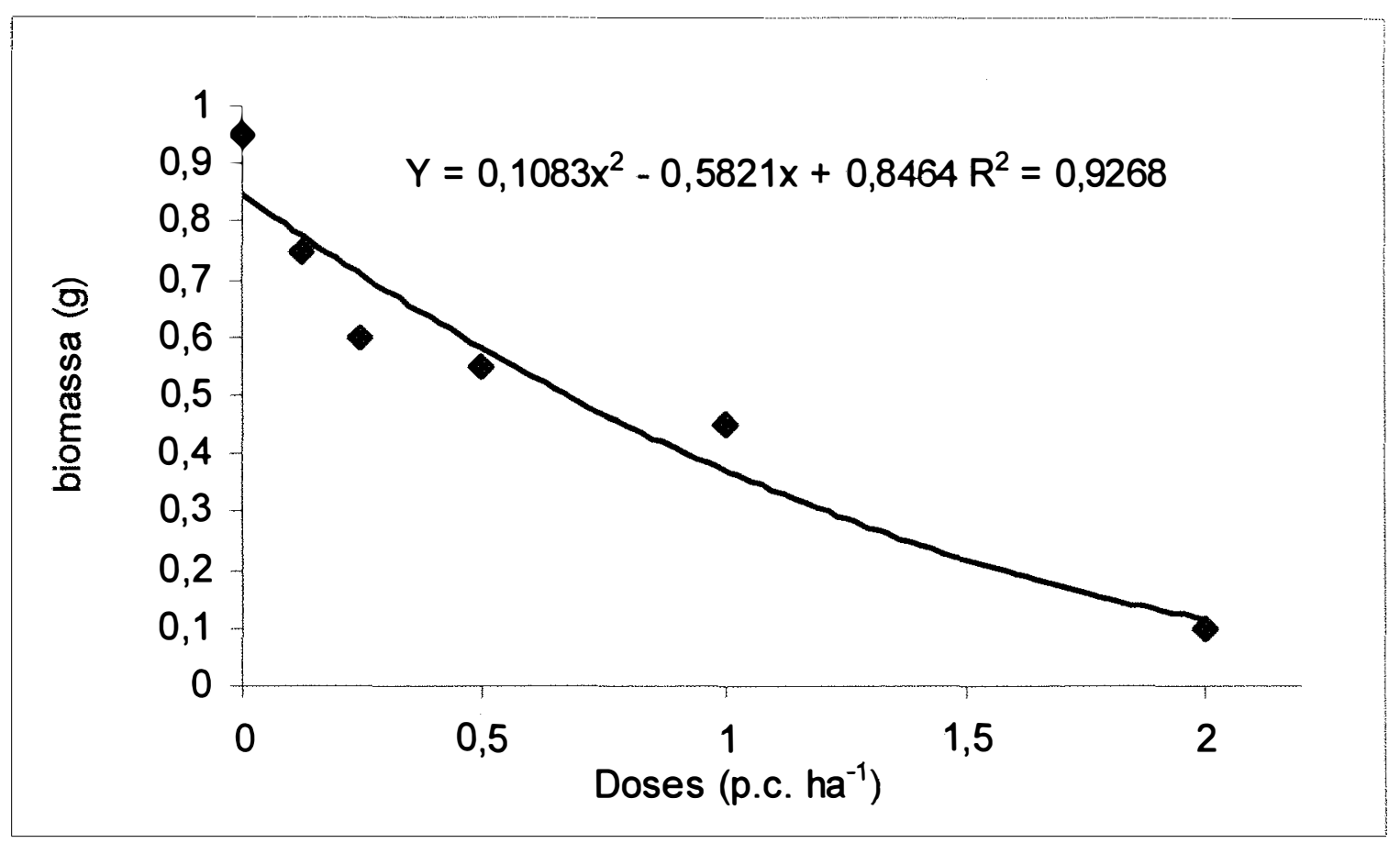

Figura 13 - Curva de dose resposta da mistura comercial dos herbicidas diuron $\left(468 \mathrm{~g} \mathrm{~kg}^{-1}\right)+$ hexazinone $\left(132 \mathrm{~g} \mathrm{~kg}^{-1}\right)$, sobre plantas de pepino.

Através da comparação da Figura 12 e Tabela 20, com a Figura 13, observa coerência entre os valores de biomassa obtidos, em função das doses do herbicida aplicado. Na Figura 12, observa-se valores de biomassa entre 0,9 e $1,0 \mathrm{~g}$, nos tratamentos testemunhas. O mesmo valor aproximado é encontrado na Figura 13, no tratamento sem a aplicação do herbicida. É possível notar ainda, que na Tabela 20 os valores de biomassa no tratamento com palha, aos $30 \mathrm{DAT}$, para todas as doses testadas, exceto a testemunha, estão em torno de 0,5 e 0,62 $\mathrm{g}$, valores estes que poderiam ser gerados por doses muito pequenas do herbicida. 


\subsection{Conclusões}

O período residual da mistura formulada dos herbicidas diuron + hexazinone é reduzido, quando é aplicado sobre a palha da colheita de canade-açúcar deixada na superfície do solo após a colheita.

De acordo com a curva de dose-resposta, a concentração do herbicida no solo, após sua aplicação sobre a palha está abaixo da concentração normalmente encontrada em solos cuja aplicação foi feita sem a presença da palha, e nas mesmas dosagem de aplicação. Em termos de ordem de grandeza, é possivel inferir que aos 30 DAT a concentração do herbicida no solo esta ao redor de 40 a $50 \%$ da dose, inicialmente aplicada.

Em áreas com cobertura de palha de cana-de-açúcar, inicialmente ocorre a retenção de uma parcela do herbicida, entretanto, a parcela que atinge o solo é capaz de proporcionar efeito residual e controle de plantas daninhas. Além disso, a parcela do herbicida retido na palha é dependente da quantidade de chuva após a aplicação. 


\section{EFEITO DA INTENSIDADE DE CHUVA E DA QUANTIDADE DE PALHA DE CANA-DE-AÇÚCAR SOBRE A EFICÁCIA DE HERBICIDAS.}

\section{Resumo}

O objetivo deste trabalho foi avaliar a eficiência da mistura formulada dos herbicidas diuron + hexazinone, nas doses de $0,0+0,0 ; 0,936+0,264$ e $1,404+0,396 \mathrm{~kg}$ i.a. $\mathrm{ha}^{-1}$, respectivamente, no controle das plantas daninhas anuais Ipomoea grandifolia (Dammer) O'Donell, Ipomoea hederifolia L., Euphorbia heterophylla L. e Digitaria horizontalis Willd, e do herbicida sulfentrazone, nas doses de 0,0;0,6; 0,7 e 0,8 kg i.a. ha ${ }^{-1}$, no controle da planta daninha perene Cyperus rotundus $\mathrm{L}$. em vasos com cobertura de palha de cana-de-açúcar, nas quantidades correspondentes a $0 ; 5 ; 10$ e $15 \mathrm{tha}^{-1}$ para os tratamentos com diuron + hexazinone e $0 ; 10$ e $15 \mathrm{t} \mathrm{ha}^{-1}$ para os tratamentos com sulfentrazone. Foram semeados cinco dissemínulos por espécie anual e 10 tubérculos de tiririca em cada vaso dos tratamentos correspondentes. Após o plantio, a superfície do solo dos vasos foi coberta por camadas de palha, dos tratamentos correspondentes, sendo feita a aplicação dos tratamentos com herbicidas. Vinte e quatro horas após a aplicação, foram simuladas chuvas de 0,$0 ; 10 ; 20 ; 30 ; 40$ e $50 \mathrm{~mm}$, sendo que $24 \mathrm{~h}$ após as chuvas, os tratamentos de palhada foram retirados da superfície do solo. Utilizou-se delineamento de blocos ao acaso, com quatro repetições e 20 dias após a retirada da palha foram feitas análises de biomassa da parte aérea das plantas daninhas anuais. Para a tiririca, a primeira análise ocorreu aos 30 dias após a aplicação do herbicida (DAT), e aos 70 DAT análise de biomassa de rebrota, biomassa e 
número de tubérculos foram avaliados. Conclui-se que a transposição dos herbicidas estudados nesta pesquisa através da palha de cana-de-açúcar é aumentada com a ocorrência de chuvas a partir de $10 \mathrm{~mm}$, em um período de $24 \mathrm{~h}$ após pulverização. Em áreas com grandes quantidades de palha de canade-açúcar ( $\left.\geq 15 \mathrm{tha}^{-1}\right)$, a redução no número de tubérculos de tiririca, esta diretamente correlacionada com a quantidade do herbicida sulfentrazone aplicado.

\section{THE EFFECT OF RAIN INTENSITY AND AMOUNT OF SUGARCANE CROP RESIDUE ON THE EFFICACY OF HERBICIDES}

\section{Summary}

The objective of this research was to evaluate the efficacy of the formulated mixture of the herbicides diuron + hexazinone, at rates of $0.0+0.0$; $0.936+0.264$ and $1.404+0.396 \mathrm{~kg}$ a.i. ha ${ }^{-1}$, respectively, on the control of the annual weeds Ipomoea grandifolia (Dammer) O'Donell, Ipomoea hederifolia L., Euphorbia heterophylla L. and Digitatia horizontalis Willd, and the herbicide sulfentrazone, at rates of $0.0 ; 0.6 ; 0.7$ and $0.8 \mathrm{~kg}$ a.i. ha ${ }^{-1}$, on the control of the weed Cyperus rotundus $\mathrm{L}$. in pots with soil covered by sugarcane trash debris resulting from the harvest without burning, corresponding to the amount of $0 ; 5$; 10 and $15 \mathrm{t} \mathrm{ha}^{-1}$ for the treatments with diuron + hexazinone and $0 ; 10$ and $15 \mathrm{t}$ $\mathrm{ha}^{-1}$ for the treatments with sulfentrazone. It was seeded five seeds for the annual species and 10 tubers of $C$. rotundus in each pot of the corresponding treatment. After planting, the surface of the soil in the pots was covered by sugarcane trash debris of the respective treatments and then herbicide treatments were sprayed. Twenty four hours later it was simulated rains of $0 ; 10$; 20; 30; 40 and $50 \mathrm{~mm}$, and 24 four hours after the application of the simulated 
rains, the sugarcane trash debris that were covering the soil surface were displaced from the soil surface. The experimental design was a randomized completely blocks, four replications, and 20 days after debris were displaced from soil surface, it was evaluated the weed shoot biomass of the annual weeds. For $C$. rotundus, the first evaluation was done at 30 days after herbicide treatments (DAT); at 70 DAT biomass of the shoot regrowth, biomass and number of tubers were evaluated. It was concluded from the experiment that all herbicides studied in this research can transpose the sugarcane trash debris and that is enhanced when rains of at least $10 \mathrm{~mm}$, in a period of $24 \mathrm{~h}$ after herbicide application occur. In areas where the amount of sugarcane debris on the soil surface is high ( $\left.15 \mathrm{t} \mathrm{ha}^{-1}\right)$, the reduction in the number of tubers of $C$. rotundus is directly correlated to the rate of sulfentrazone sprayed.

\subsection{Introdução}

O sucesso da utilização de um herbicida em uma cultura é dependente de diversos fatores que estão associados ao próprio herbicida, à cultura e as práticas culturais adotadas em sua condução e ao ambiente. $O$ sistema de produção da cana-de-açúcar, onde a colheita é feita mecanicamente sem a queima da palhada, popularmente conhecido por cana crua, apresenta um ambiente distinto do sistema convencional onde ocorre a queima da palha, em função da presença de grandes quantidades de palha deixadas na superfície do solo após a colheita, além de outros fatores (Conde \& Donzelli, 1997).

Dentre os fatores que afetam a eficácia de um herbicida, em áreas com cobertura vegetal sobre o solo, como em cana crua, apresenta grande importância a capacidade do herbicida em transpor a camada de palha. Tal característica esta relacionada com diversos fatores tanto do herbicida como do ambiente. Em relação aos fatores ambientais, a literatura aponta como sendo 
mais importante a precipitação pluvial, que lixiviaria 0 herbicida para os primeiros centímetros do perfil do solo (Rodrigues et al., 2000a), na região de maior concentração de sementes de plantas daninhas (Caetano, 2000; Ball, 1992).

Todavia, características relacionadas aos herbicidas, como solubilidade, pressão de vapor, constante de equilíbrio de ionização do ácido (pKa), coeficiente de partição octanol-água (Kow), constante da lei de Henry $(H)$, e forma de degradação da molécula, também teriam grande importância nos processos que levam a eficiência de utilização de uma molécula em sistemas de manejo sobre palhadas (Oliveira et al., 2001). Oliveira (2000), aponta ainda correlação significativa entre a quantidade de carbono orgânico e sorção de moléculas, o que poderia levar a indisponibilidade de um herbicida, principalmente no caso de bases fracas e moléculas não iônicas, como triazinas e alachlor, respectivamente, quando aplicados sobre elevadas quantidades de matéria orgânica.

Os objetivos desta pesquisa foram: a) avaliar o desempenho da mistura formulada diuron (468 $\left.\mathrm{g} \mathrm{kg}^{-1}\right)+$ hexazinone $\left(132 \mathrm{~g} \mathrm{~kg}^{-1}\right.$ ), quando aplicado sobre diferentes quantidades de palha de cana-de-açúcar, sendo submetida a diferentes quantidades de precipitação pluvial, no controle das plantas daninhas Ipomoea grandifolia (Dammer) O'Donell, Ipomoea hederifolial L., Euphorbia heterophylla L. e Digitaria horizontalis Willd; b) avaliar o desempenho do herbicida sulfentrazone, aplicado sobre diferentes quantidades de palha de cana-de-açúcar, sendo submetido a diferentes quantidades de precipitação pluvial, no controle da planta daninha Cyperus rotundus $\mathrm{L}$.

\subsection{Material e Métodos}

Os experimentos foram realizados em condições de casa-devegetação no Departamento de Produção Vegetal, USP/ESALQ. 


\subsubsection{Mistura Formulada dos Herbicidas Diuron + Hexazinone}

Cinco sementes de cada uma das espécies de plantas daninhas (I. grandifolia, I. hederifolia, E. heterifolia e D. horizontalis), totalizando 20 sementes por vaso, foram incorporadas na superfície do solo, sendo cobertas por fina camada de solo. Utilizou-se solo previamente esterilizado, cujas características são apresentadas na Tabela 21.

Tabela 21. Análises química e física do solo utilizado no experimento.

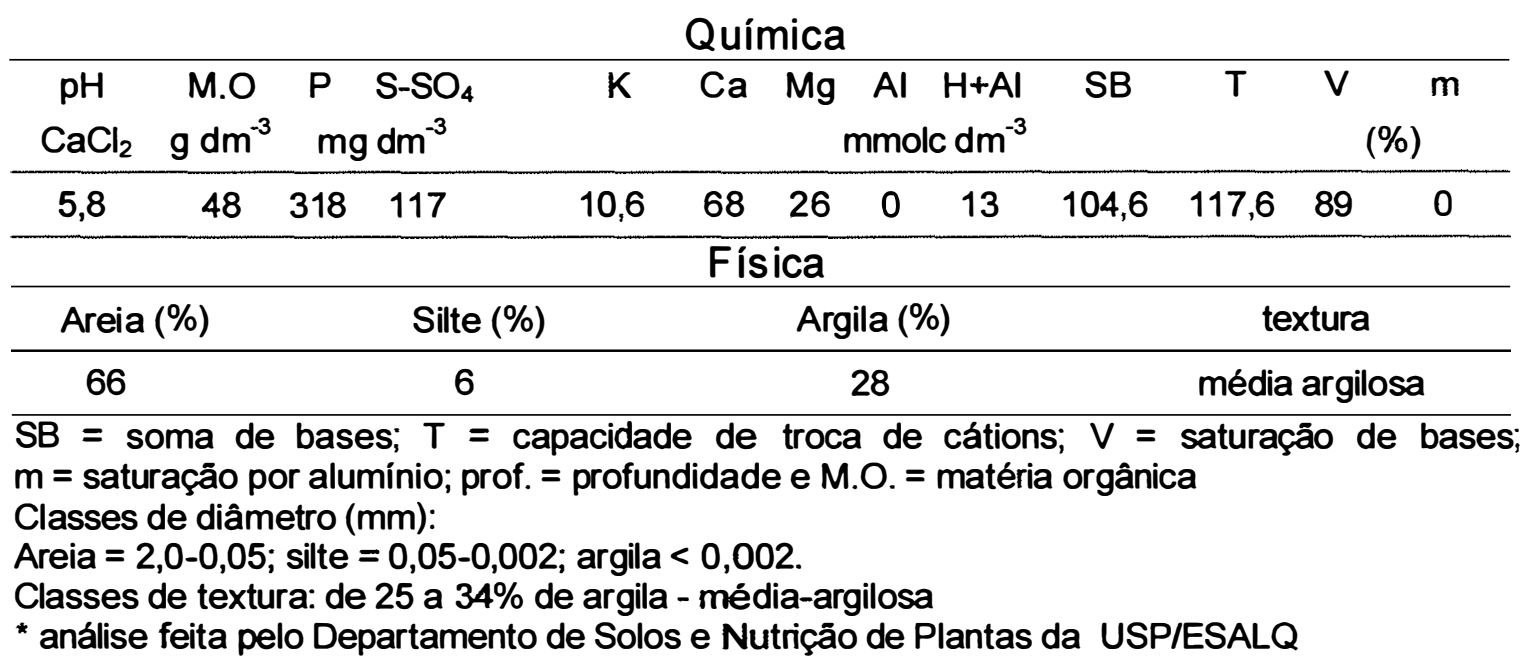

As superfícies do solo dos vasos foram cobertas com diferentes quantidades de palha (equivalente às quantidades de campo de: 5 ; 10 e 15 $\mathrm{t} \mathrm{ha}^{-1}$ ), além de uma testemunha no qual o solo foi deixado sem a presença da palha na superfície.

Após a cobertura do solo com a palha, os vasos foram colocados em casa de vegetação, sendo que no dia seguinte foi realizada a aplicação da mistura formulada dos herbicidas diuron $\left(468 \mathrm{~g} \mathrm{~kg}^{-1}\right)+$ hexazinone $\left(132 \mathrm{~g} \mathrm{~kg}^{-1}\right)$ nas doses da $0,0+0,0 ; 0,936+0,264$ e $1,404+0,396 \mathrm{~kg}$ i.a. ha ${ }^{-1}$, respectivamente.

A pulverização foi feita em câmara de aspersão, com volume de calda de $300 \mathrm{~L} \mathrm{ha}^{-1}$, aplicado com bico tipo leque Teejet $8002 \mathrm{E}$. Vinte e quatro 
horas após os vasos foram submetidos a simulação de precipitação pluvial nas quantidades de $0 ; 10 ; 20 ; 30 ; 40$ e $50 \mathrm{~mm}$, com a utilização de aparelho simulador de chuva.

Um dia após a simulação das chuvas, a palha de cana foi retirada de todos os tratamentos, e os vasos permaneceram em casa-de-vegetação, sendo que 20 dias após a retirada da palha foram feitas as coletas e pesagem de biomassa das plantas daninhas semeadas. Os dados referentes a biomassa foram submetidos à análise de variância e aplicação do teste $F$ através dos contrastes entre as médias dos tratamentos (Tabela 22). Para as interações com graus de liberdade superior a três, realizou-se análise de variância com aplicação do teste $F$ (Tabela 23); sendo que, as interações significativas foram submetidas a análise de regressão $(P<0,01)$.

Tabela 22. Grupos de contrastes aplicados entre os níveis de herbicida, dentro da variável precipitação pluvial.

\section{Precipitação $(\mathrm{mm})$}

0,$0 ; 10 ; 20 ; 30 ; 40 ; 50$

Y1 $0,0\left(\mathrm{~kg} \mathrm{ha}^{-1}\right)$ de herbicida $\times$ Doses

Y 2 Dose $1,117+0,330 \times$ Dose $1,404+0,396\left(\mathrm{~kg}^{2}\right.$ i.a. $\left.\mathrm{ha}^{-1}\right)$

Tabela 23. Quadro da Análise da Variância, com aplicação do teste F.

\begin{tabular}{lccccc}
\hline \multicolumn{1}{c}{ Causas de Variação } & G.L. & S.Q. & Q.M. & Valor F & PROB.>F \\
\hline Bloco & 3 & 0,504041 & & & \\
Palha & 3 & $\mathbf{4 , 2 4 4 8 9 6}$ & 1,414965 & 5,5384 & 0,00147 \\
Herbicida & 2 & 291,1575 & 145,57879 & 569,823 & 0,00001 \\
Chuva & 5 & 17,05858 & 3,411716 & 13,3541 & 0,00001 \\
Palha*Herbicida & 6 & 5,909164 & 0,984860 & 3,8549 & 0,00144 \\
Palha*Chuva & 15 & 12,27163 & 0,818108 & 3,2022 & 0,00019 \\
Herbicida*Chuva & 10 & 1,848785 & 0,184878 & 0,7237 & 0,70316 \\
Palha*Herbicida*Chuva & 30 & 16,25231 & 0,541743 & 2,1205 & 0,00140 \\
Resíduo & 213 & 54,41733 & 0,255480 & & \\
\hline Total & 287 & 403.664335 & C.V. $=58,81 \%$ & \\
\hline
\end{tabular}




\subsubsection{Herbicida Sulfentrazone}

Dez tubérculos de tiririca (C. rotundus) por vaso foram colocados no solo, a uma profundidade de $3 \mathrm{~cm}$. Utilizou-se solo previamente esterilizado, cujas características são apresentadas na Tabela 21.

As superfícies do solo dos vasos foram cobertas com diferentes quantidades de palha (equivalente as quantidades de campo de: 10 e $15 \mathrm{t} \mathrm{ha}^{-1}$ ), além de uma testemunha na qual o solo foi deixado sem a presença da palha na superfície.

Após a cobertura do solo com a palha, os vasos foram colocados em casa de vegetação; sendo que no dia seguinte foi realizada a aplicação do herbicida sulfentrazone nas doses de 0,$0 ; 0,6 ; 0,7$ e $0,8 \mathrm{~g}$ i.a. ha ${ }^{-1}$. A pulverização foi feita em câmara de aspersão, com volume de calda de 300 $\mathrm{L}$ ha ${ }^{-1}$, aplicado com bico tipo leque Teejet 8002E. Vinte e quatro horas após os vasos foram submetidos a simulação de precipitação pluvial nas quantidades de $0 ; 10 ; 20 ; 30 ; 40$, com a utilização de aparelho simulador de chuva.

Um dia após a simulação das chuvas, a palha de cana foi retirada de todos os tratamentos, e os vasos permaneceram em casa-de-vegetação, sendo que 20 dias após a retirada da palha foi feita a primeira avaliação de biomassa da parte aérea. Quinze dias após, repetiu-se a coleta de biomassa da rebrota de tiririca, com posterior contagem e pesagem de tubérculos.

Os dados de biomassa foram submetidos à análise de variância com aplicação do teste F (Tabela 25); sendo que, as interações significativas, foram submetidas a análise de regressão. Para melhor atender às exigências do modelo matemático utilizado, os dados foram submetidos a transformação pela raiz quadrada de $x+0,5$. Os dados sobre biomassa da rebrota, contagem $e$ número de tubérculos, foram submetidos a análise de variância com aplicação do teste $F$, sendo que as interações significativas tiveram suas médias comparadas entre si por análise de regressão e pelo contraste do teste $F$ (Tabela 24). 
Tabela 24. Quadro de contrastes entre os niveis de palha para as variáveis rebrota de tiririca ( $C$. rotundus), número e biomassa de tubérculos de tiririca (C. rotundus)

\begin{tabular}{cc}
\hline Y1 & Palha 0,0 $\left(\mathrm{t} \mathrm{ha}^{-1}\right) \times$ Palha $\left(10 ; 15 \mathrm{t} \mathrm{ha}^{-1}\right)$ \\
Y2 & Palha 10 $\left(\mathrm{t} \mathrm{ha}^{-1}\right) \times$ Palha 15 $\left(\mathrm{t} \mathrm{ha} \mathrm{a}^{-1}\right)$ \\
\hline
\end{tabular}

Tabela 25. Quadro da análise da variância, com aplicação do teste $F$.

\begin{tabular}{lccccc}
\hline Causas da variação & G.L. & S.Q. & Q.M. & Valor F & Prob. > F \\
\hline Blocos & 3 & 0,112207 & & & \\
Palha & 2 & 2,461483 & 1,230741 & 36,054 & 0,00001 \\
Herbicida & 3 & 11,22549 & 3,741831 & 109,617 & 0,00001 \\
Chuva & 4 & 1,897191 & 0,474297 & 13,8946 & 0,00001 \\
Palha*Herbicida & 6 & 0,375419 & 0,062570 & 1,9330 & 0,09443 \\
Palha*Chuva & 8 & 1,095250 & 0,136906 & 4,0107 & 0,00038 \\
Herbicida*Chuva & 12 & 0,923490 & 0,076957 & 2,2545 & 0,01124 \\
Palha*Herbicida*Chuva & 24 & 3,987721 & 0,166155 & 4,867 & 0,00001 \\
Resíduo & 177 & 6,041987 & 0,0341355 & & \\
\hline Total & 239 & 28.12024 & C.V. $=16,69 \%$ & \\
\hline
\end{tabular}

\subsection{Resultados e Discussão}

\subsubsection{Mistura Formulada dos Herbicidas Diuron + Hexazinone}

A presença da palha no solo intercepta parte do herbicida; entretanto, a passagem ou não pela palha é devido a uma série de fatores ligados ao herbicida (solubilidade, Koc, lixiviação, etc), ao sistema de colheita (quantidade de palha) e ao ambiente (principalmente quantidade de chuva). No entanto, pela análise dos resultados (Figuras 14, 15 e 16), fica evidente que os fatores relacionados ao herbicida (dose), sistema (quantidade de palha) e ao ambiente (chuva), apresentarem papel fundamental na atividade do herbicida em controlar as espécies das plantas daninhas (I. grandifolia, I. hederifolia, E. heterophylla e $D$. horizontalis). 
A mistura dos herbicidas diuron + hexazinone é formada por dois inibidores do fotossistema II. O diuron, é uma uréa substituída, e apresenta características de baixa solubilidade (42 ppm), com alta adsorção pelos colóides do solo. Já o hexazinone pertence ao grupo das triazinas, apresenta alta solubilidade em água (33.000 ppm) e é bastante móvel no solo (Ross \& Lembi, 1985). Dessa forma, existem duas situações onde pode haver no solo a presença de quantidades em diferentes proporções das encontradas no produto. Entretanto, sobre o solo ou palha, o produto pode persistir até ser carreado para o solo pela chuva, já que a principal forma de decomposição é devido ao ataque de microorganismos (Vidal, 1997).

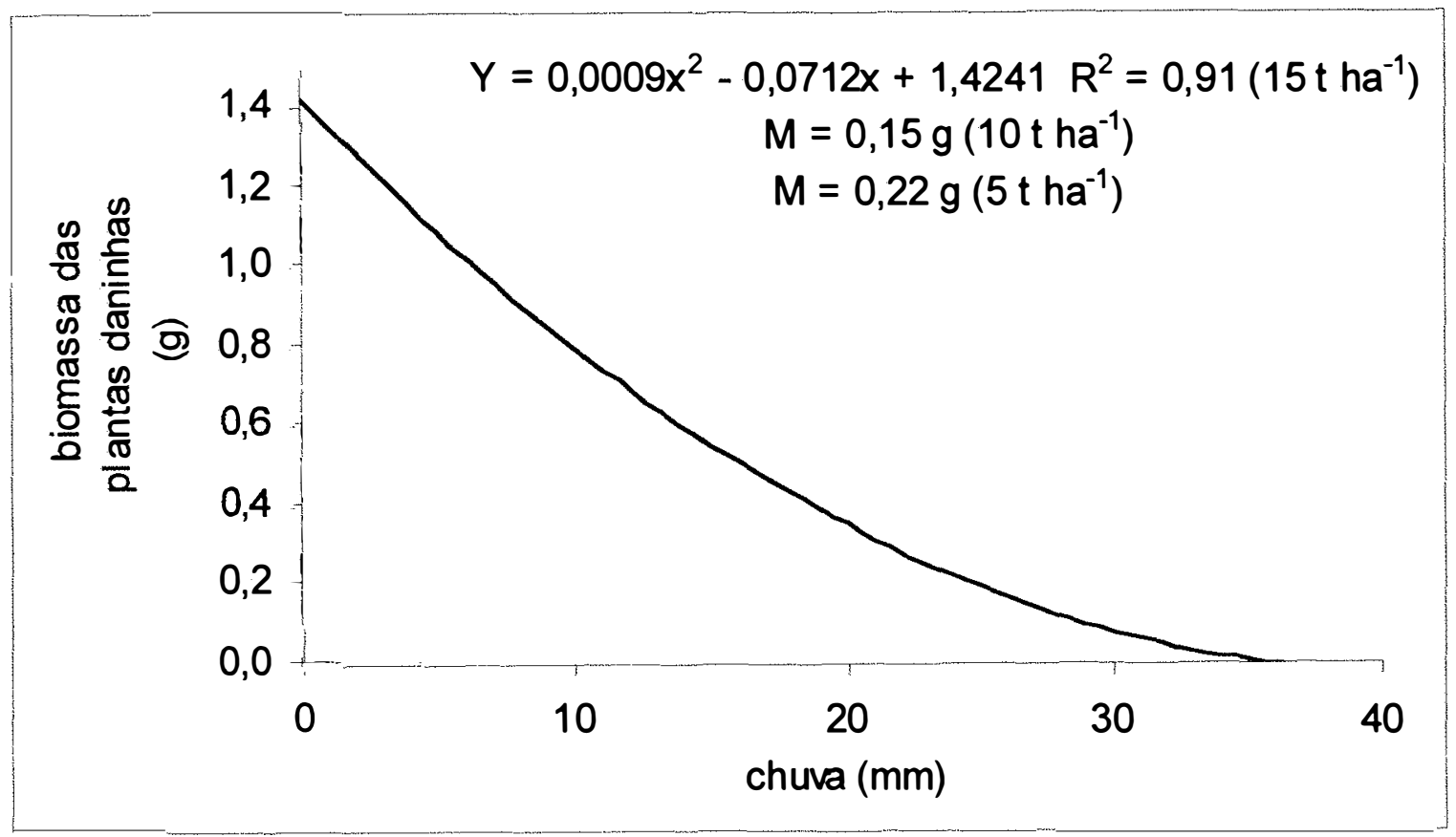

Figura 14 - Equação referente à dose dos herbicida diuron + hexazinone de $1,404+0,396\left(\mathrm{~kg} \mathrm{i}^{2} \mathrm{a} . \mathrm{ha}^{-1}\right)$, aplicados sobre diferentes quantidades de palha, em função da quantidade de chuva. $M$ - valor médio da biomassa para as quantidades de palha cujos termos da equação de regressão não foram significativos. 


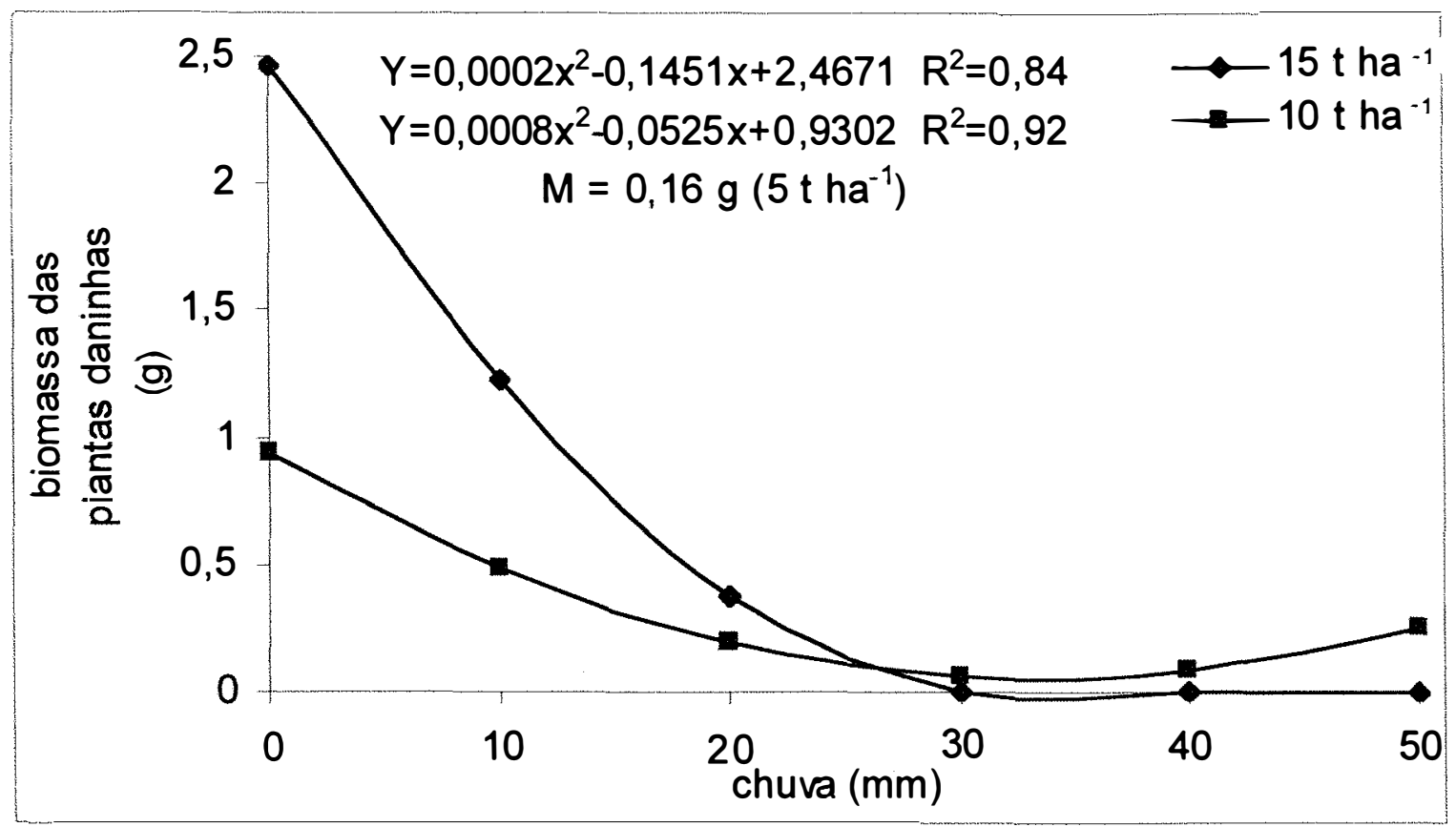

Figura 15 - Equações referentes a dose de herbicida diuron + hexazinone de $1,117+0,330\left(\mathrm{~kg}\right.$ i.a. $\left.\mathrm{ha}^{-1}\right)$, aplicado sobre diferentes quantidades de palha, em função da quantidade de chuva. $M$ - valor médio da biomassa para as quantidades de palha cujos termos da equação de regressão não foram significativos.

Na Figura 14, observa-se o efeito das doses de palha sobre a eficácia do herbicida, na dose de diuron + hexazinone de $1,404+0,396 \mathrm{~kg}$ i.a. ha ${ }^{-1}$. Nota-se que apenas o tratamento com maior quantidade de palha (15 $\mathrm{tha}^{-1}$ ), apresenta correlação com a quantidade de chuva. Nas menores quantidades de palha de cana-de-açúcar, o controle foi o mesmo, independente da quantidade de chuva que houve 24 horas após a aplicação dos herbicidas. Entretanto, na dose de $1,117+0,330 \mathrm{~kg}$ i.a. ha ${ }^{-1}$, somente $o$ tratamento com menor dose de palha $\left(5 \mathrm{t} \mathrm{ha}^{-1}\right)$ não apresentou correlação com às quantidades de chuva. De acordo com as Figuras 14 e 15, nota-se que pequenas quantidades de precipitação pluvial são suficientes para carregar o herbicida para o solo, onde valores a partir de $10 \mathrm{~mm}$ já seriam suficientes para carregar quantidades suficientes de produto. Entretanto as Figuras 14 e 15 também mostram que a 
quantidade de chuva necessária para levar o herbicida para o solo vai depender também da quantidade de palha cobrindo o solo.

Tabela 26. Análise da variância dos contrastes entre as médias de biomassa de plantas daninhas, dentro da variável precipitação pluvial.

\begin{tabular}{|c|c|c|}
\hline \multicolumn{2}{|c|}{ Contrastes } & Valores de F \\
\hline & $0,0 \mathrm{~mm}$ & \\
\hline Y1 & & $170,1517^{*}$ \\
\hline Y 2 & & $5,1362^{*}$ \\
\hline & $10 \mathrm{~mm}$ & \\
\hline Y1 & & $206,5794^{*}$ \\
\hline Y 2 & & $0,0018 \mathrm{~ns}$ \\
\hline & $20 \mathrm{~mm}$ & \\
\hline Y1 & & $215,7929^{*}$ \\
\hline Y 2 & & $0,0150 \mathrm{~ns}$ \\
\hline & $30 \mathrm{~mm}$ & \\
\hline Y1 & & $166,5258^{*}$ \\
\hline Y 2 & & 0,0040 ns \\
\hline & $40 \mathrm{~mm}$ & \\
\hline Y 1 & & $175,1929^{*}$ \\
\hline Y 2 & & 0,0926 ns \\
\hline & $50 \mathrm{~mm}$ & \\
\hline Y1 & & $207,2184^{*}$ \\
\hline Y 2 & & $0,1732 \mathrm{~ns}$ \\
\hline
\end{tabular}

De acordo, com os resultados da Tabela 26, é possivel observar com maior clareza a importância dos fatores dose e chuva (precipitação) no desempenho de um herbicida em sistemas com colheita de cana mecanizada sem queima. Desta forma, para períodos com ausência de chuva de até 48 horas após a aplicação dos herbicidas, doses maiores do produto proporcionariam maior eficiência, se aplicadas sobre a palhada seca. No entanto, conforme os contrastes da Tabela 26, quantidades de chuva iguais ou superiores a $10 \mathrm{~mm}$, resultam em controle semelhante para todas as doses testadas. 
Em relação aos valores apresentadas na Figura 16, observa-se que no presente estudo, as quantidades de chuva aplicadas, sobre as diferentes quantidades de palha, não tiveram relação alguma com a biomassa de plantas daninhas. Desta forma, pode-se afirmar, que os resultados de controle obtidos nas Figuras 14 e 15, não estão relacionados a quaisquer efeitos alelopáticos, o que era de se esperar em função do curto período de permanência da palha no solo. Entretanto, em períodos de maior permanência sobre o solo, a palha estando sujeita a maior decomposição e a maiores quantidades de precipitação ao longo do tempo, pode causar efeitos alelopáticos mais pronunciados (Gomide, 1993) e levar ao controle de determinadas espécies de plantas daninhas.

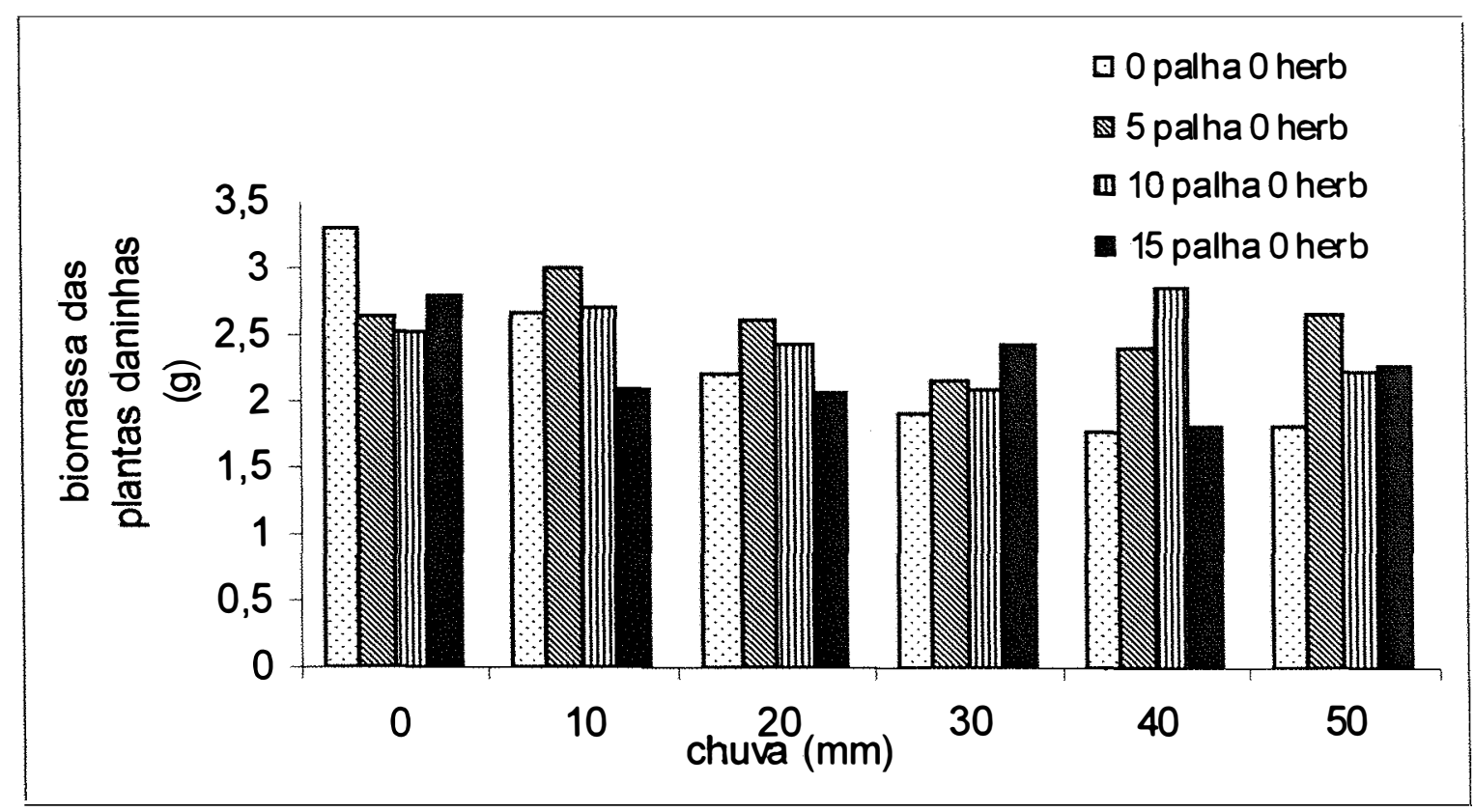

Figura 16 - Valores de biomassa de plantas daninhas com dose de $0,0+0,0 \mathrm{~kg}$ $\mathrm{ha}^{-1}$ de diuron + hexazinone, em função de diferentes quantidades iniciais de palha de cana-de-açúcar, submetidos à variação de precipitação, 48 horas após a semeadura. Não houve significância estatística para os parâmetros de regressão em nenhuma das quantidades de palha. 


\subsubsection{Herbicida Sulfentrazone}

Os resultados de eficiência do herbicida sulfentrazone no controle de tiririca ( $C$. rotundus), foram semelhantes em relação aos niveis dos fatores em estudo (palha e precipitação) quando comparados com a mistura formulada dos herbicidas diuron (468 $\left.\mathrm{g} \mathrm{kg}^{-1}\right)$ + hexazinone $\left(132 \mathrm{~g} \mathrm{~kg}^{-1}\right)$, no entanto, de acordo com as Figuras 17 e 18 o herbicida sulfentrazone apresentou menor correlação com a quantidade de chuva.

Nas Figuras 17 a 19, pode-se observar o comportamento da biomassa de tiririca, dentro dos níveis do herbicida, aplicados sobre os niveis dos fatores palha e precipitação.

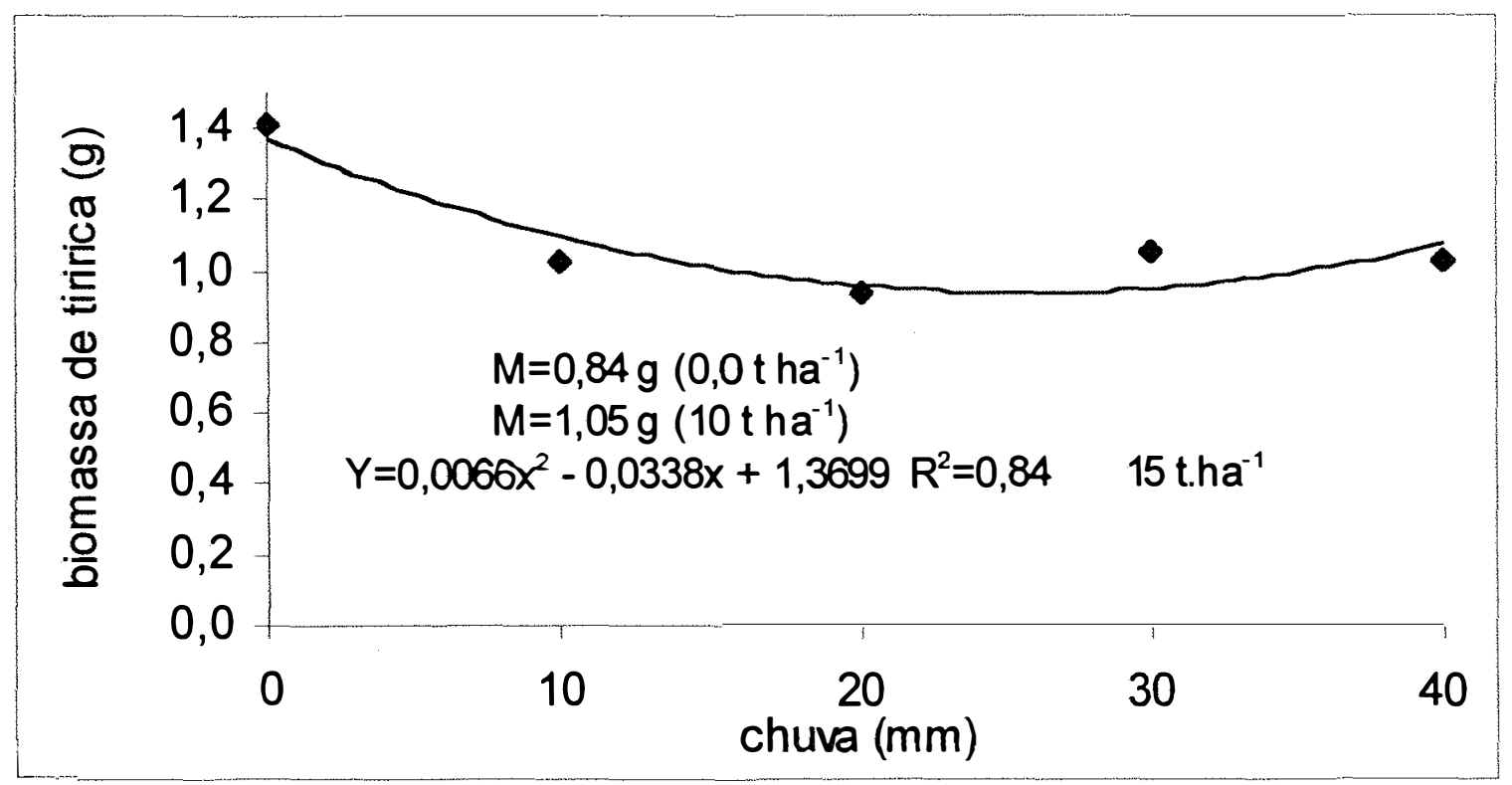

Figura 17 - Equação referente a dose de herbicida de 0,6 ( $\left(\mathrm{kg}\right.$ i.a. ha $\left.{ }^{-1}\right)$, aplicado sobre diferentes quantidades de palha, em função da quantidade de chuva. $M$ - valor médio da biomassa para as quantidades de palha cujos termos da equação de regressão não foram significativos. 


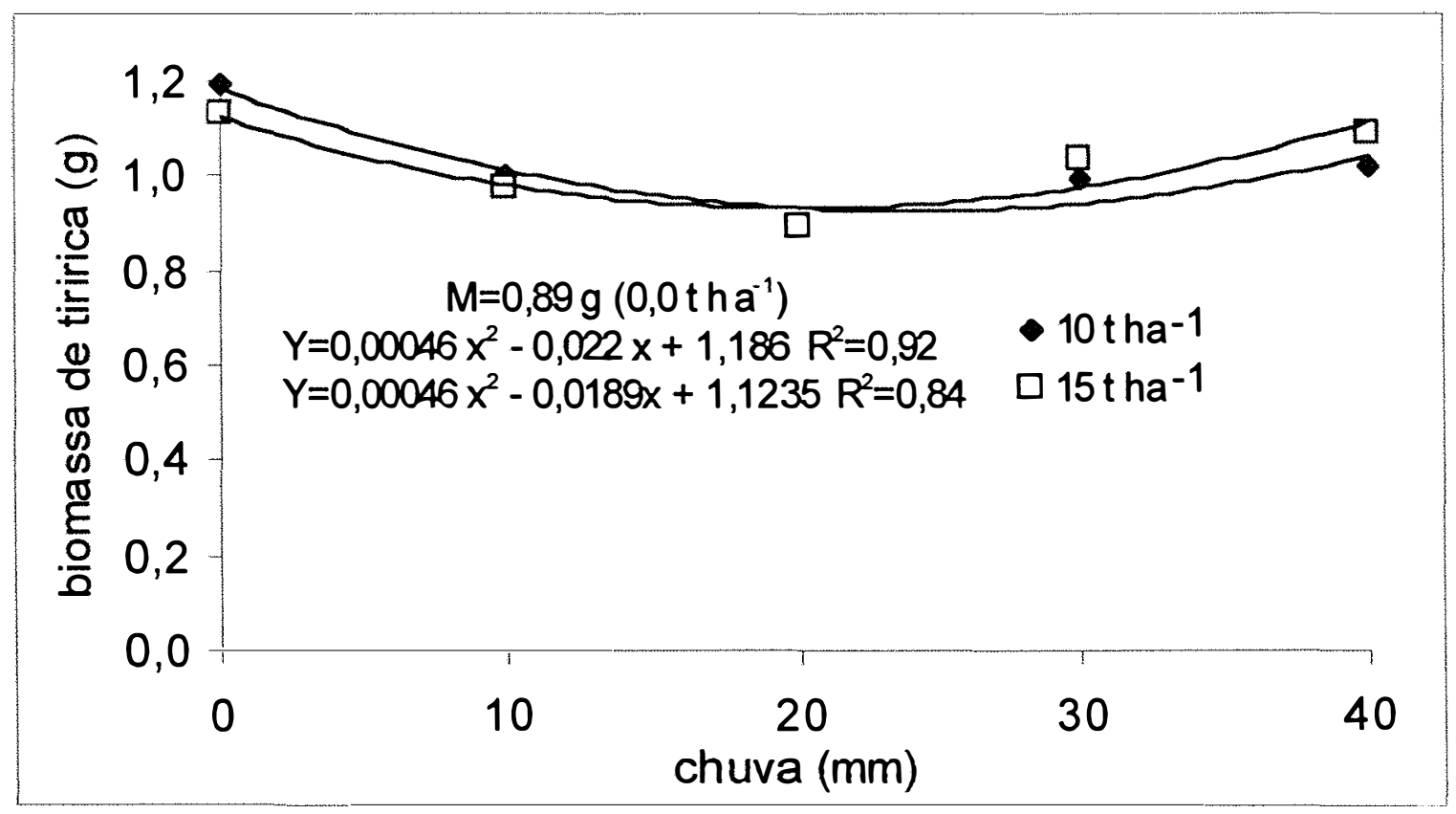

Figura 18 - Equações referentes à dose de herbicida de herbicida de 0,7 (kg i.a $\mathrm{ha}^{-1}$ ), aplicado sobre diferentes quantidades de palha, em função da quantidade de chuva. $M$ - valor médio da biomassa para as quantidades de palha cujos termos da equação de regressão não foram significativos.

$\mathrm{Na}$ Figura 17, observa-se que na menor dose testada $(0,6 \mathrm{~kg}$ i.a. ha-1 $)$, somente houve resposta aos diferentes níveis de precipitação pluvial, quando a quantidade de palha foi de $15 \mathrm{tha}^{-1}$, sendo que para os valores de $10 \mathrm{tha}^{-1}$ de palha e testemunha sem palha, são encontrados valores médios de biomassa de $0,84 \mathrm{~g}$ e $1,05 \mathrm{~g}$, respectivamente. O mesmo comportamento foi observado na dose de $0,7 \mathrm{~kg}$ i.a. ha ${ }^{-1}$ do herbicida (Figura 18), onde a testemunha, sem aplicação do herbicida apresenta o valor médio de biomassa de tiririca de 0,84 g e embora, os valores de biomassa de tiririca nas doses de palha de 10 e 15 t ha ${ }^{-1}$ apresentarem correlação negativa com a quantidade de chuva nota-se, na Figura 18, o pequeno efeito da quantidade de chuva sobre o controle desta planta daninha pelo herbicida sulfentrazone. 
Da mesma forma, os valores encontrados para o tratamento correspondente a maior dose do herbicida sulfentrazone $\left(0,8 \mathrm{~kg}\right.$ i.a. ha $\left.{ }^{-1}\right)$ de $0,83,1,0$ e 1,15 g, para as quantidades de palha correspondentes a 0,0, 10 e 15 $\mathrm{t} \mathrm{ha}^{-1}$, respectivamente demostram que $\mathrm{o}$ efeito da precipitação não foi significativo, para esta dose do herbicida.

Segundo Rodrigues \& Almeida (1998), a solubilidade do herbicida sulfentrazone é de 490 ppm, considerada de média a baixa, se comparado com outros produtos utilizados para o controle de tiririca (C. rotundus), em cana-deaçúcar. Entretanto, analisando-se as Figuras 19, 20 e 21, é possivel entender que o fator mais importante, encontrado nesta pesquisa, para a eficiência do herbicida sulfentrazone em áreas de colheita de cana crua, seria a dose do produto.

Nas Figuras 20 e 21 (10 e $15 \mathrm{t} \mathrm{ha}^{-1}$ de palha de cana, respectivamente), observa-se um padrão de controle de tiririca (C. rotundus) altamente correlacionado com a dose, independentemente da quantidade de precipitação que o tratamento foi submetido. 

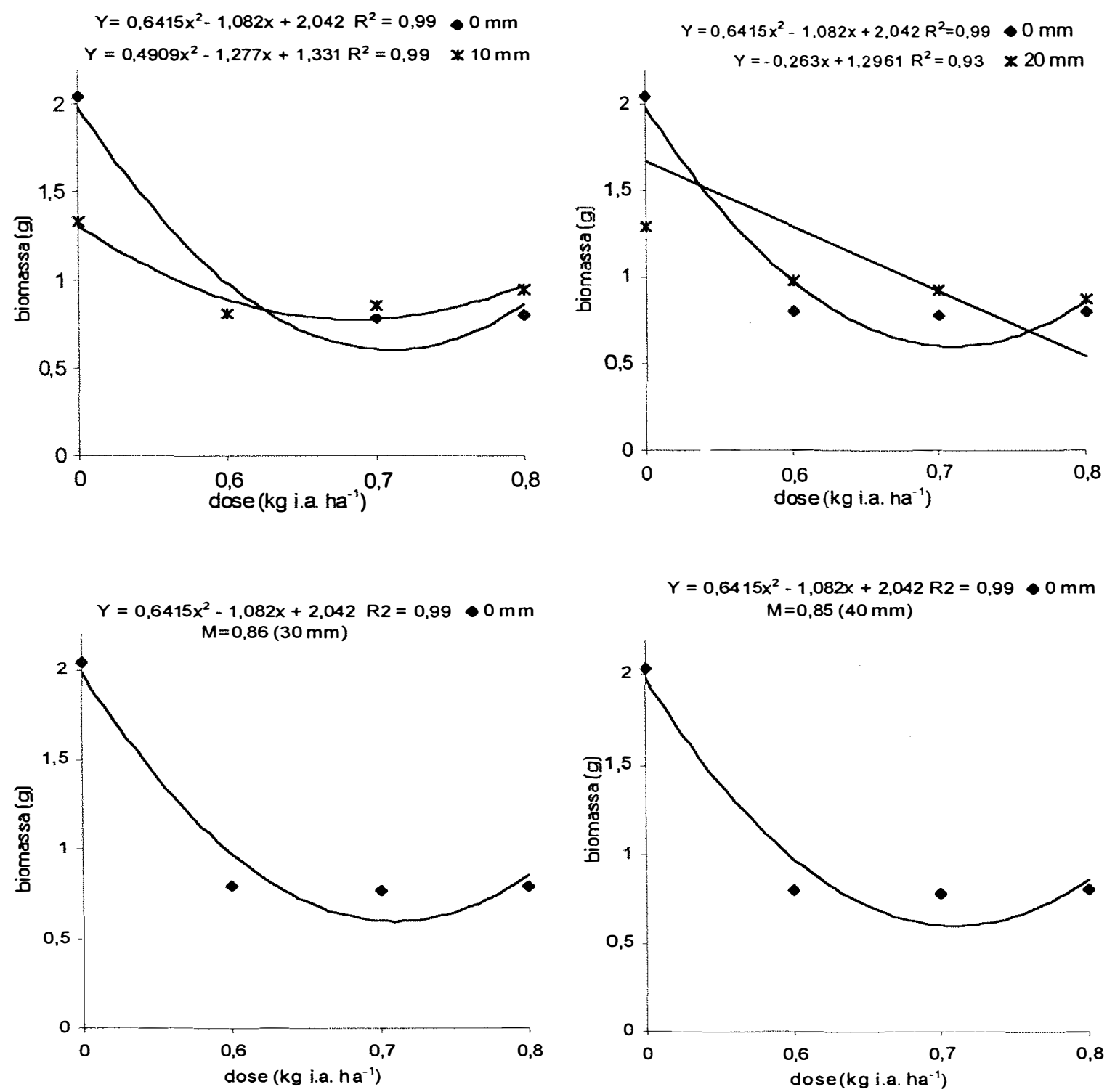

Figura 19 - Equações referentes a biomassa verde da parte aérea de plantas de tiririca (C. rotundus), em relação aos niveis do herbicida sulfentrazone, aplicados sobre $0,0 \mathrm{tha}^{-1}$ de palha de cana-deaçúcar, sendo submetidos após $24 \mathrm{~h}$, à diferentes niveis de precipitação pluvial $(0,10,20,30$ e $40 \mathrm{~mm})$. 

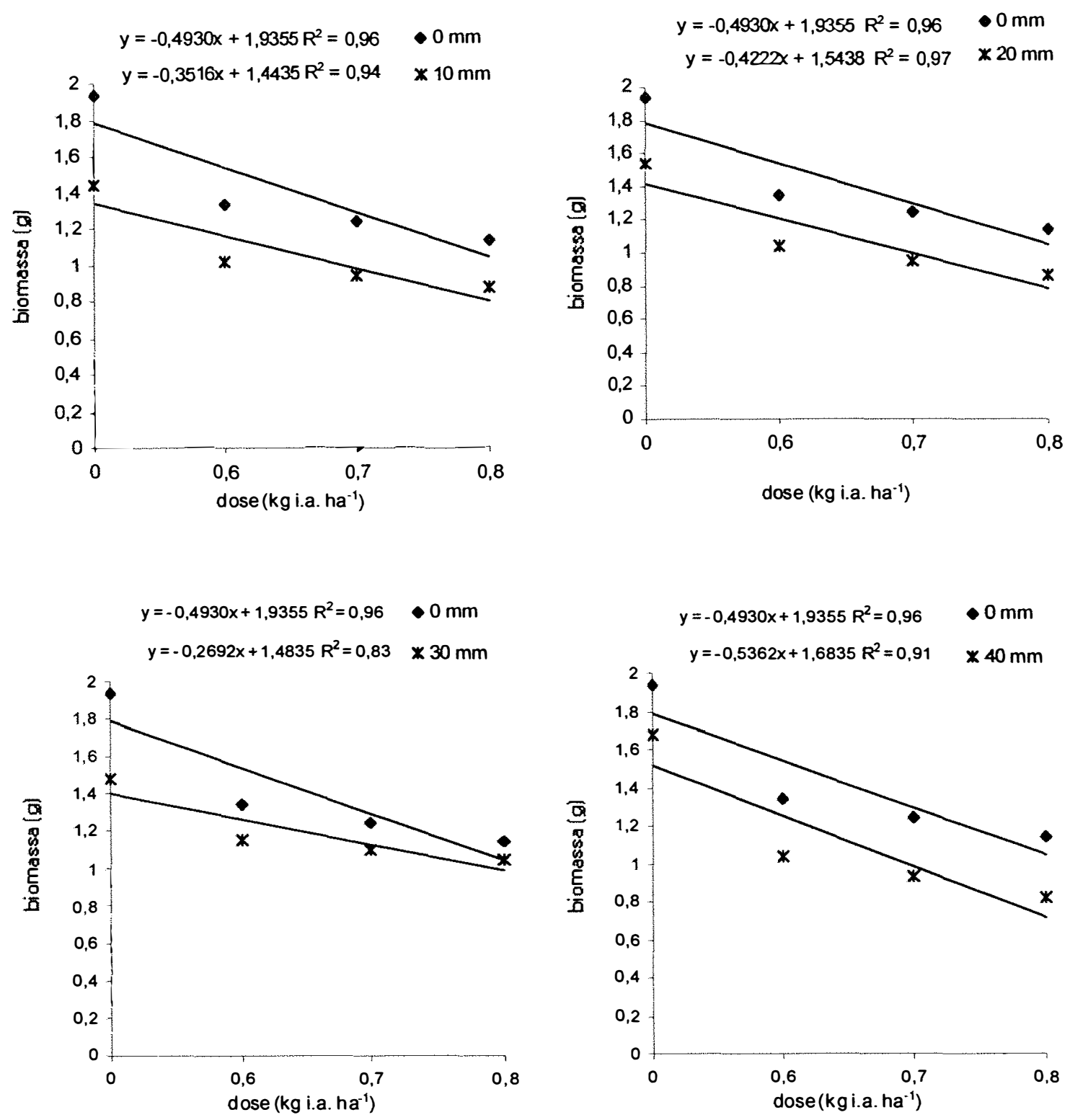

Figura 20 - Equações referentes a biomassa verde da parte aérea de plantas de tiririca (C. rotundus), em relação aos níveis do herbicida sulfentrazone, aplicados sobre $10 \mathrm{t} \mathrm{ha}^{-1}$ de palha de cana-deaçúcar, sendo submetidos após $24 \mathrm{~h}$, à diferentes níveis de precipitação pluvial $(0,10,20,30$ e $40 \mathrm{~mm})$. 

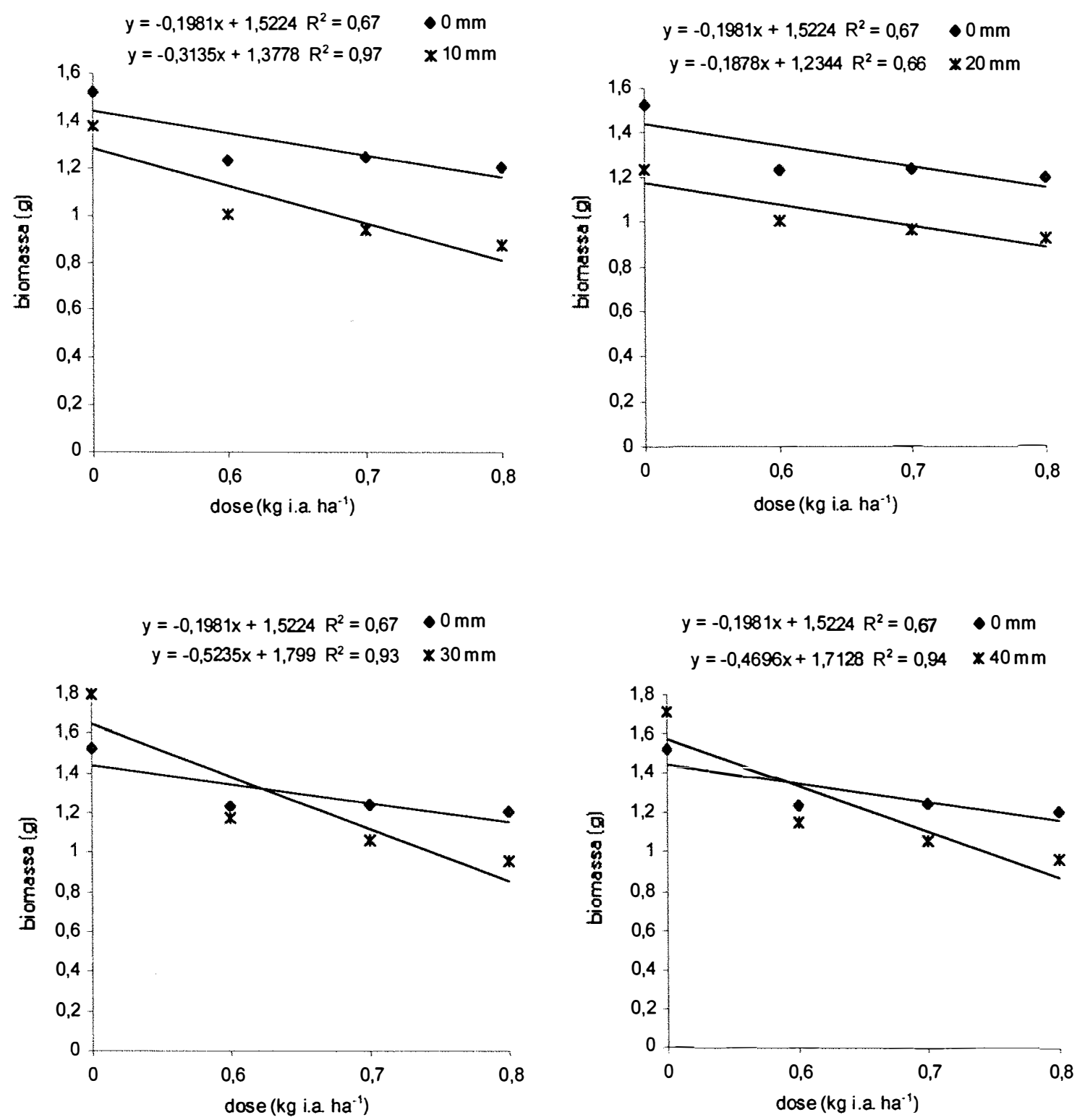

Figura 21 - Equações referentes a biomassa verde da parte aérea de plantas de tiririca ( $C$. rotundus), em relação aos niveis do herbicida sulfentrazone, aplicados sobre $15 \mathrm{t} \mathrm{ha}^{-1}$ de palha de cana-deaçúcar, sendo submetidos após $24 \mathrm{~h}$, à diferentes níveis de precipitação pluvial $(0,10,20,30$ e $40 \mathrm{~mm})$. 
Os resultados dos contrastes do teste $F$, aplicados para as variáveis rebrota de tiririca, número e biomassa de tubérculos, são apresentados nas Tabelas 27, 28 e 29.

Tabela 27. Análise da variância entre os contrastes dos níveis de palha para a variável rebrota de tiririca ( $C$. rotundus).

\begin{tabular}{cc}
\hline Contraste & Valores de F \\
\hline $\mathrm{Y} 1\left(0,0 \times 10 ; 15 \mathrm{tha}^{-1}\right)$ & $35,476^{\star}$ \\
$\mathrm{Y} 2\left(10 \times 15 \mathrm{tha}^{-1}\right)$ & $1,767 \mathrm{~ns}$ \\
\hline
\end{tabular}

Tabela 28. Análise da variância entre os contrastes dos niveis de palha para a variável biomassa de tubérculos de tiririca ( $C$. rotundus).

\begin{tabular}{cc}
\hline Contraste & Valores de F \\
\hline Y1 $\left(0,0 \times 10 ; 15 \mathrm{tha}^{-1}\right)$ & $2,864 \mathrm{~ns}$ \\
$\mathrm{Y} 2\left(10 \times 15 \mathrm{tha}^{-1}\right)$ & $0,843 \mathrm{~ns}$ \\
\hline
\end{tabular}

Tabela 29. Análise da variância entre os contrastes dos niveis de palha para a variável número de tubérculos de tiririca ( $C$. rotundus).

\begin{tabular}{cc}
\hline Contraste & Valores de $F$ \\
\hline Y $1\left(0,0 \times 10 ; 15 \mathrm{t} \mathrm{ha}^{-1}\right)$ & $15.755^{*}$ \\
Y $2\left(10 \times 15 \mathrm{tha}^{-1}\right)$ & $0,051 \mathrm{~ns}$ \\
\hline
\end{tabular}

A Tabela 27 permite observar que a rebrota da tiririca foi estatisticamente diferente nos tratamentos onde o herbicida foi aplicado sobre a palha, comparado com a aplicação na testemunha sem palha, independentemente da dose do produto e da precipitação pluvial de que o tratamento foi submetido. Este resultado sugere que na média, a presença da palha foi negativa ao desempenho do herbicida, para a variável rebrota. $\mathrm{Na}$ Tabela 29, observa-se 
comportamento semelhante ao da Tabela 27 , sendo que a presença da palha contribuiu para o maior número de tubérculos de tiririca (C. rotundus). Já em relação à Tabela 28 , não foram encontradas diferenças estatisticamente significativas entre as doses de palha testadas.

Apesar dos resultados acima terem evidenciado que a presença da palha no momento da aplicação do herbicida influi negativamente nos resultados das variáveis rebrota e número de tubérculos, a Figura 22 evidência que com o aumento da dose do herbicida, existe uma resposta de redução do número de tubérculos, dentro da maior dose de palha testada $\left(15 \mathrm{tha}^{-1}\right)$.

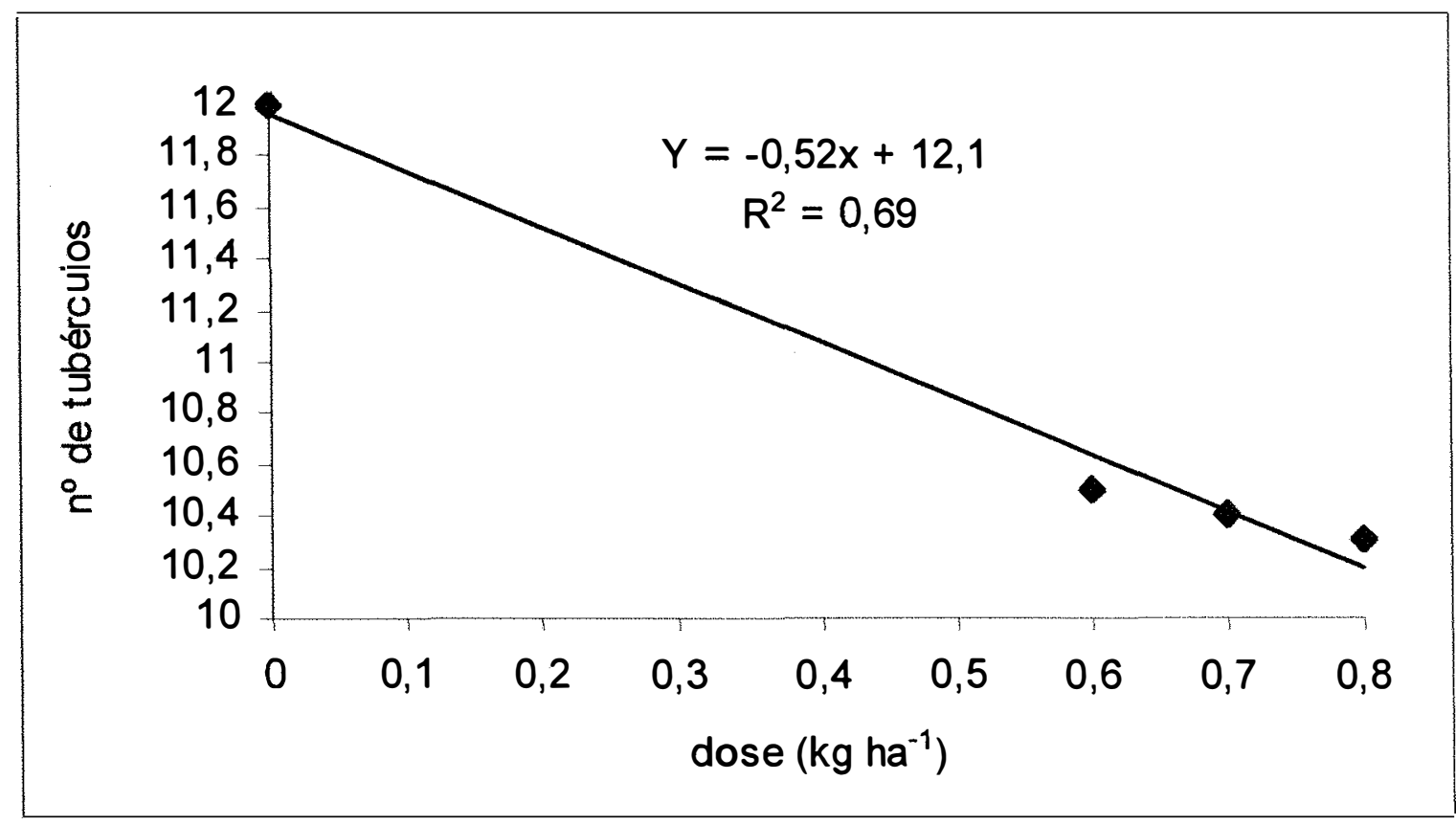

Figura 22 - Equação referente ao número de tubérculos de tiririca (C. rotundus) encontrados aos 70 DAA do herbicida sulfentrazone, sobre o correspondente a quantidade de palha de cana-de-açúcar de 15 t ha ${ }^{-1}$. 


\subsection{Conclusões}

Em relação ao herbicida diuron + hexazinone, a passagem do herbicida pela palha é altamente influenciado pela quantidade de palhada sobre a superfície do solo, porém em quantidades de até $5 \mathrm{tha}^{-1}$ já se observa os efeitos do herbicida, principalmente em doses mais elevadas, mesmo na ausência de chuva. Entretanto, nas quantidades de palha de 10 e $15 \mathrm{t} \mathrm{ha}^{-1}$, a chuva seria o principal fator que levaria o herbicida para o solo. Neste caso, chuvas a partir de 10-20 mm seriam suficientes para exercer este papel.

O herbicida sulfentrazone apresentou pequena correlação com a quantidade de chuva, para a variável biomassa da parte aérea de tiririca herbicida, para todos os niveis do fator palha, sendo que o fator mais importante para esta variável foi a dose do herbicida. Entretanto, para a variável rebrota observa-se o efeito negativo da presença da palha. Em relação ao número de tubérculos, em áreas com grande quantidade de palha de cana-deaçúcar na superfície do solo ( $\geq 15 \mathrm{t} \mathrm{ha}^{-1}$ ), sua redução esta diretamente correlacionada com a dose do produto. 


\section{DINÂMICA DO BANCO DE SEMENTES EM ÁREAS DE COLHEITA DE CANA QUEIMADA X ÁREAS DE COLHEITA MECANIZADA SEM QUEIMA DA PALHA.}

\section{Resumo}

O banco de sementes de plantas daninhas foi avaliado em relação ao número e espécies em três áreas experimentais pertencentes às Usinas da Pedra, Santa Luiza e São Martinho, localizadas nos municípios de Motuca/SP, Matão/SP e Pradópolis/SP, respectivamente. A cultura da cana-de-açúcar nestas áreas apresentavam-se no quinto corte, sendo que a coleta de amostras de solo foi feita logo após o quinto corte, para as Usinas Santa Luiza e São Martinho, e três meses após o quinto corte, para a Usina da Pedra. A amostragem de solo foi feita ao acaso em parcelas de $700 \mathrm{~m}^{2}$, representado pelos tratamentos nas áreas de: (i) colheita manual da cana após a queima; (ii) colheita mecanizada da cana sem queima. As profundidades de coleta do solo foram de 0-10 e 10-20 cm, sendo coletadas 60 amostras compostas de um quilograma, de cada tratamento nos três experimentos, que foram secas, peneiradas (peneira de 10 mesh) e subdivididas em subamostras, uma de 500 g e outra de $100 \mathrm{~g}$, sendo a primeira colocada em casa-de-vegetação, onde realizou-se durante um período de 120 dias a contagem e identificação das espécies de plantas daninhas que emergiram. A partir da segunda amostra (100 g), realizou-se a extração das sementes, através de centrifugação em solução de $\mathrm{K}_{2} \mathrm{CO}_{3}$. As sementes foram contadas e identificadas com o auxílio de uma lupa de aumento. Conclui-se que a composição específica do banco de 
sementes em áreas de colheita mecanizada sem queima, é alterada principalmente com a diminuição de plantas daninhas da família Poacea (gramíneas); porém, o tamanho total do banco de sementes é maior neste sistema. A análise da emergência em casa-de-vegetação revelou maior emergência de plantas daninhas nos tratamentos com colheita de cana sem queima. Portanto, é provável que nestas áreas ocorra uma maior quebra taxa de quebra de dormências por ocasião da reforma do canavial.

\section{WEED SEEDBANK DYNAMICS IN AREAS OF MANUAL AND BURNED $X$ MECHANICAL AND NON BURNED SUGARCANE HARVEST}

\section{Summary}

The weed seed bank was evaluated in relation to the number and species in three experimental areas of the sugarmills da Pedra, Santa Luiza and São Martinho, located in Motuca, Matão, and Pradópolis, state of São PauloBrazil, respectively. Sugarcane in the three areas was a ratoon of fifth harvest, where soil samples were collected immediately after the fifth harvest for the areas of Santa Luiza and São Martinho sugarmills, and three months after fifth cut at da Pedra sugarmill. Soil sampling was done ramdomly in plots of $700 \mathrm{~m}^{2}$, representing the treatments (i) sugarcane harvest after burning and (ii) sugarcane harvest mechanically without burning. The soil depth of sampling were $0-10 \mathrm{~cm}$ and $10-20 \mathrm{~cm}$, being collected 60 samples of one kilogram per treatment of each experiment. Each sample was dried, sieved (10 mesh), and divided into one subsample of $500 \mathrm{~g}$ and the one subsample of $100 \mathrm{~g}$, being the first placed in the greenhouse, where weed emergence was counted and identified during 120 days. From the second sample $(100 \mathrm{~g})$ it was exumed the weed seeds by centrifugation in $\mathrm{K}_{2} \mathrm{CO}_{3}$ solution. The seedlings were counted and identified. It was concluded that the specific composition of the weed seed bank in areas of sugarcane harvested mechanically without burning is altered 
mainly by diminushing the grass weeds; however, the total weed seed bank size was enhanced by this system, when compared with areas of sugarcane harvested after buming. It is likely that the areas of sugarcane harvested mecanichally without burning has the dormancy breaking of the weed soil seed bank much more intense during crop replanting.

\subsection{Introdução}

O estudo do banco de sementes de plantas daninhas é uma ferramenta importante para que se possa estabelecer a influência de determinado sistema de manejo sobre a população das plantas daninhas (Ball, 1992). Segundo Buhler et al. (1997) a característica do banco de sementes influencia tanto a dinâmica de plantas daninhas como o sucesso de manejo das mesmas em uma determinada cultura. Existem diversos trabalhos na literatura que demostram a importância do estudo do banco de sementes para o entendimento do comportamento das plantas daninhas, possibilitando assim medidas mais eficientes de manejo (Barberi et al., 1998; Carmona,1995; Martins \& Silva, 1994; Carmona,1992; Bhowmik, 1997).

Em sistemas de produção conservacionistas, observa-se grande acúmulo de sementes nos primeiros centímetros do perfil do solo (Yenish et al., 1992). Apesar da grande concentração de sementes nas camadas superficiais do solo, a germinação de várias espécies não ocorre, em função da presença de cobertura vegetal morta. No entanto, observa-se, nestes casos, a seleção de espécies que se adaptam ao padrão de distúrbio proporcionado pelo sistema que irão constituir a flora infestante (Radosevich et al., 1997a).

Segundo Thiensen \& Vidal (1999), as plantas que sobrevivem às dificuldades iniciais de estabelecimento, quando o solo for protegido com camada espessa de resíduos vegetais, geralmente são beneficiadas pela baixa 
população, cabendo-Ihes uma grande porção dos recursos do ambiente, o que favorece o seu desenvolvimento e produção de sementes.

Para que o manejo de plantas daninhas em áreas de colheita de cana crua seja planejado racionalmente, o estudo da relação entre dinâmica do banco de sementes de plantas daninhas, e este sistema de colheita é uma ferramenta de grande importância, para que este objetivo seja alcançado com sucesso. Sendo assim, foi conduzido este experimento com o objetivo de avaliar a influência da palha de cana de açúcar, deixada na superfície do solo após a colheita mecânica sobre a dinâmica do banco de sementes, comparativamente com as áreas de colheita manual, onde é feita a queima da palha antes da colheita.

\subsection{Material e Métodos}

\subsubsection{Coleta das Amostras de Solo}

As amostras de solo foram coletadas em áreas de cultivo da cana-deaçúcar pertencente às Usinas Santa Luiza (Matão-SP), da Pedra (Serrana-SP) e São Martinho (Sertãosinho-SP). Para que os resultados fossem os mais uniformes, optou-se por fazer todas as coletas na mesma época do ano (de novembro a janeiro). Desta forma, objetivou-se estabelecer com maior acurácia um padrão de comportamento do banco de sementes em áreas com colheita mecânica de cana-de-açúcar sem queima (cana crua).

O manejo de plantas daninhas durante a condução do experimento foi feito com a aplicação dos herbicidas diuron $\left(468 \mathrm{~g} \mathrm{~kg}^{-1}\right)$ + hexazinone (132 g $\mathrm{kg}^{-1}$ ) nas dose de $1,17+0,330 \mathrm{~kg} \mathrm{ha}^{-1} \mathrm{em}$ mistura de tanque com MSMA (480 g $\mathrm{L}^{-1}$ ) na dose de $0,960 \mathrm{~kg} \mathrm{ha}^{-1}$, nas parcelas com colheita de cana convencional e nas parcelas com colheita de cana crua não houve tratamento com herbicidas. 
Nas Tabelas 30,31 e 32 , são apresentadas as características químicas e físicas dos solos das áreas analisadas.

Tabela 30. Análises química e física do solo da área experimental, da Usina Santa Luiza.

Química

\begin{tabular}{|c|c|c|c|c|c|c|c|c|c|c|c|c|c|}
\hline $\begin{array}{l}\text { Prof. } \\
(\mathrm{cm})\end{array}$ & $\begin{array}{c}\mathrm{pH} \\
\mathrm{CaCl}_{2}\end{array}$ & $\begin{array}{l}\text { M.O. } \\
\mathrm{g} \mathrm{dm}^{-3}\end{array}$ & $\begin{array}{l}P S \\
m g\end{array}$ & & \multicolumn{7}{|c|}{ mmolc dm ${ }^{-3}$} & \multicolumn{2}{|c|}{$(\%)$} \\
\hline $0-10^{1}$ & 5,1 & 29 & 18 & 25 & 3,0 & 38 & 11 & 0 & 22 & 52 & 74 & 70 & 0 \\
\hline $10-20$ & 5,2 & 20 & 6 & 21 & 1,6 & 29 & 8 & 0 & 22 & 39 & 60 & 64 & 0 \\
\hline $0-10^{2}$ & 5,2 & 23 & 10 & 18 & 3,8 & 27 & 11 & 0 & 20 & 42 & 62 & 68 & 0 \\
\hline $10-20$ & 5,0 & 20 & 7 & 25 & 1,3 & 22 & 8 & 0 & 22 & 31 & 53 & 59 & 0 \\
\hline
\end{tabular}

Física

\begin{tabular}{ccccccc}
\hline $\begin{array}{c}\text { Prof. } \\
(\mathrm{cm})\end{array}$ & $\begin{array}{c}\text { Areia } \\
(\%)\end{array}$ & $\begin{array}{c}\text { Silte } \\
(\%)\end{array}$ & $\begin{array}{c}\text { Argila } \\
(\%)\end{array}$ & Classe & \multicolumn{2}{c}{$\begin{array}{c}\text { D.A. } \\
\mathrm{g} \mathrm{cm}^{-3}\end{array}$} \\
\hline $0-10^{1}$ & 74 & 6 & 20 & Média arenosa & 1,4 & 2,5 \\
$10-20$ & 74 & 6 & 20 & Média arenosa & 1,47 & 2,41 \\
$0-10^{2}$ & 76 & 4 & 20 & Média arenosa & 1,46 & 2,35 \\
$10-20$ & 74 & 6 & 20 & Média arenosa & 1,41 & 2,3 \\
\hline
\end{tabular}

${ }^{1}$ Cana crua; ${ }^{2}$ Cana queimada

$\mathrm{SB}=$ soma de bases; $\mathrm{T}=$ capacidade de troca de cátions; $\mathrm{V}=$ saturação de bases; $\mathrm{m}$ = saturação por alumínio; prof. = profundidade e M.O. = matéria orgânica

Classes de diâmetro $(\mathrm{mm})$ :

Areia $=2,0-0,05 ;$ Silte $=0,05-0,002 ;$ Argila $<0,002$

Classes de textura: de 15 a $24 \%$ de argila - média arenosa

D.A. = densidade aparente e D.R. = densidade real

* análises feitas pelo Departamento de Solos e Nutrição Mineral de Plantas da USP/ESALQ 
Tabela 31. Análises química e física do solo da área experimental, da Usina da Pedra.

Química

\begin{tabular}{ccccccccccccccc}
\hline $\begin{array}{c}\text { Prof. } \\
\text { (cm) }\end{array}$ & $\begin{array}{c}\mathrm{pH} \\
\mathrm{CaCl}_{2}\end{array}$ & $\begin{array}{c}\text { M.O. } \\
\mathrm{g} \mathrm{dm}^{-3}\end{array}$ & $\begin{array}{c}\mathrm{P} \\
\mathrm{mg} \mathrm{dm}\end{array}$ & $\mathrm{S}_{-3} \mathrm{SO}_{4}$ & $\mathrm{~K}$ & $\mathrm{Ca}$ & $\mathrm{Mg}$ & $\mathrm{Al}$ & $\mathrm{H}+\mathrm{Al}$ & $\mathrm{SB}$ & $\mathrm{T}$ & $\mathrm{V}$ & $\mathrm{m}$ \\
\hline $0-10^{1}$ & 4,79 & n.d. & 19,3 & n.d. & 0,6 & 23 & 8 & n.d & 39 & 31 & 70 & 44 & n.d \\
$10-20$ & 4,97 & n.d. & 23,0 & n.d. & 0,6 & 21 & 5 & n.d & 39 & 26 & 65 & 40 & n.d \\
$0-10^{2}$ & 4,96 & n.d. & 20,1 & n.d. & 0,4 & 19 & 4 & n.d & 32 & 24 & 56 & 43 & n.d \\
$10-20$ & 4,9 & n.d. & 23,7 & n.d. & 0,2 & 20 & 4 & n.d & 40 & 24 & 63 & 39 & n.d \\
\hline
\end{tabular}

Física

\begin{tabular}{|c|c|c|c|c|c|c|}
\hline $\begin{array}{l}\text { Prof. } \\
\text { (cm) }\end{array}$ & $\begin{array}{c}\text { Areia } \\
(\%)\end{array}$ & $\begin{array}{c}\text { Silte } \\
(\%)\end{array}$ & $\begin{array}{c}\text { Argila } \\
(\%)\end{array}$ & Classe & \multicolumn{2}{|c|}{$\mathrm{g} \mathrm{cm}^{-3}$} \\
\hline $0-10^{1}$ & 87 & 3 & 10 & Arenosa & 1,7 & n.d. \\
\hline $10-20$ & 86 & 6 & 8 & Arenosa & 1,64 & n.d. \\
\hline $0-10^{2}$ & 88 & 4 & 8 & Arenosa & 1,5 & n.d. \\
\hline $10-20$ & 86 & 4 & 10 & Arenosa & 1,6 & n.d. \\
\hline
\end{tabular}

${ }^{1}$ Cana crua; ${ }^{2}$ Cana queimada

$\mathrm{SB}=$ soma de bases; $\mathrm{T}=$ capacidade de troca de cátions; $\mathrm{V}=$ saturação de bases; $m$ = saturação por alumínio; prof. = profundidade e M.O. = matéria orgânica

Classes de diâmetro $(\mathrm{mm})$ :

Areia $=2,0-0,05 ;$ Silte $=0,05-0,002 ;$ Argila $<0,002$

Classes de textura: até $14 \%$ de argila - arenosa

D.A. = densidade aparente e D.R. = densidade real

* análises feitas pelo Departamento de Solos e Nutrição Mineral de Plantas da USP/ESALQ 
Tabela 32. Análises química e física do solo da área experimental, da Usina São Martinho.

Química

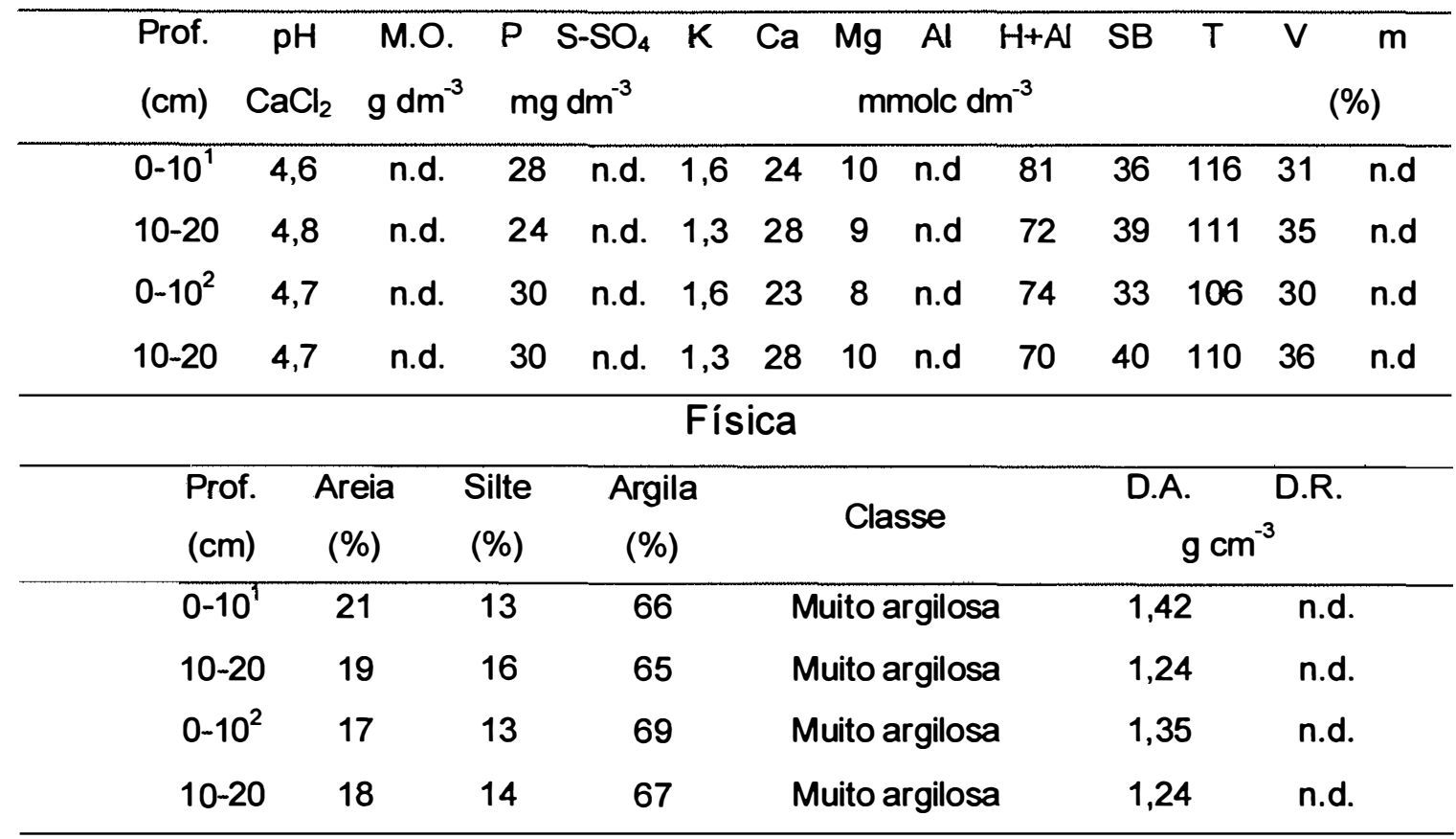

${ }^{1}$ Cana crua; ${ }^{2}$ Cana queimada

$\mathrm{SB}=$ soma de bases; $\mathrm{T}$ = capacidade de troca de cátions; $\mathrm{V}=$ saturação de bases; $\mathrm{m}=$ saturação por alumínio; prof. $=$ profundidade $\mathrm{e}$ M.O. = matéria orgânica

Classes de diâmetro $(\mathrm{mm})$ :

Areia $=2,0-0,05 ;$ Silte $=0,05-0,002 ;$ Argila $<0,002$

Classes de textura: $60 \%$ argila ou superior - muito argilosa

D.A. = densidade aparente e D.R. = densidade real

* análises feitas pelo Departamento de Solos e Nutrição Mineral de Plantas da USP/ESALQ

As três áreas experimentais foram instaladas por técnicos da COPERSUCAR, há seis anos, como parte de um estudo sobre sistemas de colheita. Em todas as áreas experimentais foram instalados os mesmos tratamentos, e com o mesmo tempo de colheita no sistema mecanizado, sendo que a safra 1999/2000 representou o quinto ano de corte nas três localidades.

$O$ delineamento experimental foi o inteiramente casualizado, onde cada amostra composta de solo foi considerada uma parcela no experimento instalado em casa-de-vegetação e extração de sementes. Os tratamentos utilizados foram sistema de colheita (convencional e mecânica sem queima) e 
profundidade de coleta de solo $(0-10 \mathrm{~cm}$ e $10-20 \mathrm{~cm})$. Cada parcela instalada na área experimental de campo, era composta por 10 linhas de cana no espaçamento entre linhas de $1,4 \mathrm{~m}$, com comprimento de $50 \mathrm{~m}$, totalizando portanto $700 \mathrm{~m}^{2}$ de área útil de parcela. Cada parcela possuia ainda uma bordadura de cinco linhas.

Para coleta do solo, foi utilizado um trado (cano de PVC adaptado) com cinco centímetros de diâmetro. Sendo assim, foram feitas coletas de 0-10 $\mathrm{cm}$ e de $10-20 \mathrm{~cm}$ de profundidade, em parcelas com e sem palha de cana na superfície do solo. Cada amostra foi composta por duas subamostras de $500 \mathrm{~g}$, totalizando aproximadamente $1000 \mathrm{~g}$ por amostra. Foram coletadas 10 amostras por parcela de campo, sendo que em de cada linha foi coletada uma amostra composta de maneira aleatória em cada profundidade, totalizando 60 amostras por tratamento de campo.

O número de amostras foi determinado de acordo com o trabalho de Benoit et al. (1989), onde foi concluído que um número entre 60 e 70 amostras seriam suficientes para estimar o banco de sementes de uma área uniforme. Portanto, no presente trabalho, foram coletadas 60 amostras por tratamento, distribuídas através de delineamento experimental, em áreas uniformes.

\subsubsection{Quantificação do Banco de Sementes pela Técnica de Emergência em Casa-de-Vegetação}

De cada amostra coletada no campo, uma subamostra de $(500 \mathrm{~g})$ foi condicionada em bandeja e colocada em condições de casa-de-vegetação adequada para a contagem e identificação das espécies de plantas daninhas emergentes durante os quatro meses subsequentes. Após cada fluxo de emergência, foi feito o revolvimento do solo para uma maior homogeneização das amostras, seguido de estresse hídrico, para quebra de dormência de 
sementes, e logo em seguida, as condições normais de umidade no solo eram retomadas.

A casa-de-vegetação possuia um sistema de irrigação automático por aspersão que condicionava umidade adequada para os bandejas, sistema de ventilação, além de sombrite com destendimento automático para controle da luminosidade incidente.

Utilizou-se o sistema de nomenclatura em códigos das plantas daninhas, de acordo com Lorenzi (2000). Nas Tabelas 33 e 34, são apresentados os nomes científicos e comuns, correspondentes aos códigos utilizados na apresentação dos resultados de identificação de plântulas e sementes para gramineas e folhas larga.

Os resultados referentes às médias totais de emergência foram submetidos a análise da variância, com aplicação do teste $F$, sendo que as interações significativas tiveram suas médias comparadas entre si pelo teste de de Tukey $(P<0,05)$. Para satisfazer as exigências do modelo matemático, os dados foram transformados em raiz quadrada. Os resultados por espécie de planta daninha não foram analisados estatisticamente em função de sua alta variabilidade.

Tabela 33. Nomes científicos e comuns de plantas daninhas gramíneas e ciperáceas, correspondentes aos códigos de identificação utilizados.

\begin{tabular}{lll}
\hline Código & Nome Científico & Nome comum \\
\hline DIGHO & Digitaria horizontalis & capim colchão \\
ERAPI & Eragrotis pilosa & capim barbicha de alemão \\
ELEIN & Eleusine indica & capim pé de galinha \\
SETGE & Setaria geniculata & capim rabo de raposa \\
BRADC & Brachiaria decumbens & capim braquiária \\
CYPRO & Cyperus rotundus & tiririca \\
\hline
\end{tabular}

Fonte: Lorenzi (2000). 


\subsubsection{Quantificação do Banco de Sementes pela Técnica de Separação de Sementes}

Das amostras provenientes do campo, foram retiradas pequenas aliquotas de solo, que foram peneiradas em malha de 50 mesh, separando-se $100 \mathrm{~g}$ de cada amostra.

Desta forma, seguindo a metodologia descrita por Buhler \& Maxwell (1993), após esta pesagem, as amostras foram colocadas em tubos de centrífuga com capacidade de $250 \mathrm{ml}$, onde foi adicionado $100 \mathrm{ml}$ da solução dispersante, formada por $250 \mathrm{ml}$ de $\mathrm{K}_{2} \mathrm{CO}_{3}$ dissolvido em $500 \mathrm{ml}$ de água. Esta solução é utilizada pois o carbonato de potássio é um sal, que tem por finalidade aumentar a densidade da solução e separar o material orgânico da parte mineral do solo. Para proporcionar maior dispersão dos agregados do solo os tubos foram agitados manualmente por um minuto e logo em seguida foram postos para centrifugar durante 15 minutos à $10.000 \mathrm{rpm}$. Utilizou-se a centrífuga "Sorval RC5C Plus" com rotor GSA.

Após centrifugação, o sobrenadante foi coletado e lavado, sendo colocado em placas de petri sobre papel filtro. Depois de secas, as sementes foram contadas e identificadas com auxílio de lupa de aumento.

Os resultados referentes as médias totais do número de sementes foram submetidos a análise da variância, com aplicação do teste $F$, sendo que as interações significativas tiveram suas médias comparadas entre si pelo teste de de Tukey $(P<0,05)$. Para satisfazer as exigências do modelo matemático, os dados foram transformados para raiz quadrada. Os resultados por espécie de planta daninha não foram analisados estatisticamente em função de sua alta variabilidade. 
Tabela 34. Nomes científicos e comuns de plantas daninhas folhas largas, correspondentes aos códigos de identificação utilizados

\begin{tabular}{cll}
\hline Código & Nome Científico & Nome Comum \\
\hline POROL & Portulaca oleracea & beldroega \\
MOLVE & Mollugo verticillata & capim tapete \\
CLEAF & Cleome affinis & mussambê \\
AMAVI & Amaranthus viridis & caruru \\
BIDPI & Bidens pilosa & picão preto \\
RCHRB & Richardia braziliensis & poaia \\
GASPA & Galinsoga parviflora & picão branco \\
COMBE & Comelina benghalensis & trapoeraba \\
SOLAM & Solanum americanum & maria pretinha \\
SIDGZ & Sida glaziovii & guanxuma \\
AGECO & Ageratum conyzoides & mentrasto \\
ERIBO & Enigeron bonariensis & buva \\
TIUBA & Triumfetta bartramia & triunfeta \\
EPHHL & Euphorbia heterophylla & amendoim bravo \\
IAOGR & Ipomoea grandifolia & corda de viola \\
EMISO & Emilia sonchifolia & falsa serralha \\
NICPH & Nicandra physaloides & joá de capóte \\
ALRTE & Alternanthera tenella & apaga fogo \\
INDHI & Indigofera hirsuta & anileira \\
CHEAL & Chenopodium album & ançarinha branca \\
\hline
\end{tabular}

Fonte: Lorenzi (2000).

\subsection{Resultados e Discussão}

As médias totais dos tratamentos e das principais espécies avaliadas na etapa de contagem de emergência e identificação nas amostras em casade-vegetação da Usina da Pedra; Santa Luiza e São Martinho, além dos dados de contagem de sementes, das Usinas Santa Luiza e São Matinho, são apresentados a seguir. 


\subsubsection{Usina da Pedra}

$\mathrm{Na}$ Tabela 35 são apresentadas as médias de emergência por espécie do número de plântulas que emergiram, durante um período de 120 dias, sob condições de casa-de-vegetação. Já na Figura 23 é colocado a somatória de todas as plantas daninhas, independente da espécie.

Tabela 35. Número médio de plântulas que emergiram das amostras colocadas em bandejas nos tratamentos de sistema de colheita $e$ profundidade de amostragem de solo, 120 dias após a colocação em casa-de-vegetação.

\begin{tabular}{lcccc}
\hline & \multicolumn{4}{c}{ Profundidade de amostragem de solo (cm) } \\
\hline \multirow{2}{*}{ Espécies } & \multicolumn{2}{c}{$0-10$} & \multicolumn{2}{c}{$10-20$} \\
\hline POROL & Cana crua & Cana queimada & Cana crua & Cana queimada \\
MOLVE & 268 & 175 & 320 & 221 \\
DIGHO & 60 & 35 & 106 & 80 \\
CLEAF & 7,9 & 19 & 3,4 & 13 \\
ERAPI & 5,5 & 0,5 & 3,2 & 0,5 \\
ELEIN & 0,7 & 1,3 & 1,1 & 0,7 \\
AMAVI & 5,5 & 1,6 & 0,5 & 0,5 \\
BIDPI & 1,8 & 1,1 & 3,6 & 2,7 \\
RCHBR & 0,4 & 0,0 & 0,7 & 0,5 \\
GASPA & 0,4 & 0,0 & 2,0 & 0,2 \\
\hline
\end{tabular}




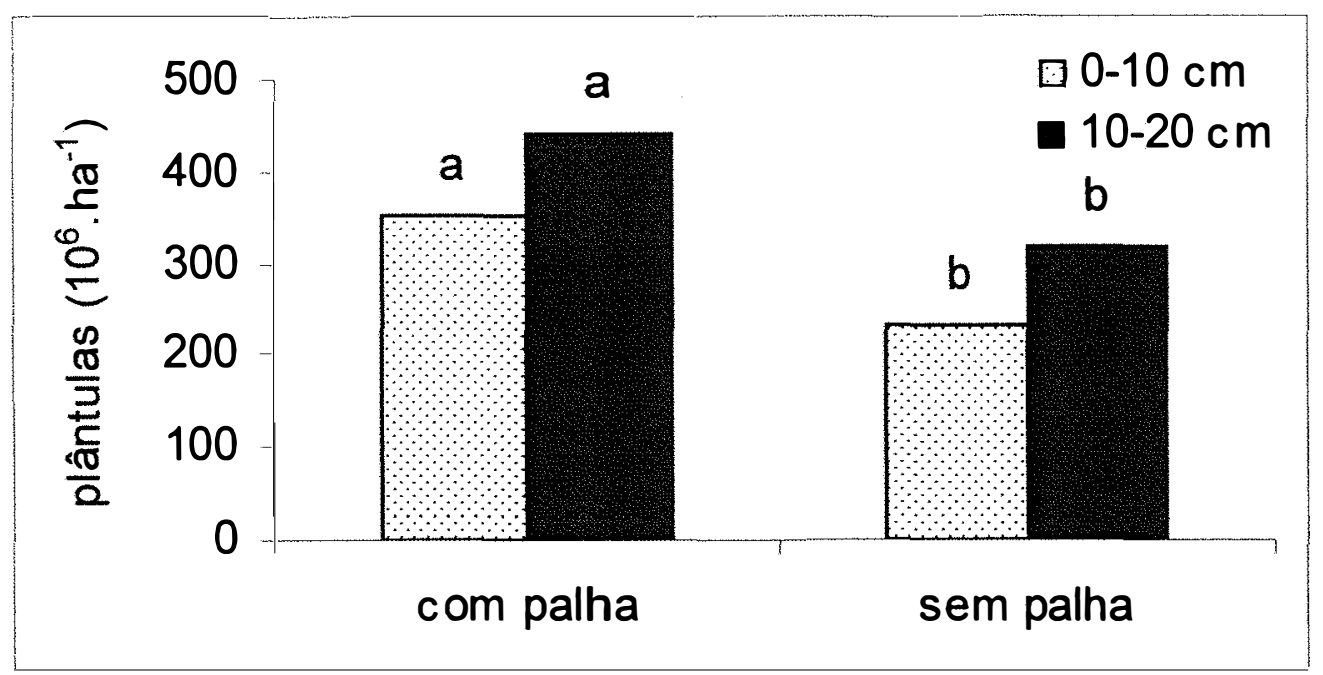

Figura 23 - Totais de plântulas emergidas nos tratamentos de cana crua (com palha) e cana queimada (sem palha), nas profundidades de coleta de amostras de 0 a $10 \mathrm{~cm}$ e 10 a $20 \mathrm{~cm}$, Usina da Pedra (C.V. = 55). Colunas com letras diferentes são estatisticamente diferentes entre si pelo teste de Tukey $(P<0,05)$.

Analisando-se a Tabela 35 e Figura 23 pode-se observar que houve maior emergência de plantas daninhas nas amostras coletadas na profundidade de 10 a $20 \mathrm{~cm}$ e nas amostras provenientes do tratamento com palha. Em relação a profundidade pode-se supor que como a reintrodução de sementes no banco de sementes foi baixa durante os 5 anos de experimentação na área, é possivel que haja um maior número de sementes na profundidade de 10 a $20 \mathrm{~cm}$, principalmente no tratamento com palha (Figura 23). A maior emergência no tratamento com palha é função de uma maior proporção de sementes dormentes nas amostras provenientes destas parcelas, e quando colocadas em condições ideais para germinar apresentaram um número superior ao tratamento sem palha. Trabalhos científicos tem evidenciado que sementes mantidas por longo período no escuro tem maior quebra de dormência induzida pela luz. 


\subsubsection{Usina Santa Luiza}

$\mathrm{Na}$ Tabela 36 são apresentadas as médias de emergência por espécie do número de plântulas que emergiram, durante um período de 120 dias, sob condições de casa-de-vegetação, e na Figura 24 a somatória de todas as espécies.

Tabela 36. Número médio de plântulas que emergiram das amostras colocadas em bandejas nos tratamentos de sistema de colheita e profundidade de amostragem de solo, 120 dias após a colocação em casa-de-vegetação.

\begin{tabular}{lcccc}
\hline & \multicolumn{4}{c}{ Profundidade de amostragem de solo $(\mathrm{cm})$} \\
\hline \multirow{2}{*}{ Espécies } & Cana crua & Cana queimada & Cana crua & Cana queimada \\
\hline POROL & 11 & 26 & 13 & 13 \\
COMBE & 2 & 4 & 1 & 0 \\
DIGHO & 7 & 15 & 10 & 10 \\
ELEIN & 7 & 5 & 5 & 7 \\
CYPRO & 10 & 7 & 5 & 4 \\
SOLAM & 9 & 3 & 22 & 17 \\
GASPA & 2 & 2 & 1 & 1 \\
BIDPI & 0 & 0 & 0 & 0 \\
SIDGZ & 1 & 0 & 1 & 0 \\
AMAVI & 1 & 1 & 2 & 1 \\
RCHBR & 0 & 0 & 0 & 0 \\
AGECO & 1 & 0 & 0 & 0 \\
ERIBO & 1 & 0 & 1 & 0 \\
TRCIN & 0 & 2 & 1 & 2 \\
ERAPI & 1 & 0 & 0 & 0 \\
\hline
\end{tabular}




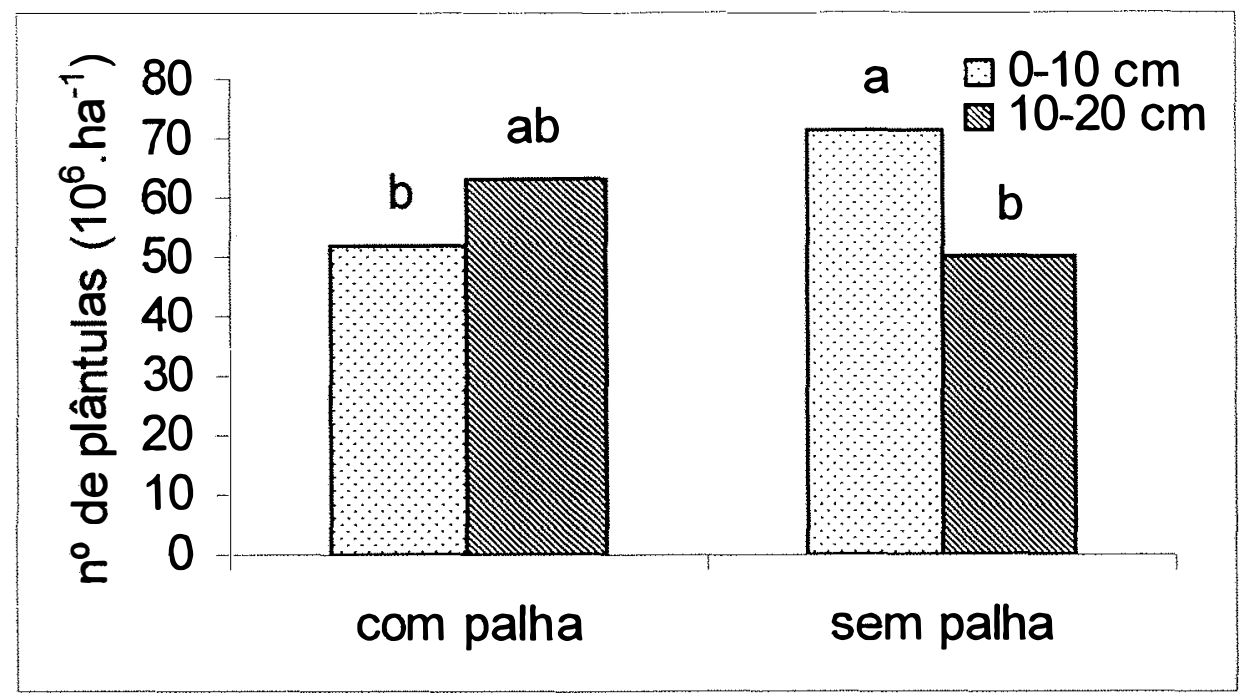

Figura 24 - Totais de plântulas emergidas por amostras, nos tratamentos de cana crua (com palha) e cana queimada (sem palha), nas profundidades de coleta de amostras de 0 a $10 \mathrm{~cm}$ e 10 a $20 \mathrm{~cm}$, Usina Santa Luiza (C.V. = 54). Colunas com letras diferentes são estatisticamente diferentes entre si pelo teste de Tukey $(P<0,05)$.

Em ambas as áreas experimentais (Usina da Pedra e Usina Santa Luiza), é possivel observar a predominância de poucas espécies de plantas daninhas no banco de sementes (Tabelas 35 e 36). Segundo Wilson ${ }^{3}$ citado por Buhler et al. (1997), os bancos de sementes são compostos por várias espécies, entretanto com a predominância de poucas espécies, compreendendo de 70 a $90 \%$ do total de sementes. Estas espécies seriam as que causariam maiores problemas, devido a alta adaptação ao sistema de cultivo. Um segundo grupo de sementes, de aproximadamente 10 a $20 \%$ do total, seria formado por espécies adaptadas a regiões mas não às práticas agrícolas usuais. E finalmente, existe um terceiro grupo, com participação muito

3 WILSON, R.G. Biology of weed in the soil. In. ALTIERI, M.A.; LIEBMAN, M. Weed management in agroecosystems: ecological approaches. Boca Raton: CRC Press, 1988. p. 25-39. 
pequena, representado por sementes introduzidas de outras áreas e sementes da cultura anterior (Wilson et al., 1985).

No levantamento do banco de sementes da Usina da Pedra, existe a predominância das plantas daninhas beldroega (POROL), capim tapete (MOLVE) e capim colchão (DIGHO), nas profundidades de 0-10 cm e $10-20 \mathrm{~cm}$. Em relação ao tratamento de palha as duas primeiras espécies tiveram maior presença nas parcelas com palha, ocorrendo o inverso com o capim colchão.

$\mathrm{Na}$ Usina Santa Luiza, também foi constatada esta dominância de espécies, sendo que na profundidade de amostragem de 0-10 cm e de 10-20 $\mathrm{cm}$, a predominância foi para as espécies beldroega (POROL), capim colchão (DIGHO), maria-pretinha (SOLAM) e capim pé-de-galinha (ELEIN) e tiririca (CYPRO).

De acordo com a Figura 24, pode-se notar que os resultados foram um tanto quanto contraditórios aos encontrados para a Usina da Pedra (Figura 23). Comparando, entretanto, todas as áreas analisadas, é possivel notar através das Figuras 23, 24 e 26, que os tratamentos com palha apresentaram maior quantidade de plântulas. Além disso, em todos os tratamentos de colheita de cana sem queima (cana crua), houve maior emergência na profundidade de coleta de 10 a $20 \mathrm{~cm}$.

$\mathrm{Na}$ Tabela 37 são apresentadas as médias por espécie da contagem de sementes de plantas daninhas extraídas a partir das amostras de solo coletadas nos tratamentos de sistema de colheita e profundidade de amostragem. 
Tabela 37. Número médio de sementes obtidas por espécie nas amostras coletadas nos tratamentos de sistema de colheita e profundidade de amostragem de solo.

\begin{tabular}{lcccc}
\hline & \multicolumn{4}{c}{ Profundidade de amostragem de solo (cm) } \\
\hline & \multicolumn{2}{c}{$0-10$} & & \multicolumn{2}{c}{$10-20$} \\
Espécies & Cana crua & Cana queimada & Cana crua & Cana queimada \\
\hline POROL & 51 & 53 & 40 & 34 \\
DIGHO & 2 & 15 & 1 & 11 \\
SETGE & 0 & 1 & 0 & 0 \\
COMBE & 1 & 4 & 4 & 4 \\
EPHHL & 0 & 1 & 1 & 0 \\
BRADC & 1 & 5 & 0 & 3 \\
IAOGR & 1 & 1 & 0 & 0 \\
SOLAM & 2 & 4 & 6 & 4 \\
GASPA & 0 & 0 & 0 & 0 \\
AMAVI & 3 & 3 & 3 & 0 \\
EMISO & 0 & 0 & 0 & 0 \\
NICPH & 1 & 0 & 1 & 0 \\
SIDGZ & 2 & 1 & 1 & 1 \\
ALRTE & 2 & 3 & 0 & 1 \\
INDHI & 1 & 0 & 0 & 0 \\
CHEAL & 2 & 1 & 1 & 2 \\
\hline
\end{tabular}

Comparando os dados de emergência da Usina Santa Luiza (Figura 24), com os dados de contagem de sementes (Figura 25), nota-se que houve maior quebra de dormência no tratamento com sistema de colheita de cana crua. Em relação a profundidade de amostragem, o tratamento 0-10 cm apresentou o maior número de sementes. 


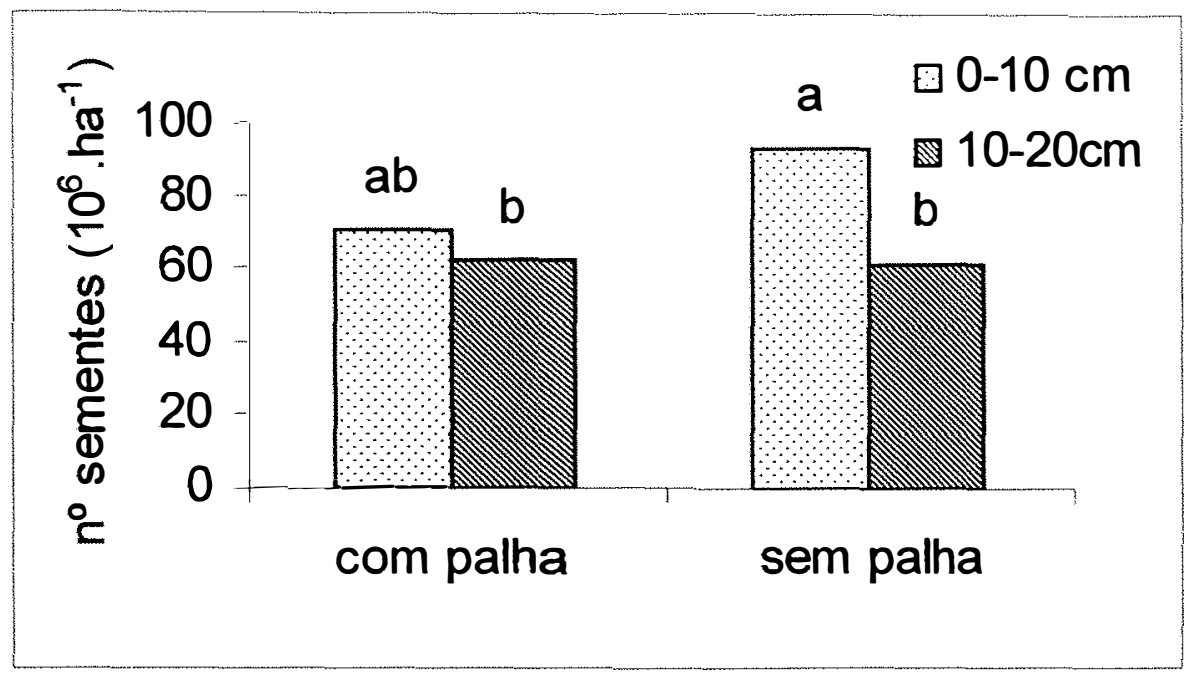

Figura 25 - Totais de sementes por amostras, nos tratamentos de cana crua (com palha) e cana queimada (sem palha), nas profundidades de coleta de amostras de 0 a $10 \mathrm{~cm}$ e 10 a $20 \mathrm{~cm}$, Usina Santa Luiza $(C . V .=50)$. Colunas com letras diferentes são estatisticamente diferentes entre si pelo teste de Tukey $(P<0,05)$.

\subsubsection{Usina São Martinho}

$\mathrm{Na}$ Tabela 38 são apresentadas as médias de emergência por espécie do número de plântulas que emergiram, durante um período de 120 dias, sob condições de casa-de-vegetação. 
Tabela 38. Número médio de plântulas que emergiram das amostras colocadas em bandejas nos tratamentos de sistema de colheita $e$ profundidade de amostragem de solo, 120 dias após a colocação em casa-de-vegetação.

\begin{tabular}{|c|c|c|c|c|}
\hline \multirow[b]{3}{*}{ Espécies } & \multicolumn{4}{|c|}{ Profundidade de amostragem de solo $(\mathrm{cm})$} \\
\hline & \multicolumn{2}{|c|}{$0-10$} & \multicolumn{2}{|c|}{$10-20$} \\
\hline & Cana crua & Cana queimada & Cana crua & Cana queimada \\
\hline POROL & 6 & 5 & 7 & 5 \\
\hline DIGHO & 11 & 5 & 9 & 5 \\
\hline ELEIN & 0 & 0 & 1 & 0 \\
\hline AMAVI & 0 & 0 & 0 & 0 \\
\hline BIDPI & 3 & 1 & 1 & 1 \\
\hline SIDGZ & 0 & 0 & 0 & 0 \\
\hline COMBE & 0 & 0 & 0 & 0 \\
\hline $\mathrm{BCHBR}$ & 0 & 0 & 0 & 0 \\
\hline BRADC & 0 & 0 & 0 & 0 \\
\hline TRCIN & 2 & 5 & 3 & 2 \\
\hline LEFFI & 0 & 0 & 0 & 0 \\
\hline GASPA & 0 & 0 & 0 & 0 \\
\hline CLEAF & 0 & 0 & 0 & 0 \\
\hline ERAPI & 0 & 0 & 0 & 0 \\
\hline SETGE & 12 & 1 & 10 & 3 \\
\hline EPHHL & 1 & 2 & 2 & 3 \\
\hline ALRTE & 0 & 0 & 0 & 0 \\
\hline
\end{tabular}




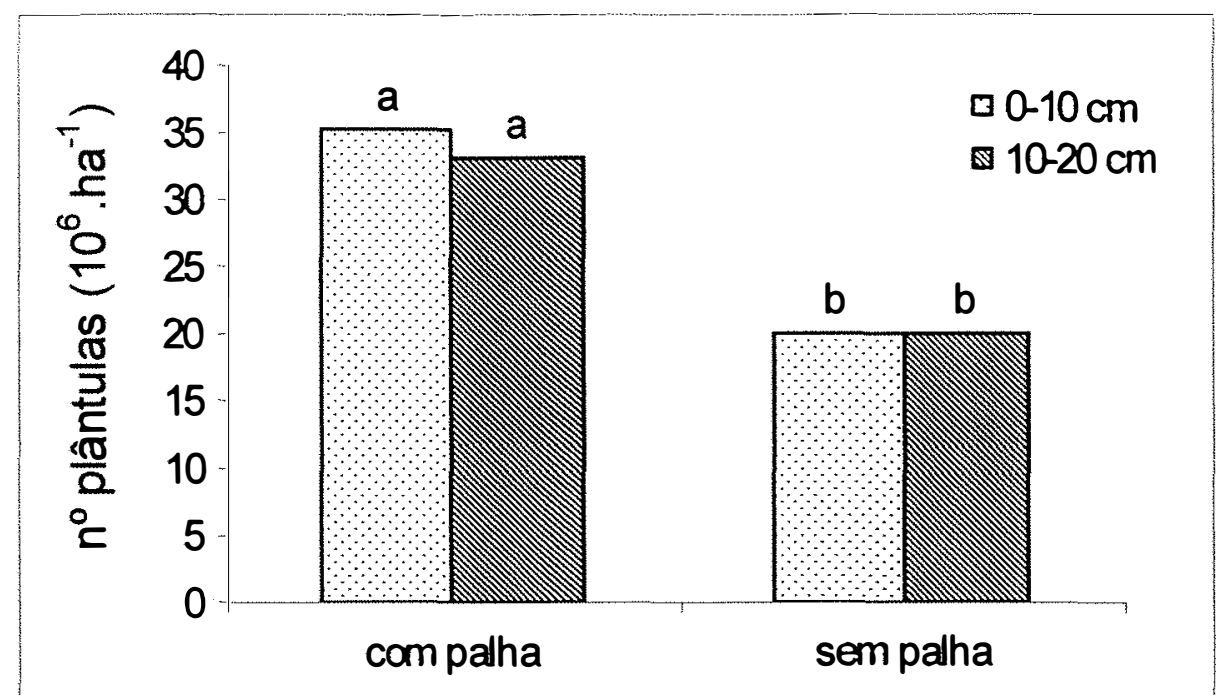

Figura 26 - Médias do número de plântulas emergidas, nos tratamentos de cana crua (com palha) e cana queimada (sem palha), nas profundidades de coleta de amostras de solo de 0-10 e 10-20 cm, Usina São Martinho (C.V. = 52). Colunas com letras diferentes são estatisticamente diferentes entre si pelo teste de Tukey $(P<0,05)$.

$\mathrm{Na}$ Tabela 39 são apresentadas as médias por espécie da contagem de sementes de plantas daninhas extraídas a partir das amostras de solo coletadas nos tratamentos de sistema de colheita e profundidade de amostragem. 
Tabela 39. Número médio de sementes obtidas por espécie nas amostras coletadas nos tratamentos de sistema de colheita e profundidade de amostragem de solo.

\begin{tabular}{lcccc}
\hline \multicolumn{5}{c}{ Profundidade de amostragem de solo $(\mathrm{cm})$} \\
\hline Espécies & \multicolumn{2}{c}{$0-10$} & \multicolumn{2}{c}{$10-20$} \\
\hline POROL & Cana crua & Cana queimada & Cana crua & Cana queimada \\
DIGHO & 17 & 14 & 14 & 14 \\
ERAPI & 3 & 5 & 2 & 3 \\
COMBE & 2 & 2 & 1 & 1 \\
EPHHL & 0 & 0 & 0 & 0 \\
BRADC & 5 & 0 & 2 & 0 \\
IAOGR & 0 & 3 & 1 & 1 \\
SOLAM & 1 & 0 & 0 & 0 \\
GASPA & 3 & 2 & 0 & 0 \\
AMAVI & 1 & 0 & 1 & 0 \\
EMISO & 2 & 1 & 1 & 1 \\
NICPH & 1 & 0 & 0 & 0 \\
SIDGZ & 2 & 0 & 2 & 1 \\
\hline
\end{tabular}

É importante ressaltar que o manejo de plantas daninhas nos cinco anos de condução do experimento de campo foi excelente; portanto, a reintrodução de sementes no banco de sementes foi pequena, e como o revolvimento do solo foi nulo na área com palha e pequeno (operação de cultivo) na área sem palha, poucas sementes foram introduzidas na superfície do solo. Da mesma forma, a introdução de sementes através dos agentes de dispersão foi pequena, pois a bordadura das parcelas era grande. No entanto, apesar da pequena introdução de sementes, observa-se nas Figuras 25 e 27 maior quantidade de sementes nos tratamentos de $0-10 \mathrm{~cm}$ de profundidade, resultado condizente com outras pesquisas sobre o banco de sementes. 


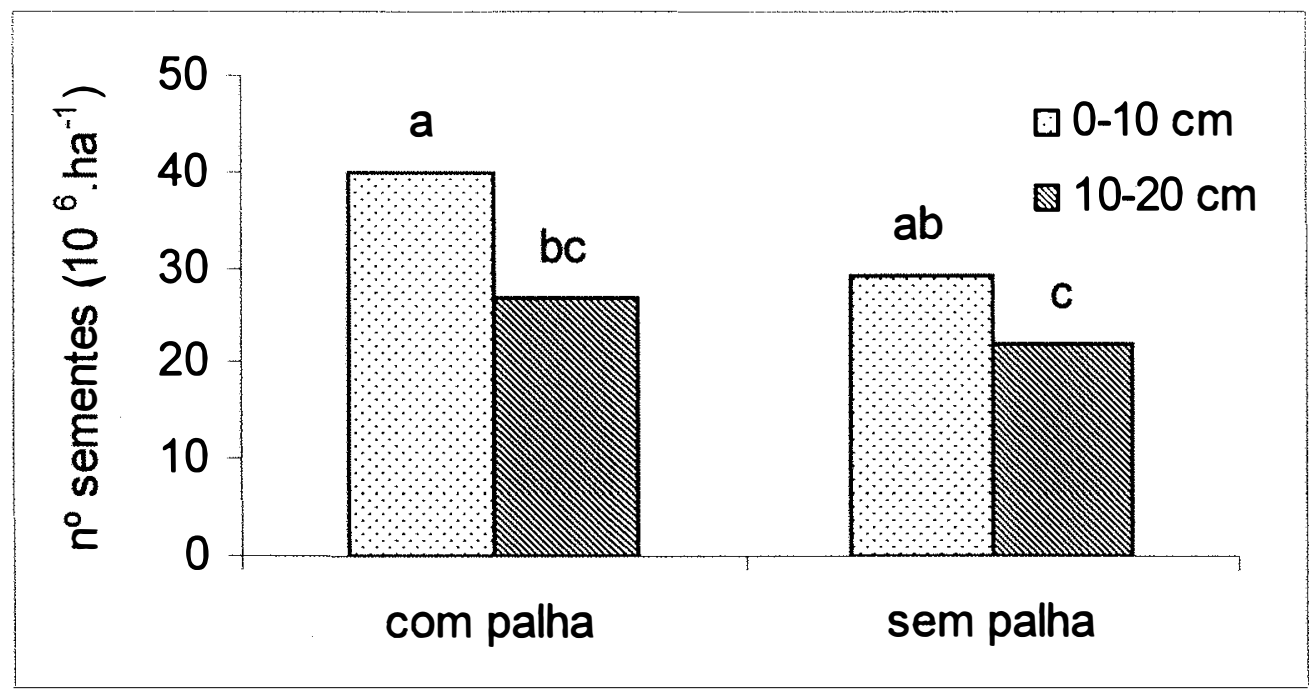

Figura 27 - Totais de sementes nos tratamentos de cana crua (com palha) e cana queimada (sem palha), nas profundidades de coleta de solo de $0-10 \mathrm{~cm}$ e $10-20 \mathrm{~cm}$, Usina São Martinho (C.V. = 33). Colunas com letras diferentes são estatisticamente diferentes entre si pelo teste de Tukey $(P<0,05)$.

Em relação aos tratamentos de sistema de colheita, verifica-se, pela comparação da Figura 27 com a Figura 26, que houve maior quebra de dormência das sementes provenientes das parcelas com colheita de cana crua, o que é observado através da diferença entre o número de sementes (Figura 27) e plântulas (Figura 26), que é menor para o sistema de cana crua.

Desta forma, tanto na Usina São Martinho como no caso da Usina Santa Luiza, observa-se que no sistema de cana crua, a proporção de sementes dormentes e a espera de condições adequadas para germinar, é maior, do que nos sistemas de colheita de cana queimada.

Além disso, observa-se ainda, nos resultados apresentados sobre contagem de sementes por espécie, a diminuição do número de sementes de plantas daninhas gramíneas, como o capim-colchão (DIGHO) e capim- 
braquiária (BRADC) nos tratamentos de colheita de cana crua. Na Usina São Martinho, os resultados de emergência de plântulas, mostram que grande parte das sementes de capim-colchão (DIGHO) estavam dormentes, uma vez que quando colocadas sob condições adequadas de temperatura a germinação no tratamento com colheita de cana crua foi muito maior do que no tratamento com colheita de cana-de-açúcar queimada. Desta forma, uma pequena quantidade de sementes desta planta daninha pode, após o estabelecimento das condições ambientais adequadas para sua germinação, fazer com que ela se torne a espécie mais frequente e abundante do banco de sementes e da área onde se encontra.

\subsection{Conclusões}

A presença da palha de cana resultante da colheita mecanizada sem queima da palhada durante cinco cortes da cultura altera a composição específica do banco de sementes aumentando a quantidade de sementes de algumas espécies e reduzindo outras, quando comparado com áreas com sistema de colheita de cana queimada.

Cinco anos de soqueiras com colheita de cana crua não foram suficientes para reduzir a quantidade de sementes no solo quando comparada com soqueiras de cana queimada.

É provável que o banco de sementes de área com palha tenha sua dormência quebrada com muito maior intensidade que as áreas de colheita de cana queimada, por ocasião da reforma do canavial. Esta quebra de dormência provavelmente deve-se ao efeito da luz, que é mais intensa em sementes que estavam submetidas ao escuro, como é o caso das amostras provenientes de áreas com colheita de cana crua. 


\section{CONCLUSÕES}

As espécies I. grandifolia e $E$. heterophylla não tem sua emergência inibidas pela camada de palha de cana-de-açúcar deixada na superfície após a colheita, entretanto, o controle destas espécies pela mistura formulada de diuron (468 g kg$\left.{ }^{-1}\right)$ + hexazinone $\left(132 \mathrm{~g} \mathrm{~kg}^{-1}\right)$, em áreas com camada de palha de $15 \mathrm{t} \mathrm{ha}^{-1}$ na superfície do solo é eficiente. Já as espécies $B$. decumbens, $B$. plantaginea, $P$. maximum e $D$. horizontalis, tem sua emergência impedida pela palha de cana-de-açúcar, em áreas com camadas iguais ou superior a $15 \mathrm{tha}^{-1}$.

O período residual da mistura formulada dos herbicidas diuron $(468 \mathrm{~g}$ $\left.\mathrm{kg}^{-1}\right)$ + hexazinone $\left(132 \mathrm{~g} \mathrm{~kg}^{-1}\right)$ é reduzido, quando é aplicado sobre camada de palha de cana-de-açúcar de $16 \mathrm{t} \mathrm{ha}{ }^{-1}$. No entanto, a parcela de herbicida que atinge o solo proporciona período residual do herbicida e controle eficaz de plantas daninhas.

A passagem dos herbicidas diuron $\left(468 \mathrm{~g} \mathrm{~kg}^{-1}\right)$ + hexazinone $(132 \mathrm{~g}$ $\mathrm{kg}^{-1}$ ) e sulfentrazone não é afetada pela camada de palha de cana-de-açúcar de até $5 \mathrm{t} \mathrm{ha}^{-1}$. Em camadas de palha acima de $10 \mathrm{tha}^{-1}$, o principal fator responsável pela transposição dos herbicidas através da palha é a chuva, onde chuvas a partir de 10-20 mm já seriam suficientes para exercer este papel.

A presença da palha de cana-de-açúcar resultante da colheita mecanizada durante cinco cortes altera a composição especifica do banco de sementes, principalmente com a redução de sementes de plantas daninhas da família Poacea (gramíneas), quando comparado com áreas com sistema de colheita de cana queimada. É provável ainda, que o banco de sementes de áreas com colheita de cana crua tenha sua dormência quebrada com maior 
intensidade que áreas com colheita de cana queimada, por ocasião da reforma do canavial. Esta quebra de dormência provavelmente deve-se ao efeito da luz, que é mais intensa em sementes que estavam submetidas ao escuro, como é o caso das amostras de solo provenientes de áreas com colheita de cana crua. 


\section{REFERÊNCIAS BIBLIOGRÁFICAS}

ALMEIDA, F.S. Influência da cobertura morta no plantio direto e na biologia do solo. In: SIMPÓSIO SOBRE POTENCIAL AGRÍCOLA DOS CERRADOS, 1., Goiânia, 1985. Anais. Goiania: Fundação Cargill; Empresa Goiana de Pesquisa Agropecuária, 1985. p.109-149.

ALMEIDA, F.S. A alelopatia e as plantas. Londrina: IAPAR, 1988. 60p. (IAPAR. Circular 53).

AREVALO, R.A. Manejo de plantas daninhas em áreas de colheita de cana crua. STAB: Açúcar, Álcool e Subprodutos. v.16, p.26-28, 1998.

ARÉVALO, R.A.; CERRILVELA, E.; AJOLEA, I.L. Recent advances in weed competition studies in sugar cane in Argentina. In: CONGRESS INTERNATIONAL SOCIETY SUGAR CANE TECHNOLOGISTS, 16., São Paulo, 1977. Proceedings. São Paulo, 1977. v.2, p.1227-1238.

AZANIA, C.A.M. Controle de plantas infestantes com diferentes herbicidas e sua seletividade às soqueiras de cana-de-açúcar (Saccharum spp.). Jaboticabal, 2000. 56p. Dissertação (Mestrado) - Faculdade de Ciências Agrárias e Veterinárias, Universidade Estadual Paulista "Julio de Mesquita Filho".

AZANIA, C.A.M.; ROLIM, J.C. Influência da palha de cana-de-açúcar nos componentes químicos do solo e na infestação de plantas daninhas. Ciência das Plantas Daninhas-Boletim Informativo, v.5, p.3, 1999. 
BALL, D. A. Weed seedbank response to tillage, herbicides, and crop rotation sequence. Weed Science, v.40, p.654-659, 1992.

BANKS, P.A.; ROBINSON, E.L. The influence of straw mulch on teh soil reception and persistence of metribuzin. Weed Science, v.30, p.164-168, 1982.

BANKS, P.A.; ROBINSON, E.L. The fate of oryzalin applied to straw-mulched and non-mulched soils. Weed Science, v.32, p.269-272, 1984.

BANKS, P.A.; ROBINSON, E.L. Soil reception and acitivity of acetochlor, and metolachlor as affected by wheat (Triticum aestivum) straw and irrigation. Weed Science, v.34, p.607-611, 1986.

BARBERI, P.; COZZANE, A.; MACCHIA, M.; BONARI, E. Size and composition of the weed seedbank under different management systems for continuons maize croping. Weed Research, v.38, p.319-334, 1998.

BARRALIS, G.;CHADOEUF, R.; LOCHAMP, J.P. Essai de determination de la taile de l'echantillon pour l'etude du potentiel de semencier dún sol. Weed Research, v.26, p.292-297, 1986.

BASHAM, G.W.; LAVY, T.L.; OLIVER, L.R.; SCOTT, H.D. Imazaquin persistence and mobility in three Arkansas soils. Weed Science, v.27, p.576-582, 1987.

BENOIT, D.L.; DERKSEN, D.A.; PANNETON, B. Innovative Approaches to Seedbank Studies. Weed Science, v.40, p.660-669, 1992.

BENOIT, D.L.; KENKEL, N.C.; CAVERS, P.B. Factors influencing the precision of soil seed bank estimates. Canadian Journal of Botany, v.67, p.2833-2840, 1989. 
BERNARDES, M.S. Fotossintese no dossel das plantas cultivadas. In: CASTRO, P.C.R.; FERREIRA, S.O.; YAMADA, T. Ecofisiologia das plantas cultivadas. Piracicaba: Associação Brasileira para a Pesquisa da Potassa e do Fosfato, 1987. cap.2, p.13-49.

BHOWMIK, P.C. Weed biology: importance to weed management. Weed Science, v.45, p.349-356, 1997.

BIGWOOD, D.W.; INOUYE, D.W. Spatial pattem analysis of seed banks: on improved method and optimized sampling. Ecology, v.69, p.497-507, 1988.

BLANCO, H.G.; OLIVEIRA, D.A.; ARAUJO, J.B.M. Competição entre plantas daninhas e a cultura da cana-de-açúcar. I. Período Critico de Competição Produzido por uma Comunidade Natural de Dicotiledôneas em Cultura de Ano. Biológico, v.45, p.131-140, 1979.

BUHLER, D.D. Influence of tillage systems on weed population dynamics and management in com and soybean production in the central USA. Crop Science, v. 35, p.1247-1257, 1995.

BUHLER, D. D.; MAXWELL, B. D. Seed separarion end enumeration from soil using $\mathrm{K}_{2} \mathrm{CO}_{3}$-centrifugation and image analysis. Weed Science, v.41, p.298302, 1993.

BUHLER, D.D.; HARTZLER, R.G.; FORCELLA, F. Implications of weed seedbank dynamics to weed management. Weed Science, v.45, p.329-336, 1997.

BUHLER, D.D.; MESTER, T.C.; KOHLER, K.A. The effect of maize residues and tillage on emergence of Setaria faberi, Abutilon theophrasti, Amaranthus retroflexus and Chenopodium album. Weed Research, v.36, p.153-165, 1996. 
CAETANO, R.S.X. Dinâmica do banco de sementes e de populações de plantas daninhas na cultura do citros (Citrus sinensis (L) Osbeck.) submetida a diferentes sistemas de manejo. Piracicaba, 2000. 105p. Tese (Doutorado) Escola Superior de Agricultura "Luiz de Queiroz", Universidade de São Paulo.

CARDINA, J.; SPARROW,D.H. A comparision of methods to predict weed seedling populations from the soil seedbank. Weed Science, v.44, p.46-51, 1996.

CARDINA, J.; REGNIER, E.; HARRISON, K. Long-term tillage effects on seed banks in three Ohio soils. Weed Science, v.39, p.186-194, 1991.

CARMONA, R. Problemática e manejo de bancos de sementes de invasoras em solos agrícolas. Planta Daninha, v.10, p.5-16, 1992.

CARMONA, R. Banco de sementes e estabelecimento de plantas daninhas em agroecossistemas. Planta Daninha, v.13, 1995.

CAVERS, P.B. Seed demography. Canadian Journal of Botany, v.61, p.35783590, 1983.

CHRISTOFFOLETI, P.J.; CAETANO, R.S.X. Soil seed banks. Scientia Agricola, v.55, p.74-78, 1998.

CLEMENTS, D. R.; BENOIT, D. L.; MURPHY, S. D.; SWANTON, C. J. Tillage effects on weed seed return and seedbank composition. Weed Science, v.44, p.314-322, 1996.

COLBACH, N.; FORCELLA, F.; JOHNSON, G.A. Spatial and temporal stability of weed populations over five years. Weed Science, v. 48, p.366-377. 2000. 
CONDE, A.J.; DONZELLI, J.L. Manejo conservacionista do solo para áreas de colheita mecanizada de cana queimada e sem queimar. In: SEMINÁRIO DE TECNOLOGIA AGRONÔMICA. 7., Piracicaba, 1997. Anais. Piracicaba: COPERSUCAR, 1997. p.193-206.

COOPERATIVA DOS PRODUTORES DE CANA, AÇÚCAR E ÁLCOOL DO ESTADO DE SÃO PAULO LTDA. Projeto cana crua: relatório final da safra 97/98. Piracicaba,1998. 25p. (Dados de Clima).

COOPERATIVA DOS PRODUTORES DE CANA, AÇÚCAR E ÁLCOOL DO ESTADO DE SÃO PAULO LTDA. Projeto cana crua: relatório final da safra 98/99. Piracicaba, 1999. 41p. (Dados de Clima).

DESSAINT, F. CHADOEF, R. BARRALIS, G. Etude de la dynamique communauté adventice: III. Influence à long terme des techiniques culturales sur la composition spécifique du stock semencier. Weed Research, v.30, p.319-330, 1990.

DEUBER,R. Botânica das plantas daninhas. In: DEUBER, R. Ciência das Plantas Daninhas. Jaboticabal: FUNEP, 1992. cap.3, p.31-73.

DZOMEKU, I.K.; MURDOCH, A.J. Implications of seed dormancy for control of Striga hermonthica in Ghana. In: THE 1999 BRIGHTON CONFERENCE WEEDS, Brighton, 1999. Proceedings. Brighton: British Crop Protection Council, 1999. v.2, p.573-574.

ESCOLA SUPERIOR DE AGRICULTURA "LUIZ DE QUEIROZ". Departamento de Física e Meteorologia. Base de dados do posto agrometeorológico do depto. de física e meteorologia - DFM - ESALQ - USP. http://www.ciagri.usp.br/dfm/seg/postocom.html (13 Jul. 2001). 
FADAYOMI, O. Weed control in sugar cane with hexazinone alone and in combination with diuron. Journal of Agricultural Science, v.111, p.333-337, 1988.

FERNANDES, A.C. Observações de campo: colheita de cana crua: lucro ou prejuízo. STAB: Açúcar, Álcool e Subprodutos, v.19, p.12, 2001.

FERNANDEZ- QUINTANILLA, C. Studying the population dynamics of weeds. Weed Research, v.28, p.443-447, 1988.

FORNAROLLI, D.A. Influência da cobertura morta no comportamento do herbicida atrazine. Londrina: 1997. Dissertação (M.S.). Universidade Estadual de Londrina

FRECKLETON, R.P.; WATKINSON, A.R. How does temporal variability affect predictions of weed population numbers ? Journal of Applied Ecology, v.35, p.340-344, 1998.

FREITAS, R.R. de. Dinâmica do banco de sementes em uma comunidade de plantas daninhas com aspectos da germinação e dormência de sementes de capim marmelada. Lavras, 1990. 118p. Tese (Doutorado) - Escola Superior de Agricultura de Lavras.

GALLAGHER, R.S.; CARDINA,J. Phytochrome-mediated Amaranthus germination II: Effect of seed burial and germination temperature. Weed Science, v.46, p.53-58. $1998 b$.

GALLAGHER, R.S.;CARDINA, J. Phytochrome-mediated Amaranthus germination I: Effect of seed burial and germination temperature. Weed Science, v. 46, p. $48-52$. $1998 \mathrm{a}$. 
GOMIDE, M.B. Potencialidades alelopáticas dos restos culturais de dois cultivares de cana-de-açúcar (Saccharum sp), no controle de algumas plantas daninhas. Piracicaba, 1993. 96p. Tese (Doutorado) - Escola Superior de Agricultura "Luiz de Queiroz", Universidade de São Paulo.

GRANATOS, F.L.; TORRES, L.G. Seed bank and other demographic parameters of broomrape (Orobanche crenata Forsk) populations in faba beans (Vicia faba L.). Weed Research, v.33, p.319-327, 1993.

GRAVELL, J.; TURCO, R. Soil principles and adsorption of herbicides in soil. In: Herbicide action: an intensive course on activity, selectivity, behavior and fate. West Lafayette: Purdue University:, 1997. p.505-553.

GROSS, K.L. A comparison of methods for estimating seed numbers in the soil. Journal of Ecology, v.78, p.1079-1093, 1990.

HARRIS, S.M.; DOOHAN, D.J.; GORDON, R.J.; JENSEN, K.I.N. The effects of thermal time and soil water on emergence of Ranunculus repens. Weed Research, v.38, p.405-412, 1998.

HERNANDEZ, D.D.; ALVES, P.L.C.A.; MARTINS, J.V.F. Influência da palha de cana-de-açúcar sobre a eficiência dos herbicidas imazapic e imazapic + pendimethalin. In: CONGRESSO BRASILEIRO DA CIENNCIA DAS PLANTAS DANINHAS, 22., Foz do Iguaçu, 2000. Resumos. Londrina: SBCPD, 2000. p.390.

HILHORST, H. W. M.; TOOROP, P. E. Review on dormancy, germination, and germination in crop and weed seeds. Advances in Agronomy, v.61, p. 112$165,1997$. 
HOFFMAN, M.L.; OWEN, M.D.K.; BUHLER, D.D. Effects of crop and weed management on density and vertical distribution of weed seeds in soil. Agronomy Journal, v. 90, p.793-799, 1998.

HOLSHOUSER, D.L.; CHANDLER, J.M.; WU, H. Temperature-dependent model for non-dormant seed germination and rhizome bud break of Johnsongrass (Sorghum halepense). Weed Science, v.44, p.257-265. 1996.

HURLE, K.; WACKER, A. Persistence and its prediction. In: HANCE, R.S. Interaction between herbicides and the soil. 1980. New York: Academic Press, cap.4, p.83-122.

KREMER, R.J.; SPENCER, N.R. Impact of a seed-feeding insect and microorganisms on velvetleaf (Abutilon theoprastis) seed viability. Weed Science, v.37, p.211-216, 1989.

KROPFF, M.J.; BASTIAANS, L.; COUSENS, R.D. Approaches used in the prediction of weed populations dynamics. In: THE 1999 BRIGHTON CONFERENCE - WEEDS, Brighton, 1999. Proceedings. Brighton: British Crop Protection Council, 1999. p.399-408.

KUVA, M.A. Efeito de períodos de controle e convivência das plantas daninhas na cultura de cana-de-açúcar (Sacharum sp) no Estado de São Paulo. Boletim Informativo-Ciência das Plantas Daninhas, v. 6, p.13, 2000.

LORENZI, H. Manual de identificação e controle de plantas daninhas: plantio direto e convencional. Nova Odessa: Plantarun, 2000. 339p.

MALDONADO, J.A.C.; OSORNIO, J.J.J.; BARRAGÁN, A.T.; ANAYA, A.L. The use of allelopathic legume cover and mulch species for weed control in cropping systems. Agronomy Journal, v.93, p.27-36, 2001. 
MALONE, C.R. A rapid method for enumeration of viable seed in soil. Weeds, v.15, p.381-382, 1967.

MALUF, A.M. Dinâmica populacional de Amaranthus hybridus L. e Amaranthus viridis L. Piracicaba, 1988. 179p. Tese (Doutorado) - Escola Superior de Agricultura "Luiz de Queiroz", Universidade de São Paulo.

MANECHINI, C. The impact of cane trash on weed control. International Cane Energy News: newsletter of the international cane energy network, p.7-11, Apr. 2000.

MANECHINI, C. Manejo agronômico da cana crua. In: COOPERATIVA DOS PRODUTORES DE CANA, AÇÚCAR E ÁLCOOL DO ESTADO DE SÃO PAULO LTDA - Relatório técnico. Piracicaba, 1998. p.309-327.

MARTINS, C. C.; SILVA, W. R. Estudos de bancos de sementes do solo. Informativo ABRATES, v.4, p.49-56, 1994.

MARTINS, D.; VELINE, E.D.; MARTINS, C.C.; SOUZA, L. Emergência em campo de dicotiledôneas infestantes em solo coberto com palha de cana-de-açúcar. Planta Daninha, v.17, p.151-161, 1999.

MELENDEZ, J.A.M. Efeito da cobertura do solo no controle de plantas daninhas na cultura do pepino (Cucumis sativus L). Piracicaba, 1990. 110p. Dissertação (Mestrado) - Escola Superior de Agricultura "Luiz de Queiroz", Universidade de São Paulo.

MILLS J.A ; WITT, W.W. Efficacy, phytotoxicity, and persistence of imazaquin, imazethapyr, and clomazone in no-till double-crop soybeans (Glycine max). Weed Science, v.37, p.353-359, 1989. 
MORTIMER, A.M. The biology of weed. In: HANCE, R.J.; HOLLY, K. (Ed.). Weed controle handbook: principles. London: Blackwell Scientific, 1990. cap.1., p.142.

OLIVEIRA, M.F. Comportamento de herbicidas no ambiente. In: OLIVEIRA, R.S.; CONSTANTIN, J (Ed.). Plantas daninhas e seu manejo. Guaiba: Guaiba Agropecuária, 2000. cap. 7, p. 314-362.

OLIVEIRA, R.S.; KOSKINEN, W.C.; FERREIRA, F.A. Sorption and leaching potencial of herbicides on Brazilian soils. Weed Research, v.41, p.97-110, 2001b.

PEREIRA, E.S. Avaliações qualitativas e quantitativas das plantas daninhas na cultura da soja (Glycine max (L) Merril), submetidas aos sistemas de plantio direto e convencional. Boletim Informativo-Ciência das Plantas Daninhas, v.5, p.12, 1999.

PITELLI, R.A. Plantas daninhas no sistema de plantio direto de culturas anuais. In: CONGRESO LATINOAMERICANO DE MALEZAS, 12., Montevideu 1995. Resumos. Montevidéu: INIA, 1995. p.37-42. (INIA. Série Técnica, 56).

RADOSEVISH, S.R.; HOLT, J.S. Weed ecology: implications for vegetation management. Oregon: Willey-Interscience, 1984. 265p.

RADOSEVICH, S.; HOLT, J.; GHERSA, C. Genetic and Evolution of Weeds. In: RADOSEVICH, S.R. (Ed) Weed ecology: implications for management. 2.ed. New York: Jhon Wiley, 1997a. cap.3, p.69-102.

RADOSEVICH, S.R.; HOLT, J.; GHERSA, C. Other types of interference. In: RADOSEVICH, S.R. (Ed) Weed ecology: implications for management. 2.ed. New York: Jhon Wiley, 1997b. cap.7, p.302-330. 
ROBERTS, H. A . Seed banks in the soil. In: ROBERTS, H.A. (Ed.) Advances in applied biology. Cambridge: Academic Press, 1981. v.6, p.1-55.

ROBERTS, H.A.; NEILSON, J.E. Changes in the soil seed bank of four long-term crop/herbicide experiments. Journal of Applied Ecology, v.18, p.661-668, 1981.

RODRIGUES, B.N.; ALMEIDA, F.S. Guia de herbicidas. 4.ed. Londrina:1998. $648 p$.

RODRIGUES, B.N.; LIMA, J.; YADA, I.F.U. Retenção pela palhada, de herbicidas aplicados em pré-emergência na cultura do milho, em plantio direto. Revista Brasileira de Herbicidas, v.1, p.123-128, 2000b.

RODRIGUES, B.N.; LIMA, J.; YADA, I.F.U.; FORNAROLLI, D.A. Influência da cobertura morta no comportamento do herbicida trifluralin. Planta Daninha, v.16, p.163-173, 1998.

RODRIGUES, B.N.; FORNAROLLI, D.A.; LIMA, J.; CAETANO, E.S.; GALVÃO, J.M. Comportamento de herbicidas pré-emergentes aplicados sobre cobertura morta em plantio direto. In: CONGRESSO BRASILEIRO DA CIÊNCIA DAS PLANTAS DANINHAS, 22., Foz do Iguaçu, 2000a. Resumos. Londrina: SBCPD, 2000. p.380.

ROLIM, J.C.; CHRISTOFFOLETI, P.J. Período critico de competição de plantas daninhas com cana planta de ano. Saccharum, n.22, p.21-26, 1982.

ROSS, M.A.; LEMBI, C.A. Foliar and soil applied herbicide groups. In: ROSS, M.A. (Ed.) Applied weed science. Purdue University: Macmillan; Collier Macmillan, 1985. cap.9, p.178-199. 
RUIZ, O.R.A.; PITALÚA, M.J.L.; VALENZUELA, D.J.A. Influência de la temperatura, luz, estratificação mecanica sobre la germinacion de cuatro espécies de malezas de importância agrícola em México. Chapingo, n.67/68, p.168-171, 1990.

SAUER, J.; STRUIK, G. A possible ecolgical relation between soil disturbance, light flash and seed germination. Ecology, v.45, p.884-886, 1964.

SCOPELL, A.L.; BALLAERÉ, C.L; RADOSEVICH. S.R. Photostimilation of seed germination during soil tillage. New Phytologist. v.126, p.145-152, 1994.

SENTELHAS, P.C.; PEREIRA, A.R.; MARIN, F.R.; ANGELOCCI, L.R.; ALFONSI, R.R.; CAMARONI, P.H.; SWART, S. Nurma: Núcleo de Monitoramento Agroclimático. http://ce.esalg.usp.br/dce/nurma.htm. (10 Jul. 2001).

SILVA, J.B. Plantio direto: redução dos riscos ambientais com herbicidas. In.: SATURNINO, H.M.; LANDERS, J.N. (Ed.) O meio ambiente e o plantio direto. Brasília: Embrapa, SPI, 1997. cap.6. p.83-88.

STANDIFER, L.C. A technique for estimating weed seed populations in cultivated soil. Weed Science, v.28, p.134-138, 1980.

TEASDALE, J.R.; MOHLER, C.L. Light transmittance, soil temperature, and soil moisture under residue of hairy vetch and rye. Agronomy Journal, v.85, p.673680, 1993.

THEISEN, G.; VIDAL, R.A. Efeito da cobertura do solo com resíduos de aveia preta nas etapas do ciclo de vida do capim-marmelada. Planta Daninha, v.17, p189196, 1999. 
TOLEDO, V.; BEGLIOMINI, E. Controle de plantas daninhas em plantio direto. In.: PEREIRA, M.H. (Ed) Guia para plantio direto. Cuiabá: FEBRADAP, 2000. cap.5, p.45-51.

TURCO, R.F. Microbial and non-microbial breakdown of herbicide in soil. In: Herbicide action: an intensive course on activity, selectivity, behavior and fate herbicides in plants and the environment. West Lafayette: Purdue University:, 1997. p.554-596.

VASCONSELOS, M.T.C. Estudos bio-ecológicos das infestantes na cultura do tomateiro. Lisboa, 1984. 122p. Dissertação (M.S.) - Instituto Superior de Agronomia, Universidade Técnica de Lisboa.

VELINI, E.D.; NEGRISOLI, E. Controle de plantas daninhas em canacrua. In: CONGRESSO BRASILEIRO DA CIÊNCIA DAS PLANTAS DANINHAS, 22., Foz do Iguaçu, 2000. Anais. Londrina: SBCPD, 2000. p.148-165.

VICENT, E.M.; ROBERTS, E.H. The interaction of light, nitrate and alternating temperature in promoting the germination of dormant seeds of common weed species. Seed Science \& Technology, v.5, p.650-670, 1977.

VIDAL, R.A. Inibidores do PS2. In: VIDAL, R.A (Ed.) Herbicidas: mecanismos de ação e resistência de plantas. Porto Alegre: Autor, 1997. cap.9, p.91-99.

WATTS, D.W.; HALL, J.K. Tillage and applicatios effects on herbicide leaching and runoff. Soil \& Tillage Research, v.39, p.241-257, 1996.

WESSON, G.; WARING, P.F. The induction of light sensitivity in weed science by burial. Journal of Exprimental Botany, v.20, p.413-425, 1969a. 
WESSON, G.; WARING, P.F. The role of light in the germination of naturally occuring populations of buried weed seeds. Journal of Exprimental Botany, v.20, p.402-413. 1969b.

WILSON, R.G.; KERR, E.D.; NELSON, L.A. Potencial for using weed seed content in the soil to predict future weed problems. Weed Science, v.33, p.171-175, 1985.

YENISH, J. P.; DOLL, J. D.; BUHLER, D. D. Effects of tillage on vertical distribution and viability of weed seed in soil. Weed Science, v.40, p.429-433, 1992.

ZINDAHL, R.L. Weed reproduction and dispersal. In.: ZINDAHL, R.L. (Ed.) Fundamentals of weed science. San Diego: Academic Press, 1999. cap.5, p.71-107. 